UNIVERSIDADE DE BRASÍLIA

FACULDADE DE EDUCAÇÃO FÍSICA

PROGRAMA DE PÓS-GRADUAÇÃO EM EDUCAÇÃO FíSICA

\title{
FORÇA MUSCULAR E SUPLEMENTAÇÃO AGUDA DE CAFEÍNA - UM ESTUDO BALANCEADO CONTROLADO POR PLACEBO
}

ORIENTANDO: EDGARD DE MELO KEENE VON KOENIG SOARES

ORIENTADORA: KEILA ELIZABETH FONTANA 


\title{
FORÇA MUSCULAR E SUPLEMENTAÇÃO AGUDA DE CAFEÍNA - UM ESTUDO BALANCEADO CONTROLADO POR PLACEBO
}

\author{
Dissertação de mestrado apresentada ao \\ Programa de Pós-graduação Stricto Sensu da \\ Faculdade de Educação Física da Universidade \\ de Brasília como requisito parcial para a \\ obtenção do Grau de Mestre em Educação \\ Física
}

ORIENTADORA: KEILA ELIZABETH FONTANA

BRASÍLIA-DF 


\section{DEDICATÓRIA}

Entre todos quais merecem os meus agradecimentos, não tenho como não agradecer primeiro ao Senhor Deus, pois, todas as coisas foram feitas por Ele e para Ele. Se me levanto todos os dias, se tenho fôlego para respirar e força para me mover é por causa do sustento Dele. Sem Ele nada faz sentido, nem esse trabalho todo, e sem Ele, induvidavelmente esse não trabalho não seria possível, nem teria conseguido chegar até aqui, todas as coisas aconteceram por causa da Sua boa mão sobre nós. Louvado seja o Senhor que renova sobre nós sua bondade todos os dias. Dedico também este trabalho a minha esposa, Maciana por todo seu companharismo, carinho, amor, suporte e compreensão, sem ela também não conseguiria chegar até aqui. Seu amor incondicional me dá forças para buscar uma vida melhor para nós. Não menos importante, dedico este trabalho a minha família, especialmente meus pais, Gabriel e Kenia e meu irmão Gabriel, como não há árvores sem raízes, não há homem sem família. Obrigado Pai e Mãe por tudo que fizeram e fazem por mim, não chegaria aqui sem o a educação, valores e amor transmitido por vocês. Ao meu irmão, minha sincera saudação e gratidão pelo carinho, amizade e companheirismo de tantos anos. 


\section{AGRADECIMENTOS}

Não posso deixar de agradecer aos voluntários, que pacientemente e com muita dedicação atenderam ao chamado dessa pesquisa sem os quais, obviamente, este trabalho não seria possível. Obrigado.

Aos mestres e professores que tive ao longo desta jornada, tantos contribuíram para com a minha formação acadêmica e pessoal. Alguns, eu tive o prazer de ter os laços estreitados e chamar também de amigos. Entre tantos gostaria de agradecer a Profa. Dra Keila Elizabeth Fontana, que tenho o prazer de trabalhar junto a tantos anos. Lembro-me quando conversamos a primeira vez sobre a possibilidade de um projeto de iniciação científica. Muito obrigado Professora por todo conhecimento passado e todas as oportunidades ao longo destes anos.

Ao Prof. Dr. Guilherme Molina, pelas orientações, conversas e todo conhecimento transmitido. Tem um sido um prazer conviver e trabalhar com o senhor. Obrigado Professor.

Ao Prof. Dr. Luiz Guilherme Porto que também tenho tido o prazer de trabalhar e conhecer, eu agradeço pelos ensinamentos transmitidos. Obrigado Professor.

Agradeço ao Prof. Dr. Martim Bottaro pela disponibilidade e cordialidade com que sempre se apresentou, bem como com a prontidão para ajudar no tocante a disponibilidade da utilização dos equipamentos do Laboratório de Força.

A Técnica do Laboratório de Fisiologia do Exercício Lúcia Kobayashi, por todas as conversas, orientações e aprendizado nestes anos, bem como ajudando nas questões relacionadas à suplementação neste estudo.

Aos acadêmicos Waydson Rabelo, Arthur Vasconcelos, Paula Melo pelo auxílio prestado no Laboratório de Fisiologia do Exercício e disposição para ajudar.

Aos funcionários da Faculdade de Educação Física que de um modo ou outro auxiliaram a execução deste trabalho, mantendo nossa querida Faculdade em pleno funcionamento. Obrigado a todos.

A Phamacéutica (unidade Shopping Conjunto Nacional), por toda a presteza e atenção relacionada ao atendimento e manipulação dos suplementos.

Ao amigo Giliard Garcia, pelas contribuições, debates, reflexões realizadas ao longo desta jornada. Muito obrigado.

Aos queridos amigos e irmãos em Cristo que de alguma forma me apoiaram, minha sincera gratidão. 


\section{SUMÁRIO}

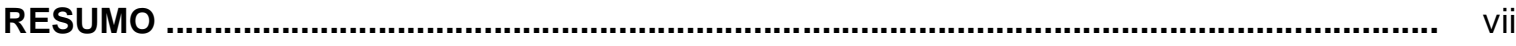

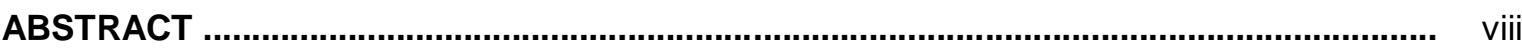

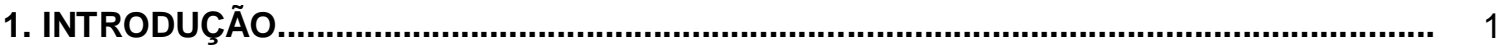

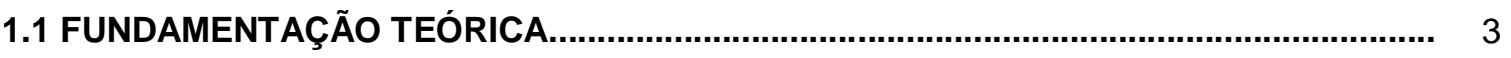

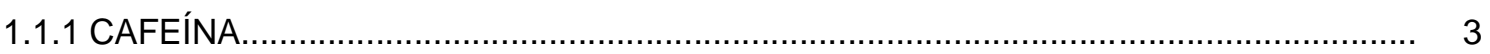

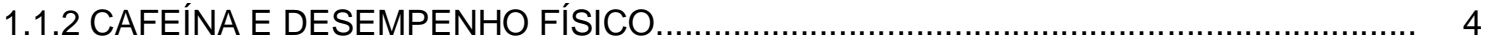

1.1.2.1 CAFEÍNA E FORÇA MUSCULAR ................................................................ 4

1.1.2.2 CAFEÍNA E ENDURANCE MUSCULAR ............................................................ 5

1.1.3 FUNDAMENTOS FISIOLÓGICOS DA ERGOGENIA DA CAFEÍNA............................ 5

1.1.3.1 MECANISMOS CENTRAIS DE ATUAÇÃO DA CAFEÍNA...................................... 6

1.1.3.2 MECANISMOS PERIFÉRICOS DE ATUAÇÃO DA CAFEÍNA.................................. 7

1.1.4 SEGURANÇA NA SUPLEMENTAÇÃO DE CAFEÍNA.............................................. 7

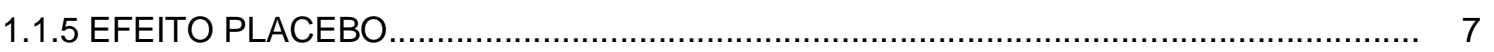

1.1.5.1 EFEITO PLACEBO NO EXERCÍCIO ......................................................... 8

1.1.5.2 EFEITO PLACEBO E DESENHO EXPERIMENTAL ......................................... 9

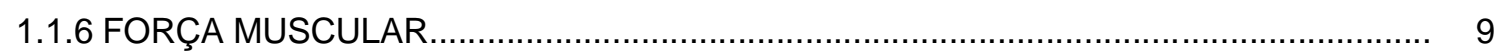

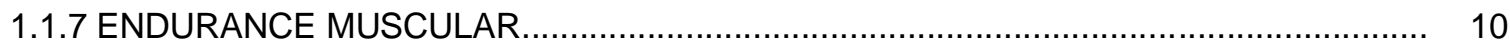

1.1.8 ESCALA DE PERCEPÇÃO DO ESTADO DE RECUPERAÇÃO

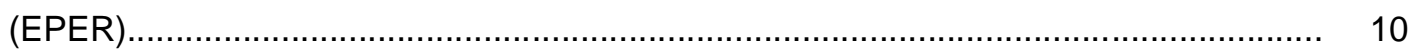

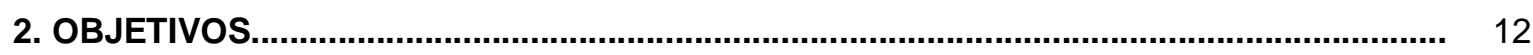

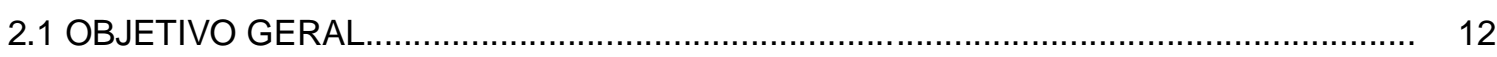

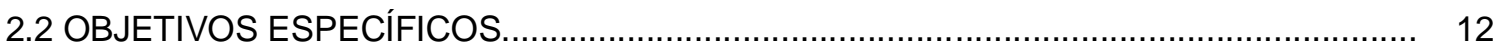

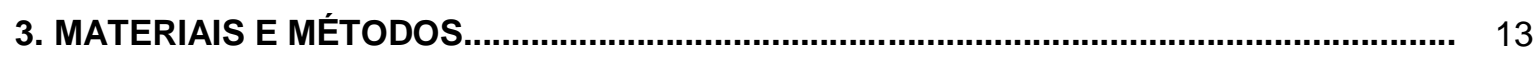

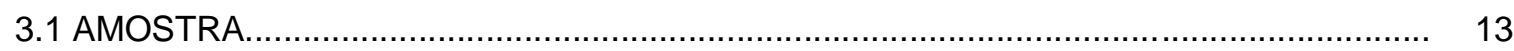

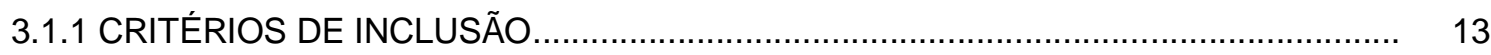

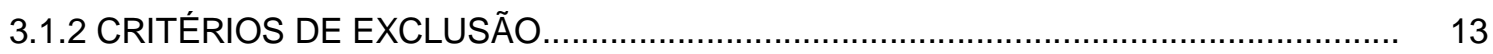

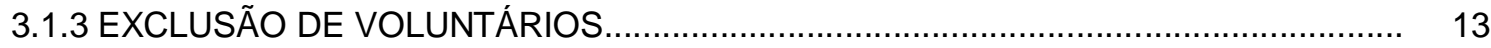

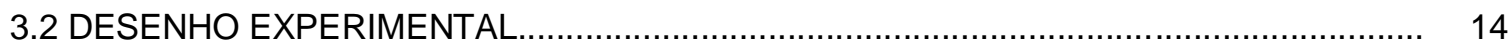

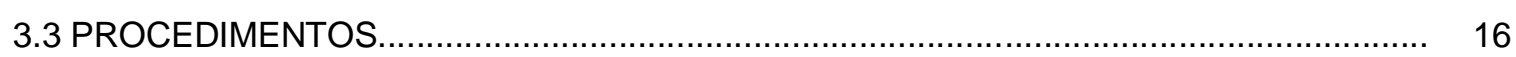

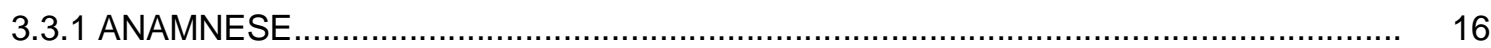

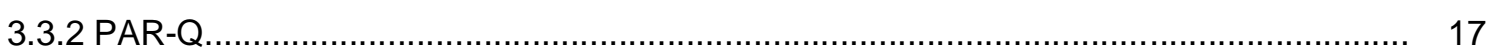

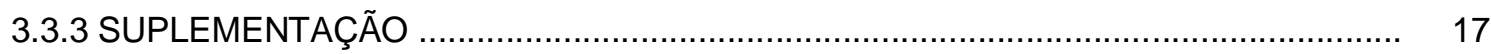

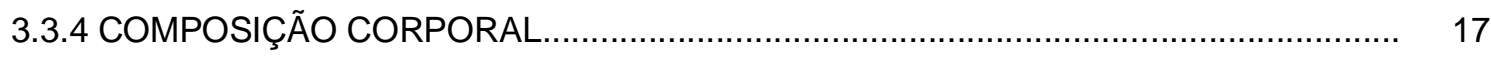

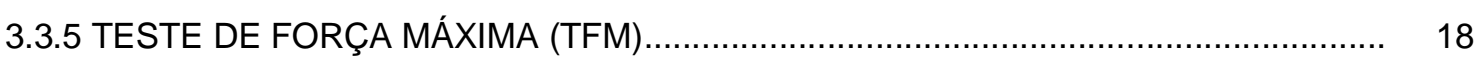

3.3.5.1 TESTE DE FORÇA MÁXIMA CONCÊNTRICA (TFMC) ..................................... 18

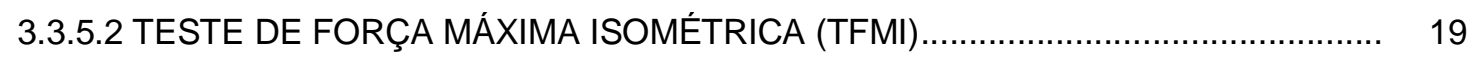

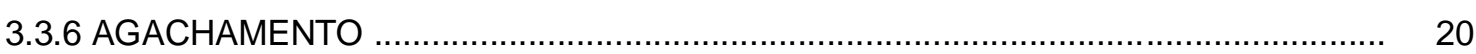

3.3.7 TESTE DE 1 REPETIÇÃO MÁXIMA (1RM) ........................................................... 20

3.3.8 TESTE DE ENDURANCE MUSCULAR (TEM) ................................................. 21

3.3.8.1 LACTACIDEMIA E COLETA SANGUÍNEA ........................................................ 22 
3.3.9 ESCALA DE PERCEPÇÃO DO ESTADO DE RECUPERAÇÃO (EPER).

3.3.10 QUESTIONÁRIO DE EFEITOS DA CAFEÍNA (QEC) ........................................ 22

3.3.11 ANÁLISE DO CONSUMO DE CAFEÍNA ............................................................... 23

3.4 PROCEDIMENTOS ESTATÍSTICO................................................................... 23

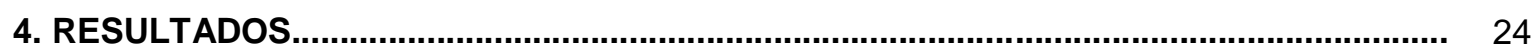

4.1 CARACTERIZAÇÃO DA AMOSTRA ............................................................... 24

4.2 ESCALA DE PERCEPÇÃO DO ESTADO DE RECUPERAÇÃO - EPER ......................... 25

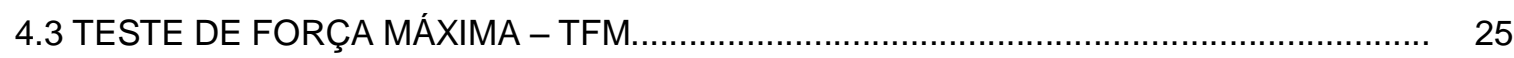

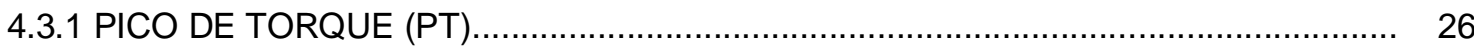

4.3.2 PICO DE TORQUE RELATIVO A MASSA CORPORAL (PT/MC) ............................ 26

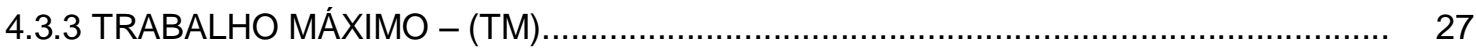

4.4 TESTE DE ENDURANCE MUSCULAR (TEM) …................................................. 28

4.5 QUESTIONÁRIO DE EFEITOS DA CAFEÍNA - QEC ................................................ 31

4.5.1 QUESTIONÁRIO DE EFEITOS DA CAFEÍNA - DOR MUSCULAR............................ 32

4.6 EFEITO DA CAF E EXPECTATIVA - EFF E EXP ................................................... 32

4.6.1 RESPONDEDORES E NÃO RESPONDEDORES.................................................. 36

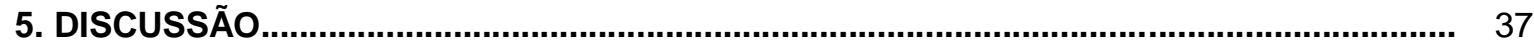

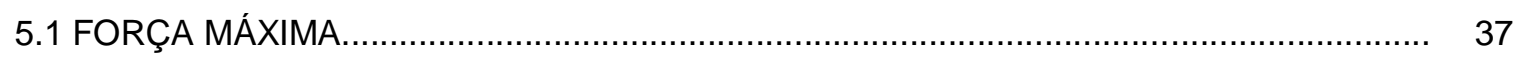

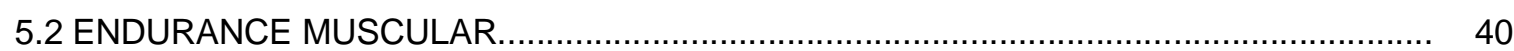

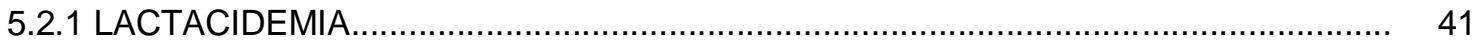

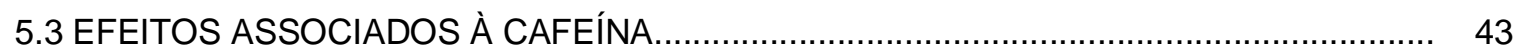

5.4. FATORES INTERVENIENTES ..................................................................... 44

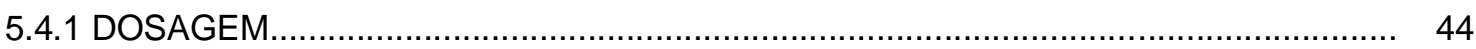

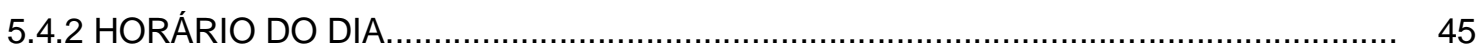

5.4.3 CONSUMO HABITUAL DE CAFEÍNA................................................................. 46

5.4.4 RESPONDEDORES E NÃO RESPONDEDORES................................................ 47

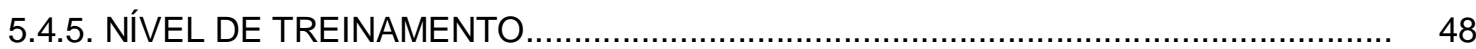

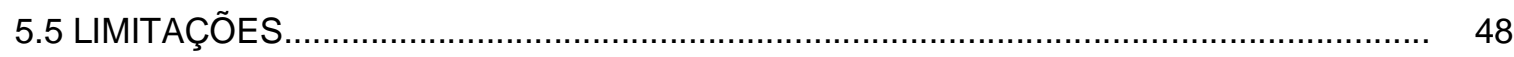

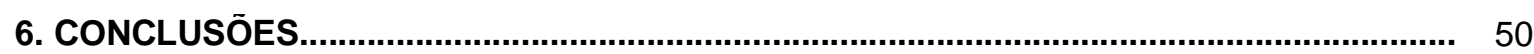

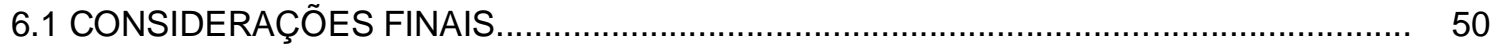

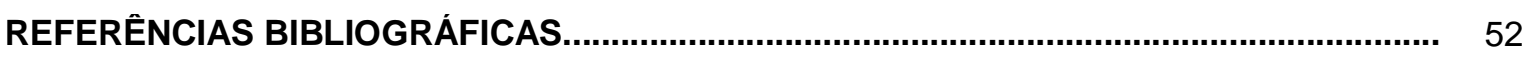

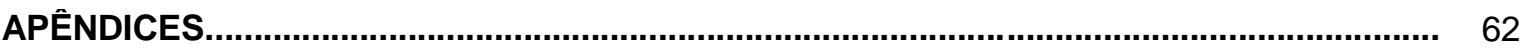

I. TERMO DE CONSENTIMENTO LIVRE E ESCLARECIDO ............................................... 62

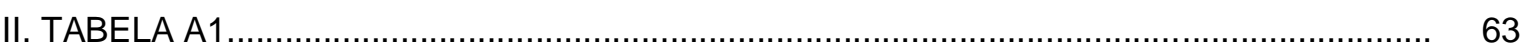

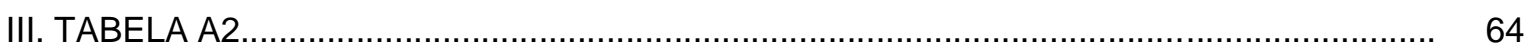

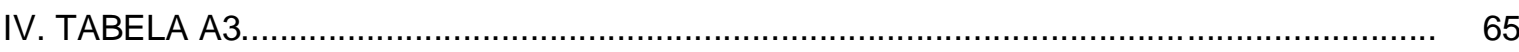

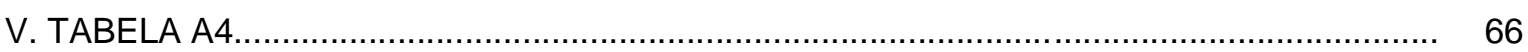

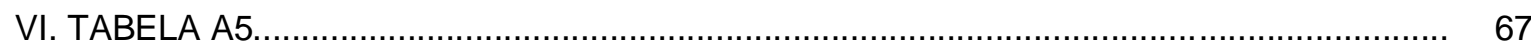

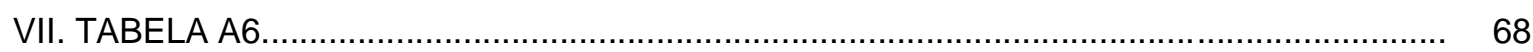

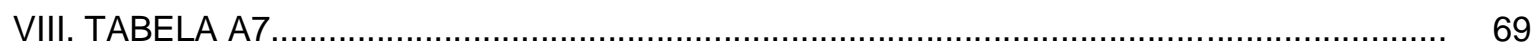




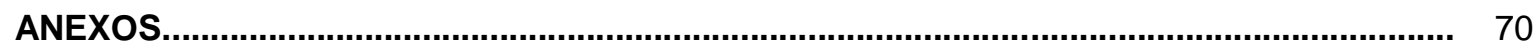

I. ESCALA DE PERCEPÇÃO DO ESTADO DE RECUPERAÇÃO.......................................... 70

II. CONCENTRAÇÃO DE CAFEÍNA EM ALIMENTOS POPULARES, BEBIDAS, REFRIGERANTES E ENERGÉTICOS .................................................................... 71

III. PRINCIPAIS FONTES DE CAFEÍNA NA DIETA ..................................................... 72 


\section{RESUMO}

A cafeína (CAF) é uma substância que faz parte do consumo habitual de grande parte da população, e vem sendo utilizada em larga escala por atletas há décadas em competições internacionais e nacionais com o objetivo de melhoria de desempenho. Seu efeito ergogênico é bem conhecido no exercício aeróbio, porém, no treinamento de força seu uso é controverso. Uma recente meta-análise apontou que o efeito da CAF na força máxima e endurance muscular é modesto. Um ponto que pode contribuir para essa controvérsia é o efeito placebo, que pode influenciar significativamente o desempenho físico em determinadas situações. Desta forma, o objetivo é verificar o efeito da suplementação aguda de cafeína na força máxima (FM) e endurance muscular (EM) - para isso será utilizado um desenho experimental que visa diferenciar o efeito fisiológico da CAF do efeito da expectativa de receber CAF (efeito placebo). Homens jovens (18 a 30 anos, $n=16$ ) fisicamente ativos foram submetidos a seis sessões: uma de familiarização, uma de controle e quatro experimentais. Na primeira sessão o voluntário foi familiarizado com os testes e procedimentos da pesquisa: a escala de percepção do estado de recuperação, o questionário de efeitos da cafeína, ao dinamômetro isocinético e ao exercício de agachamento, onde foi realizado o teste de uma repetição máxima (1RM) para determinação da carga a ser utilizada no teste de endurance muscular. Foram coletados: dados pessoais (idade, tempo de treinamento) e sobre o consumo de CAF, massa corporal e estatura. A segunda sessão foi a sessão controle, onde foram realizados os testes de FM e EM, esses foram repetidos nas sessões experimentais. Nas sessões experimentais foi utilizado o desenho balanceado por placebo realizado em quatro possibilidades: 1 sessão C/C em que o avaliador informou dar um suplemento de cafeína ( $5 \mathrm{mg} / \mathrm{kg}$ de massa corporal) e o voluntário de fato recebeu $\mathrm{CAF} ; 2$ - sessão $\mathrm{C} / \mathrm{P}$ em que o avaliador informou dar CAF, porém, o voluntário recebeu placebo (PLA); 3 - sessão P/C em que o avaliador informou dar PLA, porém o voluntário recebeu CAF; 4 - sessão P/P em que o avaliador informou dar PLA e o voluntário de fato recebeu PLA. Foram coletados $25 \mu \mathrm{l}$ de sangue para análise de lactato sanguíneo, antes do exercício, no $2^{\circ}, 4^{\circ}$ e $6^{\circ}$ minuto. A composição corporal foi analisada por meio do método de absortometria por emissão de raios $X$ de dupla energia (DXA) em um dia separado. A CAF aumentou significativamente $(p<0,05)$ : o pico de torque nas velocidades 0 e $60 \%$, o pico de torque relativo à massa corporal nas velocidades 0,60 e $180 \%$, o trabalho máximo em todas as velocidades. O efeito da CAF na força muscular foi independente de informar uso de CAF ou de PLA. A CAF não produziu diferenças significativas na EM. A CAF aumentou significativamente a lactacidemia bem como informar que seria usada CAF $(p<0,05)$. $O$ efeito da CAF e a expectativa de receber CAF variaram consideravelmente entre sujeitos, em especial na EM, foi claramente observável um grupo de respondedores e não respondedores a CAF. Os diversos mecanismos de ação da CAF podem estar ligados a variação nas respostas da CAF. Novos estudos envolvendo CAF devem utilizar esse mesmo desenho experimental, tendo em vista que a expectativa de CAF pode influenciar o desempenho além de variáveis fisiológicas.

Palavras-chave: Cafeína. Força muscular. Efeito placebo. "Balanced placebo design". 


\section{ABSTRACT}

Caffeine (CAF) is a substance that is part of the habitual consumption of great part of the population, and has been widely used by athletes for decades aiming to improve their performance in international and national competitions. Its ergogenic effect is well known in aerobic exercise, however, its use in strength training is controversial. Recently, a meta-analysis showed that the effect of CAF in maximum strength and muscular endurance is modest. One point that may be contributing to this controversy is the placebo effect, which can significantly influence physical performance in certain situations. Thus, the objective is to verify the acute effect of caffeine supplementation in maximum strength (MS) and muscle endurance (ME) - using an experimental design aimed at differentiating CAF physiological effect caffeine from the effect caused by expecting CAF (placebo effect). Young physically active men (18 to 30 years, $n=16$ ) underwent six sessions: a familiarization, one control and four experimental. The first session occured the familiarization with the testing and procedures of the research: the perceived recovery status scale, the caffeine effects questionnaire, the isokinetic dynamometer and the squat exercise, which was carried out the one repetition maximum test (1RM) for determining the load to be used in muscle endurance test. Was also collected: personal data (age, time of training) and habitual CAF consumption, body weight and height. The second session was the control session, where the MS and ME test were performed, which were repeated in the experimental sessions. In the experimental sessions we used the balanced placebo design with four session possibilities: 1 - Session $\mathrm{C} / \mathrm{C}$ where the evaluator informed giving a caffeine supplement ( $5 \mathrm{mg} / \mathrm{kg}$ body weight) and in fact the volunteer received CAF; 2 - Session C/P in which the evaluator informed giving CAF, however, the volunteer actually received placebo (PLA); 3 - Session P/C where the evaluator informed giving PLA, but volunteer actually received CAF; 4 - Session P/P in which the evaluator informed giving PLA and the volunteer actually received PLA. For blood lactate analysis, 25 $\mu \mathrm{l}$ of blood were collected before exercise, 2, 4 and 6 minutes after exercise. Body composition was analyzed through absorptiometry method using the dual energy X-ray absorptiometry (DXA) on a separate day. CAF increased significantly $(p<0.05)$ : the peak torque at speeds 0 and $60 \%$, peak torque relative to body mass at speeds 0,60 and $180 \%$, and maximum work in all speeds. The effect of CAF in muscle strength was independent of the information given. CAF produced no significant differences in ME. CAF significantly increased lactacidemy, as also informing that CAF would be given $(p<0.05)$. The effect of CAF and the expectation of receiving CAF varied considerably between subjects, especially in $M E$, it was clearly possible to observe a group of responders and nonresponders to CAF. The various CAF mechanisms of action may be linked to the great variety of responses to CAF. New studies involving CAF should use the same experimental design in view of the expectation of CAF can influence performance in addition to physiological variables.

Key-words: Caffeine. Muscle Strength. Placebo effect. Balanced placebo design. 


\section{INTRODUÇÃO}

A cafeína (1,3,7 - trimetilxantina) é uma substância que faz parte do consumo habitual de grande parte da população, pois, está presente em uma grande variedade de alimentos, como: chás, cafés, bebidas energéticas, chocolates e refrigerantes (ALTIMARI et al., 2006a). Essa substância também é muito conhecida pelos seus efeitos ergogênicos, de tal modo que várias instituições e revistas científicas possuem algum posicionamento a respeito de seu uso como suplemento nutricional, principalmente no que se refere ao esporte e ao exercício aeróbio (ALVES; LIMA, 2009; GOLDSTEIN et al., 2010; STEAR et al., 2010).

Pensando no aprimoramento de desempenho em exercício físico, a cafeína é utilizada como agente ergogênico por muitas pessoas, inclusive atletas. Ela é utilizada em larga escala há várias décadas, contudo, devido ao seu uso indiscriminado a cafeína chegou a ser incluída na lista de substâncias proibidas pelo Comitê Olímpico Internacional na década de 1980, contudo, desde 2004, a substância é apenas monitorada pela Agência Mundial Anti-Doping ("World Anti-Doping Agency" WADA) e não é mais considerada doping. Esse fato aumentou ainda mais o seu consumo entre atletas, tendo sido observado que $74 \%$ dos atletas utilizaram essa substância em competições internacionais e nacionais (DEL COSO; MUÑOZ; MUÑOZ-GUERRA, 2011).

A cafeína é um dos principais elementos presentes nos suplementos alimentares conhecidos como "pré-treinos" consumidos por praticantes do treinamento de força. Com o objetivo de aumentar o desempenho nas sessões de treino, mais especificamente aumentar de forma aguda a força máxima e a endurance muscular (ALVES; LIMA, 2009; EUDY et al., 2013). Contudo, a ergogenia da cafeína nestas valências físicas ainda é controversa, algumas pesquisas encontraram resultados positivos com a suplementação de cafeína enquanto outras não. Algo bem diferente do que é visto no exercício com predominância do metabolismo aeróbio, em que o efeito ergogênico é bem conhecido e divulgado (GOLDSTEIN et al., 2010; STEAR et al., 2010).

A força muscular desempenha um papel importante na saúde, sendo a baixa força muscular um preditor de mortalidade, de câncer e de perda de funcionalidade (BRILL et al., 2000; RUIZ et al., 2008, 2009), enquanto que no campo atlético, ela é uma variável indispensável para vários esportes que dependem diretamente dos altíssimos níveis de produção de força, como: halterofilismo, arremesso de peso entre outros (BURKE, 2008). Um suplemento que seja eficaz em melhorar o desempenho físico pode interessar tanto aqueles que buscam o desempenho atlético quanto aos que necessitam de melhoria funcional, como no caso de sobreviventes de câncer de próstata, em quem a suplementação de $6 \mathrm{mg} / \mathrm{kg}$ de massa corporal de cafeína aumentou a capacidade física e tolerância ao esforço (CORNISH; BOLAM; SKINNER, 2015).

Infelizmente, ao considerar a produção de força máxima e endurance muscular, existe uma grande divergência nos achados das pesquisas. A literatura comumente aponta que a dispersão dos resultados obtidos com a suplementação se deve principalmente a: sensibilidade do instrumento utilizado para mensuração de desempenho, o nível de treinamento dos voluntários avaliados, o grupamento muscular utilizado, o tipo de contração muscular, tipo de teste utilizado, idade, gênero e capacidade individual de metabolização da cafeína (ASTORINO; ROBERSON, 2010; GOLDSTEIN et al., 2010; PALLARÉS et al., 2013; WARREN et al., 2010). 
Em meio a essas controvérsias, surge outro fator importante - o efeito placebo. Um indivíduo ao receber uma substância, caso ele tenha expectativas positivas quanto ao seu efeito, mesmo sem ter ação fisiológica real, pode afetar positivamente seu desempenho físico - em especial o uso da cafeína (BEEDIE, 2010; POLLO; CARLINO; BENEDETTI, 2008). O efeito placebo é muito estudado na área médica relacionada à analgesia, e pode ser definido como sendo a resposta positiva como diminuição da dor, da depressão e/ou melhora de desempenho físico quando uma substância, ou intervenção ou tratamento inerte é aplicado (BENEDETTI, 2013; BÉRDI et al., 2011). A ocorrência desse efeito pode ser afetada por fatores culturais e psicossocias como: as expectativas do indivíduo, sua experiência prévia, o ambiente da intervenção, cor, gosto e formato das medicações aplicadas, entre outros (BENEDETTI, 2013).

$\mathrm{Na}$ área do exercício físico, BÉRDI et al., (2011) concluíram em sua meta-análise que o efeito placebo pode ser um fator de grande importância no campo do desempenho atlético, campo em que pequenas melhorias significam muito, apesar do tamanho do efeito ser considerado médio, tendo sido observado tamanho de efeito $(0,40)$ maior que o encontrado por WARREN et al., (2010), em sua metaanálise sobre os efeitos da cafeína na força máxima e endurance muscular. Eles relataram que embora os efeitos da cafeína fossem significativos, o tamanho do efeito calculado foi considerado pequeno, tanto na força máxima quanto na endurance muscular - 0,19 e 0,28 respectivamente. Surge então uma dúvida, será que o aumento na força máxima ou endurance muscular devido ao consumo de cafeína é um efeito ergogênico legítimo, ou, na verdade é um efeito placebo.

Normalmente o modelo de pesquisa duplo-cego é utilizado com o objetivo de controlar o efeito placebo, contudo não tem se mostrado plenamente eficiente (BENEDETTI, 2013), tanto na área médica (POLLO et al., 2001), quanto na área do exercício físico (DUNCAN; LYONS; HANKEY, 2009). Considerando que a esmagadora maioria dos trabalhos utilizou o desenho duplo-cego (WARREN et al., 2010), justifica-se o uso de um desenho experimental diferenciado para mensurar o efeito da cafeína, visando distinguir se o aumento de desempenho realmente é um efeito fisiológico ou se é proveniente da expectativa de um elemento ergogênico - efeito placebo (BEEDIE, 2010; BÉRDI et al., 2011).

Desta forma o objetivo do presente trabalho é verificar o efeito da suplementação de $(5 \mathrm{mg} / \mathrm{kg}$ de massa corporal) cafeína na força máxima e na endurance muscular de homens jovens treinados, utilizando o desenho experimental conhecido como "balanced placebo design" (BEEDIE; FOAD, 2009; MCCLUNG; COLLINS, 2007). 


\subsection{FUNDAMENTAÇÃO TEÓRICA}

\subsubsection{CAFEÍNA}

A cafeína (CAF) é a substância farmacológica e psicoativa mais consumida no mundo, seus efeitos benéficos são bem conhecidos pela humanidade, sendo utilizada desde a Idade da Pedra com vistas a usufruir dos diversos benefícios de seu consumo (ASTORINO; ROBERSON, 2010), ela é facilmente consumida por todo tipo de pessoa, pois, está presente em diversas fontes nutricionais como, café, chá, chocolate, refrigerantes além de medicamentos que não precisam de prescrição médica (DAVIS; GREEN, 2009). Seu consumo mundial é em média $73 \mathrm{mg}$ por dia por pessoa, contudo, em alguns países chega ser mais de 400 mg de cafeína por pessoa diariamente (FREDHOLM et al., 1999).

A CAF ou 1,3,7-Trimetilxantina $\left(\mathrm{C}_{8} \mathrm{H}_{10} \mathrm{~N}_{4} \mathrm{O}_{2}\right)$ pode ser descrita como um alcaloide - grupo este caracterizado por moléculas ricas em nitrogênio com propriedades básicas e que apresentam pelo menos um anel heterocíclico - ela está representada na FIGURA 1 (PEARCE et al., 2012; SENCHINA et al., 2012).

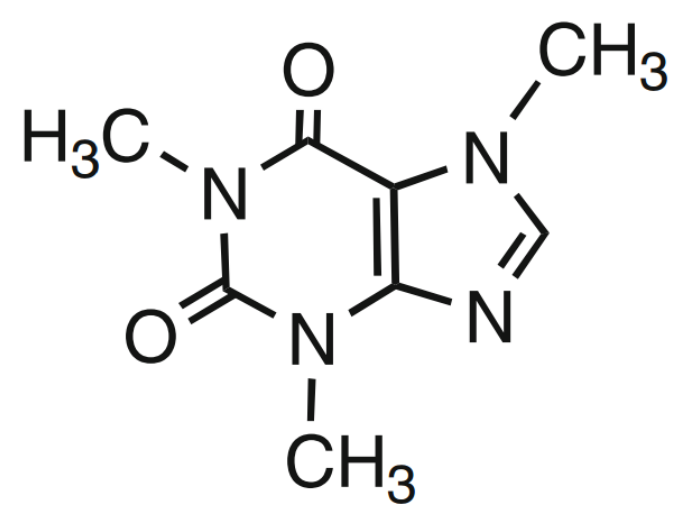

FIGURA 01 - Representação esquemática da molécula de cafeína.

Fonte: (ASHIHARA; KATO; CROZIER, 2011)

A CAF é absorvida rapidamente pelo trato gastrointestinal, sendo totalmente absorvida em 60 minutos, sendo que em 45 minutos, já foram absorvidas $99 \%$ da CAF ingerida, com ligeiras diferenças entre as formas de ingestão. A absorção da cafeína em chiclete é mais rápida que em cápsula que é mais rápida que em café. A absorção pelo trato gastrointestinal é tão eficiente que sua farmacocinética é comparável à administração intravenosa (FREDHOLM et al., 1999; MAGKOS; KAVOURAS, 2005). A CAF possui propriedades lipofílicas que the permitem passar por todas as membranas celulares, inclusive a barreira hematoencefálica. É possível observar uma importante associação entre a concentração de CAF sanguínea e de líquido extracelular de diversos tecidos, por exemplo, no cérebro, na placenta e também no líquido cefalorraquidiano (ARNAUD, 2011; MAGKOS; KAVOURAS, 2005).

Há muito tempo se sabe dos benefícios do uso de CAF no que se refere ao estado mental, como maior estado de alerta, diminuição da sensação de cansaço, menor sensação de dor e aumento da concentração (GLADE, 2010). A facilidade de acesso e o baixo custo fizeram com que a CAF fosse amplamente procurada por públicos diversos, desde trabalhadores que precisam manter seu estado de 
alerta a universitários que precisam passar a noite estudando (GILES et al., 2012; SMITH, 2002). Além de benefícios mentais, a CAF também age no desempenho físico.

\subsubsection{CAFEÍNA E DESEMPENHO FÍSICO}

Não é novidade que a CAF poderia aumentar desempenho físico, pois, desde o início do século XX, Rivers; Webber (1907) publicaram o que provavelmente foi o primeiro estudo científico sobre a CAF. A partir da década de 70 , houve aumento considerável na produção científica que continuava confirmando efeitos ergogênicos para a CAF, o que despertou um grande interesse por partes dos atletas competitivos que buscavam meios de melhorar seu desempenho físico. Contudo, no período entre 1980 e 2003, o consumo de CAF foi bastante limitado, pois nessa época a suplementação de cafeína foi considerada doping (BURKE, 2008; STEAR et al., 2010). Entretanto, o cenário atual se mostra diferente, uma vez que desde 2004 a cafeína passou a ser apenas uma substância observada pela Agêncial Mundial Antidoping (WADA), o que refletiu no aumento do consumo anual, sendo possível em atletas relacionar o consumo aumentado de cafeína com o fato de não ser considerada substância relacionada como doping (DESBROW; LEVERITT, 2007). Del Coso; Muñoz; Muñoz-Guerra (2011) observaram em uma competição internacional que aproximadamente $74 \%$ dos atletas usavam CAF. As modalidades que mais utilizavam CAF foram o triatlo e o ciclismo. Mesmo não apresentando diferença significativa entre as outras doze modalidades analisadas, foi possível observar que outras modalidades, independentemente de serem classificadas de longa duração, provavelmente fizeram uso de CAF, devido ao fato de terem apresentado elevado nível de cafeína na urina. Enquanto que o efeito da CAF sobre atividades de longa duração estão bem documentados (ALTIMARI et al., 2006a; AMERICAN DIETETIC ASSOCIATION et al., 2009; ASTORINO et al., 2012; DOHERTY; SMITH, 2004, 2005; GANIO et al., 2009; SPRIET, 2014), o seu efeito em outros tipos de atividades como as que dependem de força e potência, ou até de modalidades coletivas, carecem ainda de mais estudos para se obter consenso (ALTIMARI et al., 2006b; ASTORINO; ROBERSON, 2010; BISHOP, 2010; GOLDSTEIN et al., 2010).

Estudos envolvendo força e potência no final da década de 80 e início dos anos 90 ajudaram a impulsionar a curiosidade sobre a cafeína em diversas modalidades, incluindo esportes coletivos, apesar de resultados divergentes seguiram-se anos de estudos sobre os efeitos da cafeína na força muscular e na capacidade do músculo de continuar realizando trabalho - esta capacidade física será doravante referida como endurance muscular. Um dos trabalhos mais importantes sobre o assunto foi realizado por Warren et al., (2010). Trata-se de uma meta-análise realizada em estudos publicados e não publicados, que analisou o efeito da CAF sobre a força e a endurance muscular, buscando analisar também os mecanismos de ação que pudessem explicar seu efeito.

\subsubsection{CAFEÍNA E FORÇA MUSCULAR}

Diversos estudos apontam a existência de um efeito ergogênico da CAF sobre a força muscular em suas diversas manifestações, conforme pode ser visto em várias revisões importantes sobre o assunto (ASTORINO; ROBERSON, 2010; BURKE, 2008; GOLDSTEIN et al., 2010; STEAR et al., 2010). Contudo, Warren et al., (2010) foi o primeiro a trazer um valor matemático sobre esse efeito ergogênico 
da CAF, resumindo os achados de diversos estudos. Eles observaram um efeito pequeno da CAF, mas, um efeito pequeno, pode significar muito, para atletas competitivos, onde diferenças mínimas podem impedir que um atleta chegue ao pódio (STEAR et al., 2010).

Os resultados supracitados parecem animadores, contudo, na realidade o fenômeno não é tão simples assim. No mesmo estudo, WARREN et al., (2010) observaram que o efeito da CAF é maior nos músculos dos membros inferiores do que nos superiores, e maior nos extensores de joelho do que nos flexores de joelho. Sem considerar ainda que vários outros estudos não observaram efeito da CAF na força, mesmo quando analisaram exercícios envolvendo os extensores de joelhos (ASTORINO et al., 2010; ASTORINO; ROHMANN; FIRTH, 2008; BOND et al., 1986; JACOBSON; EDWARDS, 1991; MORA-RODRÍGUEZ et al., 2012; TARNOPOLSKY et al., 1989). Assim sendo, evidencia-se o quanto ainda precisamos entender sobre a suplementação de CAF. Considerando ainda que o efeito da CAF é modesto, reforça-se a importância da utilização de métodos com maior precisão, para que os possíveis efeitos da utilização de CAF possam ser detectados e mensurados (GOLDSTEIN et al., 2010).

\subsubsection{CAFEÍNA E ENDURANCE MUSCULAR}

Diversos estudos reportaram efeitos significativos da CAF na endurance muscular. WARREN et al., (2010) apontaram o tamanho do efeito de apenas 0,28 , considerado pequeno. Contudo, foi observado que houve diferenças significativas entre os diferentes tipos de teste - teste de desfecho fixo e desfecho livre, além de uma interessante relação dose resposta da CAF com o efeito na endurance muscular - ainda que explicasse pouco da variação entre os estudos. Diferentemente da força muscular, não houve interação entre efeito e grupo muscular.

\subsubsection{FUNDAMENTOS FISIOLÓGICOS DA ERGOGENIA DA CAFEÍNA}

A cafeína é capaz de ultrapassar a barreira hematocefálica, com grande atuação no sistema nervoso central, onde ocorreria sua principal ação, a de antagonismo à adenosina, isto é, a CAF se acopla a um receptor de adenosina, impedindo a ação da mesma (ASTORINO; ROBERSON, 2010; FREDHOLM et al., 1999; MATTOS et al., 2014; WARREN et al., 2010), mas, como a cafeína é uma substância lipofílica, apresentando alta afinidade com as moléculas de gordura, é capaz de ultrapassar as membranas celulares, tendo potencial para agir em diversos tecidos no corpo (FREDHOLM et al., 1999; SKINNER et al., 2014).

Os mecanismos que fundamentam os possíveis efeitos ergogênicos da CAF na força máxima e na endurance muscular não estão totalmente esclarecidos. O principal mecanismo apontado pela literatura é o antagonismo aos receptores de adenosina (DAVIS; GREEN, 2009). Existe também a possibilidade de que alguns mecanismos periféricos possam atuar em conjunto (WARREN et al., 2010). Desta forma, os possíveis mecanismos que fundamentam a ergogenia da CAF podem ser divididos em centrais e periféricos. 


\subsubsection{MECANISMOS CENTRAIS DE ATUAÇÃO DA CAFEÍNA}

Considerando as diversas ações que a CAF poderia exercer no sistema nervoso central, sabe-se que em doses fisiológicas elas se restringem a antagonismo dos receptores de adenosina (FREDHOLM et al., 1999). A adenosina é o produto (praticamente) final da adenosina trifosfato, que após doar seu grupamento fosfato de alta energia se torna uma adenosina difosfato então sob a ação da adenilato cinase uma 5' adenosina monofosfato para finalmente sob a ação da enzima citosólica 5'nucleotidase perder seu último grupamento fosfato de alta energia. (DUNWIDDIE; MASINO, 2001). A adenosina é considerada um neuromodulador, não sendo liberada como um neurotransmissor, mas, possui afinidade com diversas células tendo a capacidade de hiperpolarizar membranas, afetando a transmissão sináptica dos neurônios (SEBASTIÃO; RIBEIRO, 2000). A atuação da adenosina é definida pelo receptor que ela se ligar. São quatro principais receptores conhecidos - $A_{1}, A_{2 A}, A_{2 B}$ e $A_{3}$ - com atuações consideravelmente amplas e em alguns casos até antagônicas sendo encontrados principalmente no sistema nervoso central, embora possam sejam também encontrados em outros tecidos importante do corpo (DUNWIDDIE; MASINO, 2001; FREDHOLM et al., 1999).

Mesmo a CAF sendo um antagonista não seletivo, isto é, ela poderia se ligar a qualquer um dos receptores e bloquear a ação da adenosina, sua ação está mais associada ao bloqueio de receptores $A_{1}$ e $A_{2 A}$, que são os mais abundantes e nos quais a adenosina mais age em condições normais (FREDHOLM et al., 1999).Estudos usando modelo animal tem indicado que os efeitos da CAF na parte motora parecem estar ligados principalmente ligados ao bloquei dos receptores $A_{2 A}$. El Yacoubi et al., (2000) observaram os efeitos da CAF em camundongos normais e sem os receptores de adenosina $A_{2 A}$. A ergogenia ocorreu somente nos camundongos normais.

Quanto a questão do sítio de atuação, tendo em vista que existem receptores de adenosina nas células musculares, Davis et al., (2003) comparam o efeito de injeção de CAF na região intraperitoneal (região das vísceras) com intracerebroventricular - a CAF fez efeito somente na injeção cerebroventricular - mostrando que atuação mais importante da CAF é diretamente no sistema nervoso central.

Por consequência, alguns mecanismos que poderiam gerar um aumento de força e endurance muscular tem sido investigados, sendo principalmente: o aumento do recrutamento das unidades motoras, diminuição do tempo da reação, maior estado de alerta e diminuição da percepção subjetiva de dor (ASTORINO et al., 2010). Uma das explicações com mais evidências para o aumento de força é o aumento do número de recrutamento de unidades motoras, estudos que observaram esse fenômeno, normalmente observaram também aumento de força (WARREN et al., 2010). Algumas outras hipóteses como uma maior excitabilidade das unidades motoras, aumento no número de disparos das unidades motoras e similares tem sido proposto, porém, ou não são observados ou apresentam resultados contraditórios (KALMAR, 2005). Um mecanismo possível para aumentar a endurance muscular é a redução da sensação de dor (DUNCAN; OXFORD, 2012; KALMAR, 2005; O'CONNOR et al., 2004). 


\subsubsection{MECANISMOS PERIFÉRICOS DE ATUAÇÃO DA CAFEÍNA}

Os mecanismos pelos quais a CAF atua perifericamente são alvos de significante controvérsia. Teoricamente as doses em que a CAF atuaria sobre o músculo diretamente seriam tóxicas (FREDHOLM et al., 1999), só recentemente foi visto aumento de força em células musculares (animais) com doses fisiológicas para humanos (TALLIS; DUNCAN; JAMES, 2015). Ainda assim, diversos estudos mostram que a CAF aumenta a força sob a condição de contrações eletricamente induzidas (WARREN et al., 2010), as quais provavelmente não podem ser afetadas por expectativas (efeito placebo), bem como aumento de força em condições de fadiga eletricamente induzida, ou uma maior resistência a fadiga quando estimulada eletricamente (MOHR et al., 1998; TARNOPOLSKY; CUPIDO, 2000). Os principais mecanismos apontados são a maior liberação de cálcio pelo retículo sarcoplasmático, maior sensibilidade do músculo ao cálcio e menor acúmulo de potássio intersticial (MOHR; NIELSEN; BANGSBO, 2011; TARNOPOLSKY; CUPIDO, 2000).

Considerando diversas pesquisas apontando o aumento de força em contrações eletricamente induzidas, não podemos descartar que a CAF possa atuar tanto de forma central quanto de forma periférica, podendo inclusive ser uma explicação para divergência de resultados entre as pesquisas, algumas pessoas serem mais sensíveis aos mecanismos centrais, outras aos periféricos e outros aos dois (MIZUNO et al., 2005).

\subsubsection{SEGURANÇA NA SUPLEMENTAÇÃO DE CAFEÍNA}

Suplementação de CAF é seguro, isso é atestado por diversas revisões sistemáticas e metaanálises apontando para sua segurança e até propriedades protetoras, como por exemplo, para fibrilação atrial (CHENG et al., 2014), diabetes tipo 2 (DING et al., 2014), mortalidade por todas as causas (JE; GIOVANNUCCI, 2014) e acidente vascular cerebral (KIM et al., 2012). Não há relatos de efeitos colaterais graves nas pesquisas recentes sobre cafeína e treinamento de força, em diversas doses, que impedisse a realização de exercício (MORA-RODRIGUEZ; PALLARÉS, 2014; PALLARÉS et al., 2013; WARREN et al., 2010). Existem sim, pessoas que são sensíveis a CAF e nessas, há relação entre problemas de saúde e consumo de CAF (CORNELIS et al., 2006; PALATINI et al., 2009). Não existe um padrão exato para definir uma dose tóxica, geralmente níveis sanguíneos acima de $50 \mathrm{mg} / \mathrm{L}$ são considerados tóxicos e acima de $100 \mathrm{mg} / \mathrm{L}$ são letais (POUSSEL et al., 2013). Uma dose de CAF de $6 \mathrm{mg} / \mathrm{kg}$ de massa corporal - dose próxima a adotada pelo presente trabalho, resulta em uma concentração máxima de aproximadamente 35 $\mu \mathrm{g} / \mathrm{L}$ (SKINNER et al., 2014). Assim a suplementação de CAF com os valores tipicamente usados em estudos envolvendo exercício (PALLARÉS et al., 2013), são seguros para a saúde da grande maioria das pessoas.

\subsubsection{EFEITO PLACEBO}

O efeito placebo (PLA) ou resposta placebo tem seus primeiros registros na ciência a mais 250 anos, quando fisiologistas eram "desafiados" a descobrir se um determinado tratamento realmente funcionava, possivelmente, o primeiro experimento utilizando um tratamento falso (PLA) para comparar 
com um potencial tratamento genuíno tenha sido feito por Benjamin Franklin na segunda metade do século XVIII (BENEDETTI, 2013). Os anos se passaram e o uso do PLA na pesquisa se consolidou como corriqueiro, sendo ignorado o potencial efeito do mesmo. Um efeito PLA é quando um tratamento, uma substância, ou qualquer forma intervenção que por si só não possui ação fisiológica direta gera resultados benéficos, podendo ser os mais diversos, de diminuição de dor a alivio de sintomas de doenças até melhora no desempenho físico (POLLO; CARLINO; BENEDETTI, 2011).

Recentemente tem sido observado que esse efeito PLA pode ser significativo e ter um sentido mais amplo que se pensava, estudos com medicamentos analgésicos aplicados de modo oculto demonstram que deve ser aplicada uma dose cinco vezes maior (dependendo do medicamento) para que a mesma ação analgésica seja alcançada do que quando o indivíduo é informado que ele vai receber o medicamento (BENEDETTI, 2013). O Efeito PLA passa longe de ser uma superstição, suas vias de ação fisiológicas começam a ser delimitadas, podendo inclusive ser bloqueado farmacologicamente (POLLO; CARLINO; BENEDETTI, 2011). A ação do efeito PLA parece estar muito ligada a analgesia, principalmente por meio de receptores opióides e canabinoides. A ação PLA no Mal de Parkinson demonstra que ela provavelmente também pode interagir com a dopamina nos gânglios basais.

Poderia o PLA interagir também com as regiões do sistema nervoso ligados ao exercício físico, no sentido de prolongar o tempo de exercício e retardar a fadiga?

\subsubsection{EFEITO PLACEBO NO EXERCÍCIO}

Possivelmente o primeiro estudo tratando do efeito PLA no exercício foi o de Ariel e Saville (1972), eles verificaram o efeito da administração de um esteroide anabolizante nos ganhos de força. Eles observaram que mesmo depois de já acompanharem os jovens por oito semanas, quando eles administraram o anabolizante seus ganhos de força em cinco semanas foram maiores que no período de oito semanas - o pequeno detalhe é que era um placebo e não um anabolizante. Desta forma, fica evidente o "poder" do placebo, mesmo falando de adaptações crônicas ao exercício físico. Quase 30 anos depois, outro estudo observou resultados muito similares (MAGANARIS; COLLINS; SHARP, 2000), deram PLA a atletas informando que estariam recebendo um anabolizante de ação rápida. Em apenas uma semana, eles observaram ganhos elevados de todo grupo, após isso, metade do grupo foi informado que eles na verdade eles estavam recebendo um PLA. No próximo teste, o grupo que foi informado que estava utilizando um PLA teve seu desempenho piorado, voltando ao começo da pesquisa enquanto o outro continuo aumentando o desempenho. Nenhum dos estudos tentou explorar os mecanismos por trás de resultado.

Desde então, os estudos envolvendo efeito PLA no exercício caminharam muito (CLARK et al., 2000; FOAD; BEEDIE; COLEMAN, 2008; MCCLUNG; COLLINS, 2007)\, colocando em cheque, um ponto crucial, não seria o desenho duplo-cego clássico adequado para examinar o efeito de um suplemento, por exemplo, tendo em vista que ele não sabe o que está recebendo? Estudos com PLA simulando um desenho duplo cego trazem informações muito interessantes (BEEDIE et al., 2006). Ainda que não se saiba as quais as vias fisiológicas de atuação, a atuação do PLA parece se associar a 
mecanismos de condicionamento, isto é, certas condições podem facilitar ou até aumentar o efeito PLA (BENEDETTI; POLLO; COLLOCA, 2007; POLLO; CARLINO; BENEDETTI, 2008).

\subsubsection{EFEITO PLACEBO E DESENHO EXPERIMENTAL}

Igualmente na área médica e na área do exercício, tem sido observado que devido a influência elevada do PLA nos resultados talvez o modelo duplo-cego clássico não seja o ideal para avaliar o efeito de fármacos e suplementos. A expectativa daquele que é avaliado pode afetar os resultados da pesquisa (BEEDIE et al., 2006; DUNCAN; LYONS; HANKEY, 2009; POLLO et al., 2001).

Especialistas na área têm recomendado o desenho experimental conhecido como "balanced placebo design" - desenho balanceado por placebo. Apesar de enganar o participante, esse modelo tem sido o mais indicado para este tipo de pesquisa (BEEDIE; FOAD, 2009; BENEDETTI, 2013). Entretanto, é importante ressaltar que esse tipo de abordagem possui apoio ético pela sociedade americana de psicologia (APA, 2010), desde que os reais procedimentos sejam contados ao participante o mais cedo possível - preferencialmente logo após o fim da coleta de dados e não depois do encerramento da pesquisa. Este modelo trabalho comparando os resultados de quatro sessões, 1 - Informa dar droga/ dá droga; 2 - Informa dar dorga / dá placebo; 3 - Informa dar placebo / dá droga; 4 - Informa dar placebo / dá placebo (BEEDIE; FOAD, 2009). Seja por meio de uma análise de variância de dois fatores (ANOVA $2 \times 2$ ) sejam usando cálculos secundários (CLARK et al., 2000; FOAD; BEEDIE; COLEMAN, 2008), esse desenho experimental fornece meios para analisar o efeito da expectativa que normalmente não seriam possíveis em um modelo duplo-cego tradicional.

\subsubsection{FORÇA MUSCULAR}

A força muscular da aptidão física relacionada à saúde, podendo ser definida como a capacidade do musculo exercer tensão (GARBER et al., 2011; WARREN et al., 2010). Ela desempenha um papel importante na saúde, sendo a baixa força muscular preditora de mortalidade, câncer e de perda de funcionalidade (BRILL et al., 2000; RUIZ et al., 2008, 2009). Ela também é fundamental no campo atlético, sendo determinante para vários esportes que envolvem a produção máxima de força, como: levantamento de peso, arremesso de peso e outros (BURKE, 2008).

A cafeína é uma substância muito presente nos suplementos alimentares consumidos pelos praticantes de atividades físicas que necessitam de força e potência, em produtos conhecidos como "pré-treinos" que visam aumentar o desempenho do indivíduo de forma aguda (ALVES e LIMA, 2009; EUDY et al., 2013). Mesmo sendo muito utilizada, os efeitos da cafeína ainda são controversos na área do treinamento de força, mais especificamente no seu efeito na força máxima, diferentemente do exercício aeróbio em que seu efeito ergogênico é bem conhecido e documentado (GANIO et al.,2009). Diferentemente do exercício aeróbio (FOAD; BEEDIE; COLEMAN, 2008), ainda não se sabe a expectativa de CAF pode exercer efeito, há indícios que sim (POLLO; CARLINO; BENEDETTI, 2008), tendo em vista que alteração nas expectativas podem influenciar o desempenho da força muscular (ARIEL; SAVILLE, 1972). 


\subsubsection{ENDURANCE MUSCULAR}

A endurance muscular pode ser definida como a capacidade de resistir à fadiga, ou tempo em que o músculo consegue manter determinada tensão alvo (HICKS; KENT-BRAUN; DITOR, 2001).

O número de repetições em uma série de exercício no treinamento de força é importante, pois é um indicador do trabalho realizado na sessão, enquanto que em modelos animais de treinamento é possível quantificar o esforço realizado na sessão (trabalho) com precisão (PHILIPPE et al., 2015), a realidade em ambientes de academia não oferecem tantas possibilidades, sendo normal avaliar o trabalho usando um cálculo matemático simples (séries $\mathrm{x}$ repetições $\mathrm{x}$ carga) para estimar o mesmo $\mathrm{e}$ quantificar o esforço físico realizado na sessão de treinamento (MCBRIDE et al., 2009), alguns autores se referem a essa variável (séries $x$ repetições $x$ carga) como volume de treino ou da sessão (LORENZ; REIMAN; WALKER, 2010), o presente trabalho usará o termo volume (da sessão ou total) para se referir a essa variável. Alguns autores da área de treinamento de força recomendam o uso do volume da sessão para monitorar o treinamento, havendo um incremento gradual do mesmo para que possa continuar havendo adaptações ao treinamento (PETERSON; RHEA; ALVAR, 2004; RHEA et al., 2003), inclusive, um das princípios fundamentais para a progressão no treinamento de força previsto pelo Colégio Americano de Medicina do Esporte (ACSM) é o aumento da sobrecarga utilizando o volume da sessão, seja alterando a carga ou o número de repetições (ACSM, 2009).

$O$ volume da sessão realizado durante o treinamento apresenta uma associação significativa com o aumento de força tanto em homens quanto em mulheres (PETERSON et al., 2011), por isso, aumentar o trabalho realizado em uma sessão pode ser um modo de gerar maiores adaptações ao longo do tempo, justificando o uso de CAF para tentar aumentar o trabalho em uma sessão.

\subsubsection{ESCALA DE PERCEPÇÃO DO ESTADO DE RECUPERAÇÃO (EPER)}

Para a realização de um treinamento físico ótimo, ou até de sucessivas sessões de exercício em uma pesquisa, faz-se necessário saber se aquele que pratica está suficientemente recuperado para executar uma nova sessão de exercício. Uma forma acessível para tentar sabe se o avaliado está é recuperado é utilizando escalas subjetivas em que o avaliado relata sua prontidão para o exercício, por exemplo, Ahtiainen et al., (2011) obtiveram resultados interessantes em seu estudo em que a escala subjetiva que propuseram estava alterada em relação ao repouso por dois dias, período em que a força muscular estava diminuído os marcadores biológicos de inflamação estavam elevados, contudo, a falta de uma análise mais aprofundada sobre sua escala, validação, números de falsos positivos e falsos negativos acabou limitando seu uso, ainda que tenha sido usada em outros trabalhos científicos (FERREIRA, 2015). No mesmo ano LAURENT et al., (2011) propuseram uma escala de zero a dez contendo âncoras verbais (frases ilustrativas) a cada dois números para analisar o quão recuperado está a pessoa para treinar, denominada de Escala de Percepção do Estado de Recuperação (EPER). Eles esperavam que em relação ao desempenho no teste físico anterior caso o voluntário marcasse na EPER entre 8 e 10 ele melhoria, entre 6 a 4 seria igual e 0 e 2 pioria o desempenho. Na realização do estudo sua teoria não ser confirmou, mas, ao analisar os dados com base nos valores maiores ou menores que 5, ele conseguiu prever com acurácia (para uma escala subjetiva) a piora de desempenho e a melhora 
do mesmo com 85,7 e $76,5 \%$ de acerto respectivamente. Esta escala foi utilizada por outros trabalhos científicos publicado em periódicos indexados. Sikorski et al., (2013) tentaram relacionar esta escala com variáveis fisiológicas após uma sessão de treinamento de força e observou relações interessantes, 48 horas após a sessão de exercício, o estado de recuperação (a prontidão para treinar) havia diminuído em relação ao valor anterior ao exercício, e a enzima Creatina Cinase (CK) (marcador de dano muscular) estava elevado. Foi observada uma relação cúbica significativa entre o valor reportado na escala e 0 nível de CK $\left(R^{2}=0,59 ; p<0,05\right)$, bem como associações com a dor muscular (quanto menor o valor na escala maior a dor muscular) e com a testosterona livre. Ziemann et al., (2013) observaram após um período de treinamento de tenistas maiores valores de EPER concomitante a aumento de marcadores de proteção contra estresse oxidativo e diminuição de alguns marcadores anti-inflamatórios. A EPER também se mostrou sensível a intervenções que aumentam a recuperação (WILSON et al., 2013).

Assim sendo, o pesquisador optou por usar a EPER para monitorar a eficácia dos intervalos entre as sessões. A mesma foi traduzida através de uma parceria do pesquisador com um tradutor da língua inglesa que possui elevado domínio da língua (CPE CAMBRIDGE). A mesma não foi validade em português. 


\section{OBJETIVOS}

\subsection{OBJETIVO GERAL:}

Verificar o efeito da suplementação aguda de cafeína na força máxima e endurance muscular.

\subsection{OBJETIVOS ESPECÍFICOS:}

1. Avaliar se o aumento de força muscular devido à ação da cafeína é diferente do aumento de força causada pela expectativa de receber cafeína.

2. Avaliar o efeito das diferentes combinações de informar e receber cafeína - sessões experimentais - na força muscular.

3. Avaliar o efeito da cafeína em diferentes velocidades de contrações musculares.

4. Avaliar o efeito da cafeína na força muscular

5. Avaliar o efeito da expectativa de receber cafeína na força muscular.

6. Avaliar se o aumento de endurance muscular devido à ação da cafeína é diferente do aumento de força causada pela expectativa de receber cafeína.

7. Avaliar o efeito das diferentes combinações de informar e receber caféína - sessões experimentais - na endurance muscular.

8. Avaliar o efeito da cafeína na endurance muscular.

9. Avaliar o efeito da expectativa de receber cafeína na endurance muscular.

10. Avaliar o efeito da suplementação de cafeína na lactacidemia após protocolo de exercício.

11. Avaliar se existe associação entre o efeito da cafeína na força e endurance muscular.

12. Avaliar o efeito das diferentes combinações de informar e receber cafeína - sessões experimentais - nos efeitos associados à suplementação de cafeína. 


\section{MATERIAIS E MÉTODOS}

\subsection{AMOSTRA}

O método de amostragem foi não casual, por conveniência. Recrutou-se um total de 25 homens jovens (18 a 30 anos) fisicamente ativos, que atenderam todos os critérios de inclusão. Os voluntários foram encaminhados para o Laboratório de Treinamento de Força da Faculdade de Educação Física, tendo sido excluídos da análise final nove voluntários, portanto, ficando com $\circ \mathrm{n}$ amostral de 16 voluntários. Esta pesquisa foi aprovada pelo Comitê de Ética em Pesquisa com Seres Humanos da Faculdade de Ciências da Saúde (CEP-FS) sob o CAAE: 44527715.0.0000.0030.

\subsubsection{CRITÉRIOS DE INCLUSÃO:}

- Homens jovens (18 a 30 anos);

- Experiência de pelo menos seis meses em treinamento de força;

- Ser saudável, especialmente considerando aspectos cardiovasculares e metabólicos;

- Não apresentar nenhum tipo de lesão ou problema articular, muscular ou ósseo que afetem o exercício de extensão de joelho;

- Não relatar sensibilidade aumentada ou alergia à cafeína;

- Não estar utilizando esteroides anabolizantes;

- Não estar utilizando suplementos que envolvam cafeína por pelo menos uma semana;

- Estar familiarizado com o exercício agachamento;

- Não ser fumante.

\subsubsection{CRITÉRIOS DE EXCLUSÃO:}

- Não completar todas as sessões previstas;

- Realizar sessão de exercícios resistidos, exercícios cíclicos ou qualquer outro tipo de exercício para os membros inferiores durante o período do experimento que possa afetar o desempenho do avaliado durante os testes;

- Usar substâncias ergogênicas diferentes das previstas durante o período do estudo;

- Realizar consumo de cafeína adicional, não previsto durante o período experimental e que possam afetar os resultados dos testes.

\subsubsection{EXCLUSÃO DE VOLUNTÁRIOS}

Quanto aos voluntários excluídos, a principal causa foi não terem completado todas as sessões experimentais, o que ocorreu devido a diversos motivos. Um voluntário contraiu dengue e por ter se hospitalizado não pode completar a pesquisa, outro relatou sentir dores nas costas no dia seguinte a execução do teste de endurance muscular (TEM) e preferiu deixar a pesquisa os outros sete foram por 
motivos pessoais, sendo principalmente por falta de tempo para se deslocar ao laboratório pelas manhãs ou por motivo de viagem.

\subsection{DESENHO EXPERIMENTAL:}

O estudo foi dividido em seis sessões sendo uma de familiarização, uma de controle e quatro experimentais. A FIGURA 2 apresenta o esquema do desenho experimental.

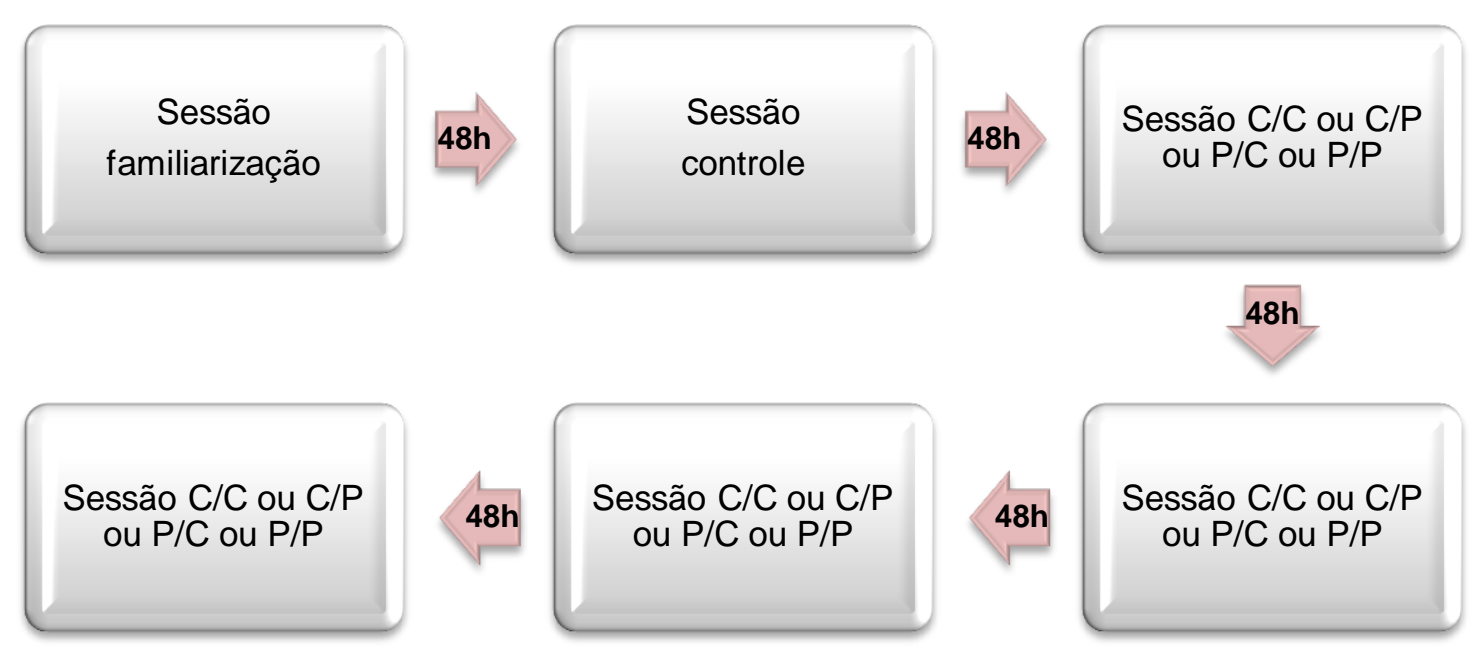

FIGURA 02 - Representação esquemática do desenho experimental.

Na primeira sessão houve a familiarização aos testes e aos procedimentos da pesquisa, sendo apresentado ao voluntário à escala de percepção do estado de recuperação e o questionário de efeitos da cafeína. Também foi realizada uma breve anamnese quando alguns dados pessoais foram coletados como: tempo de treinamento de força, experiência do usuário com suplementos que envolvem cafeína, estado de saúde atual (se apresentava alguma virose ou infecção do trato respiratório superior). Nesse mesmo momento foi aplicado o Par-Q, questionário sob prontidão para prática de exercício, bem como, foram checados os critérios de inclusão. Após isso, o participante foi informado sobre todos os cuidados exigidos durante a participação da pesquisa, incluindo os critérios de exclusão. Em seguida foi aplicado o inquérito sobre o consumo de cafeína e realizadas as medidas de massa corporal e estatura. A massa corporal foi medida por meio de balança eletrônica com precisão de 0,5 kg (P 150M, Líder, Brasil) e a estatura por estadiômetro de parede com precisão de 0,1 mm (ES2020, Sanny, Brasil). A composição corporal foi avaliada por meio do método de absortometria por emissão de raios $X$ de dupla energia (DXA). Devido à elevada demanda por esse tipo de avaliação por diversas pesquisas realizadas na Faculdade de Educação Física, foi necessário a marcação de um dia a parte para realizar essa avaliação.

Também nessa primeira sessão os participantes foram submetidos a familiarização com o dinamômetro isocinético para realização do teste de força máxima (TFM) e depois de um intervalo de no mínimo dez minutos, realizou-se o teste de uma repetição máxima (1RM). Em sequência foram 
explicados os procedimentos para o teste de endurance muscular (TEM), seguido de uma breve familiarização.

Na segunda sessão, sessão controle, foram realizados o TFM e o TEM.

Nas sessões experimentais o participante foi relembrado de forma padronizada sobre os efeitos ergogênicos da cafeína (maior força e endurance muscular, maior disposição para o exercício) bem como dos efeitos ergolíticos que podiam acontecer (desconforto gastrointestinal, cefaleia, diurese e outros). Depois disso, foram realizados os testes de força máxima e de endurance muscular, agora sob efeito de suplementação - que foi oferecida uma hora antes da execução dos testes, variando entre suplementação de cafeína ou placebo. A dosagem usada foi de $5 \mathrm{mg}$ de cafeína por quilograma de massa corporal.

Considerando a influência significativa do efeito placebo em testes físicos conforme relatado por Bérdi et al., (2011), adotou-se um modelo de pesquisa diferente do duplo-cego convencional, tendo em vista as atuais recomendações para avaliar o efeito placebo (BEEDIE, 2010; BENEDETTI, 2013). Este estudo utilizará o modelo de pesquisa "balanced placebo design" (BEEDIE; FOAD, 2009; MCCLUNG; COLLINS, 2007) em que, durante as sessões experimentais o voluntário recebe em duas sessões a suplementação de cafeína e em outras duas o placebo. A FIGURA 03 apresenta um esquema das sessões experimentais. Em todas as sessões os voluntários receberam pílulas (contendo placebo ou cafeína) sem ser possível discriminá-las. Este procedimento teve por objetivo analisar separadamente o efeito placebo do efeito fisiológico da cafeína (FOAD e cols., 2008). São quatro tipos de sessões experimentais:

- $\quad$ sessão C/C em que o pesquisador informou ter dado o suplemento de cafeína (C) e o voluntário de fato recebeu esse suplemento $(C)$;

- $\quad$ sessão $C / P$ em que o pesquisador informou ter dado um suplemento de cafeína (C), porém, o voluntário recebeu placebo $(\mathrm{P})$;

- sessão P/C em que o pesquisador informou ter dado cápsulas placebo $(P)$, porém, 0 voluntário recebeu cafeína $(C)$ e, por fim,

- sessão P/P em que o pesquisador informou ter dado cápsulas placebo $(\mathrm{P})$ e o voluntário de fato receberá placebo $(\mathrm{P})$.

\begin{tabular}{|c|c|c|c|}
\hline & & \multicolumn{2}{|c|}{ INFORMADO } \\
\hline & & INFORMOU DAR CAFEÍNA & INFORMOU DAR PLACEBO \\
\hline \multirow{2}{*}{ RECEBIDO } & $\begin{array}{l}\text { RECEBEU } \\
\text { CAFEÍNA }\end{array}$ & $\begin{array}{l}\text { Informou cafeína/ recebeu } \\
\text { cafeína } \\
(\mathbf{C} / \mathbf{C})\end{array}$ & $\begin{array}{l}\text { Informou placebo/ recebeu placebo } \\
\qquad(\mathbf{P} / \mathbf{C})\end{array}$ \\
\hline & $\begin{array}{l}\text { RECEBEU } \\
P L A C E B O\end{array}$ & $\begin{array}{l}\text { Informou cafeína/ recebeu } \\
\text { placebo } \\
\text { (C/P) }\end{array}$ & $\begin{array}{l}\text { Informou placebo/ recebeu placebo } \\
(\mathbf{P} / \mathbf{P})\end{array}$ \\
\hline
\end{tabular}

FIGURA 03 - Quadro esquemático do desenho balanceado por placebo (o primeiro elemento é o informado e o segundo o recebido). 
Para esse tipo de desenho experimental o mais adequado é proceder estatisticamente a análise de variância de dois fatores (ANOVA two-way), para analisar o efeito dos dois fatores - usar ou receber a CAF e informar a administração ou não de CAF (crença, ou expectativa). Foad; Beedie e Coleman, (2008) propuseram utilizar outra forma de análise complementar, fornecendo assim, mais informações sobre os resultados. Essa forma de análise se baseia em duas equações, a equação I para calcular o efeito da CAF e a equação II que tem o objetivo de calcular o efeito da crença ou da expectativa que a CAF pode gerar (FIGURA 04).

$$
\text { Equação 1: EFEITO DA CAFEÍNA: } \frac{(\mathrm{C} / \mathrm{C}+\mathrm{P} / \mathrm{C})-(\mathrm{C} / \mathrm{P}+\mathrm{P} / \mathrm{P})}{2}
$$

$$
\text { Equação II: EFEITO DA CRENÇA: } \frac{(C / C+C / P)-(P / C+P / P)}{2}
$$

FIGURA 04: Equações do efeito da cafeína (equação I) e da expectativa ou crença (equação II).

Fonte: (FOAD; BEEDIE; COLEMAN, 2008).

Nas equações são utilizados os valores percentuais de variação de cada sessão respectiva em relação ao valor da sessão controle - assim, o efeito calculado passa a ser um incremento percentual frente a sessão controle (sem intervenção). Isso nos informa o quanto que a CAF e sua expectativa podem aumentar o desempenho frente ao cenário de ausência de intervenção.

O intervalo dado entre as sessões experimentais foi de no mínimo 48 horas visando a plena recuperação entre as sessões de exercício e a completa eliminação da cafeína consumida - "wash-out" (Pallares e cols., 2013).

\subsection{PROCEDIMENTOS}

\subsubsection{ANAMNESE:}

O voluntário foi recebido pelo pesquisador com uma série de perguntas com vistas a obter informações secundárias que pudessem ser relevantes para o andamento da pesquisa, tais como: Data de nascimento, tempo de prática de treinamento de força, bem como frequência semanal e duração das sessões, se fazia agachamento livre ou no Smith, se executa outras atividades e sua frequência semanal e duração diária, se já utilizou suplementos anteriormente, qual a percepção sobre suplementos prétreinos, estado de saúde crônica, agudo, se fuma, se apresenta sensibilidade à cafeína, se faz uso de fármacos, se já usou esteroides anabolizantes e qual a expectativa em relação à suplementação de cafeína. Ao final da anamnese aplicou-se o questionário PAR-Q. 


\subsubsection{PAR-Q:}

É um instrumento de ampla utilização e cujo objetivo foi examinar a prontidão para a prática de exercício dos voluntários. O questionário possui sete perguntas simples, exigindo respostas sim ou não. Apesar de originalmente ser autoaplicável, as perguntas foram feitas pelo avaliador com o objetivo de ganhar agilidade no processo e de evitar falsos positivos (SHEPHARD, 2015).

\subsubsection{SUPLEMENTAÇÃO:}

Para esse estudo foi adotada a dosagem de 5 miligramas por quilo de massa corporal. Essa dosagem foi escolhida por ter se mostrado eficaz em estudos anteriores (ASTORINO; ROBERSON, 2010; BLACK; WADDELL; GONGLACH, 2015), mantendo seu efeito ergogênico e havendo uma menor ocorrência de efeitos colaterais (PALLARÉS et al., 2013), facilitando o vendamento (cegamento) do voluntário e do pesquisador.

Uma hora antes da sessão experimental o participante recebia a suplementação, podendo ser cafeína $(5 \mathrm{mg} / \mathrm{kg})$ ou placebo - cápsula contendo talco farmacêutico com aspecto idêntico a cápsula de cafeína (ASTORINO; ROBERSON, 2010). As cápsulas foram formuladas em farmácia de manipulação contendo 50 ou $100 \mathrm{mg}$ de cafeína, e elas foram somadas de forma a alcançar o valor desejado, de acordo com a dosagem relativa à massa corporal do indivíduo $(5 \mathrm{mg} / \mathrm{kg}$ de massa corporal). Nas cápsulas de $50 \mathrm{mg}$ foi necessário o uso de $1 \mathrm{~g}$ de excipiente (Celulomax E® - celulose microcristalina) para completar o preenchimento da cápsula. As cápsulas de placebo foram formuladas com a dosagem necessária de talco farmacêutico para terem a aparência idêntica a de cafeína. As cápsulas tinham cores diferentes, de acordo com os dias de teste - em um total de quatro cores. Utilizou-se a variação das cores com o objetivo de aumentar a chance de "cegar" (vendar) o avaliado e o avaliador. Foi dado ao voluntário $300 \mathrm{ml}$ de água para auxiliar a ingestão das cápsulas, que foi consumida no prazo de um minuto.

A suplementação ocorreu de modo duplo-cego, ou seja, nem o avaliado nem o pesquisador sabiam de fato o que estava sendo oferecido ao voluntário, de tal forma que o técnico de laboratório, que não participou do experimento, separava previamente as cápsulas para compor a dosagem individual adequada para cada sessão experimental. Para garantir a aleatoriedade das sessões, foram construídas pela orientadora duas tabelas. Uma para auxiliar o técnico de laboratório que organizava a suplementação de modo que ele soubesse o que deveria preparar para cada dia do experimento. A outra tabela orientava o pesquisador que realizava os testes, o que deveria ser informado ao participante a cada sessão. As tabelas foram elaboradas de forma a apresentar diversas combinações entre as sessões para dificultar e confundir a ordem de execução por parte do pesquisador e do voluntário, bem como, para que a ordem das sessões não afetasse os resultados da pesquisa.

\subsubsection{COMPOSIÇÃO CORPORAL:}

A composição corporal foi mensurada utilizando o método de absortometria por emissão de raios X de dupla energia (DXA) (Lunar 8743 software Encore 2005, GE Health Care, Reino Unido), 
considerado como padrão ouro para composição corporal. O avaliado permaneceu na posição supina sobre a maca do aparelho, alinhado cuidadosamente no centro da máquina de acordo com as linhas de orientação, em roupas leves, sem portar nenhum objeto de metal. A dose de radiação foi desprezível aproximadamente 0,5 $\mu \mathrm{Sv}$ (BRAULIO et al., 2010; LIMA et al., 2009), equivalente a cerca de 6000 vezes menos radiação do que uma tomografia computadorizada de tórax (CALEGARO, 2007). Obteve-se dessa forma o percentual de gordura corporal de cada voluntário.

\subsubsection{TESTE DE FORÇA MÁXIMA (TFM):}

Para a mensuração de força máxima foi utilizado dinamômetro isocinético (System IV, Biodex Medical, Shirley, EUA), instrumentos padrão ouro para avaliação, e de grande sensibilidade para as alterações na produção de força (BOTTARO et al., 2010; BROWN; WEIR, 2001). Fato esse importante para estudos que pretendem detectar pequenas diferenças, na força de membros, que podem ser significativas para o desempenho esportivo (BÉRDI et al., 2011; PALLARÉS et al., 2013).

\subsubsection{TESTE DE FORÇA MÁXIMA CONCÊNTRICA (TFMC):}

O voluntário, sentado na cadeira, tinha o braço do dinamômetro ajustado com o côndilo lateral do fêmur do joelho direito. Para evitar movimentos corporais desnecessários o avaliado foi fixado por cintos, nas regiões da coxa, quadril e tronco. O voluntário foi instruído para realizar o máximo de força possível na fase concêntrica da extensão de joelho e não fazer força na fase de flexão. $O$ teste em si consistiu na execução de duas séries de três segundos de contração máxima isométrica com um intervalo de um minuto entre as séries, seguida por duas séries de quatro repetições de contrações voluntárias máximas, em três velocidades distintas $(60 \% / \mathrm{s}, 180 \% \mathrm{~s}, 300 \%$ ), nesta mesma ordem, com intervalo de dois minutos entre cada série. Todas as séries foram realizadas no membro inferior direito (BOTTARO et al., 2010; BROWN; WEIR, 2001). Há muito tempo existem diversos protocolos de aquecimento (KEATING; MATYAS, 1996), estudos tem mostrado que o protocolo de aquecimento, desde que haja familiarização, é indiferente para o resultado final do teste com isocinético (ALTAMIRANO et al., 2012; FERREIRA-

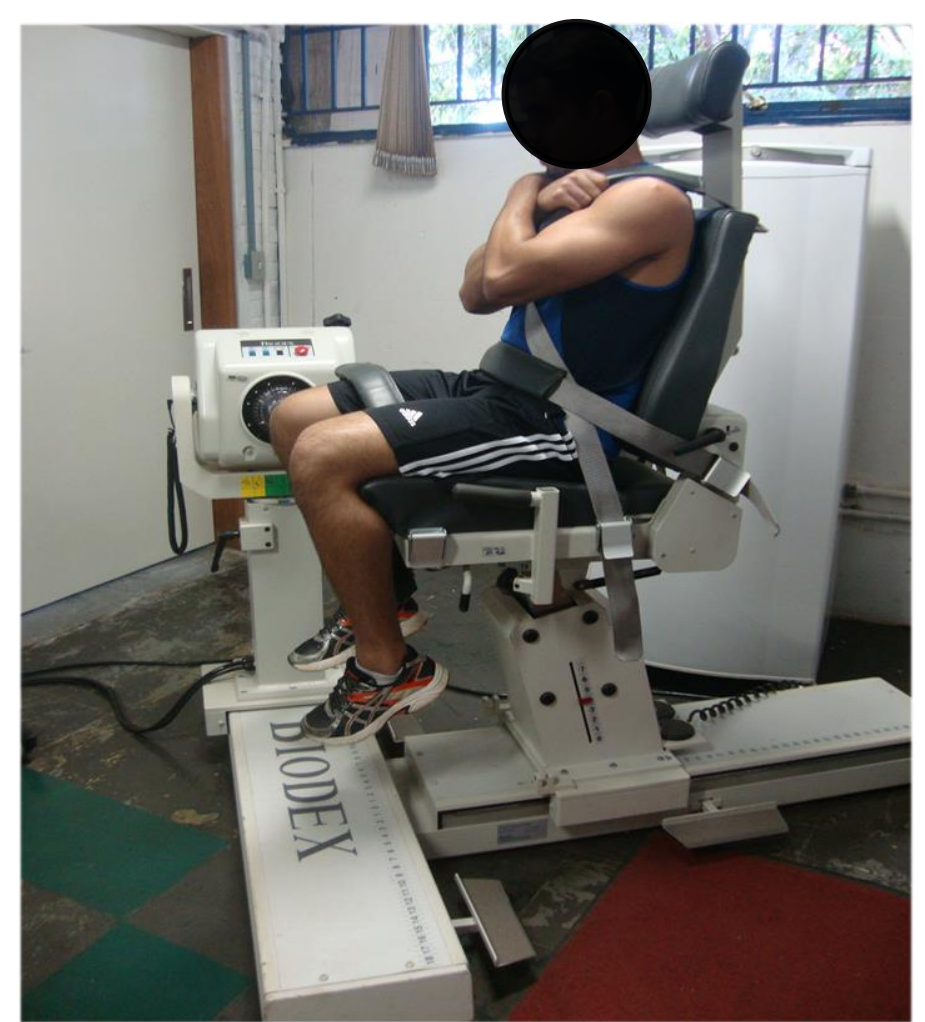


JÚNIOR et al., 2013; SIM; BYUN; YOO, 2015). O protocolo de aquecimento utilizado foi de doze repetições à $180^{\circ} / \mathrm{s}$, começando com contrações fracas, indo para moderadas e terminando com contrações máximas (BROWN; WEIR, 2001).

FIGURA 05 - Indivíduo sentado em um dinamômetro isocinético.

Através dos relatórios gerados pelo software do equipamento que controla o dinamômetro Biodex Advantage 4.0 (Biodex Medical, Shirley, EUA) - foram obtidas três variáveis: pico de torque (PT), pico de torque relativo à massa corporal (PT/MC) e trabalho máximo (TM). A FIGURA 5 mostra um indivíduo sentado no dinamômetro isocinétic Biodex IV, aguardando as instruções para preparação e execução do teste.

\subsubsection{TESTE DE FORÇA MÁXIMA ISOMÉTRICA (TFMI):}

O voluntário foi posicionado na cadeira de modo igual ao do TFMC. O voluntário tinha sua perna posicionada em um ângulo de flexão de joelho de $60^{\circ}\left(0^{\circ}\right.$ sendo a extensão de joelho) para então realizar uma contração voluntária máxima (BROWN; WEIR, 2001; KRISHNAN; WILLIAMS, 2014).

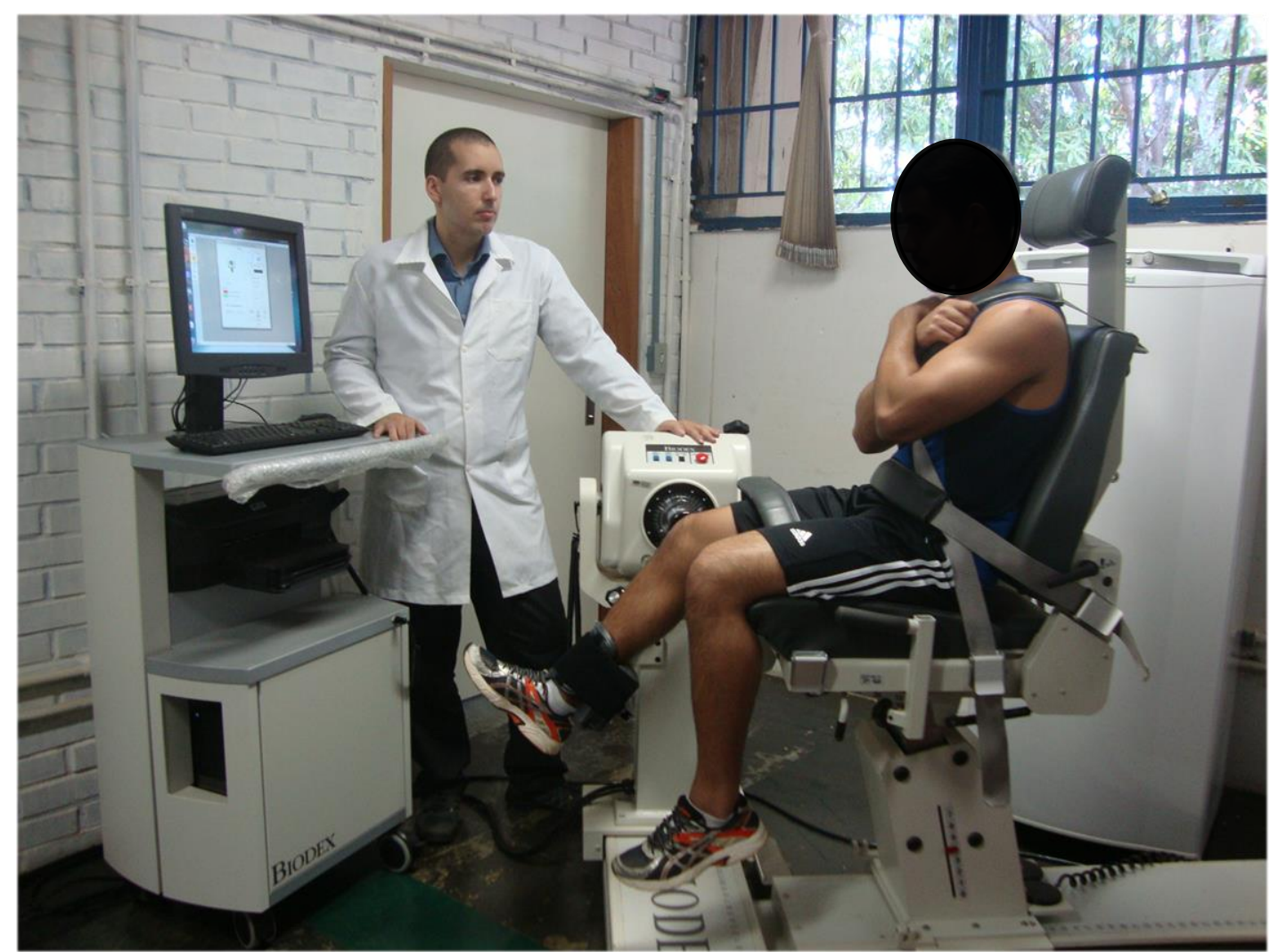

FIGURA 06 - Indivíduo posicionado para execução do TFMI.

Foi utilizado um tempo de contração de três segundos, segundo o padrão do laboratório - tempo este que parece adequado para a análise do PT (BELTMAN et al., 2004; BROWN; WEIR, 2001). Através dos relatórios gerados pelo software do equipamento que controla o dinamômetro obteve-se duas variáveis: $O$ pico de torque (PT) e o pico de torque relativo à massa corporal (PT/MC). A FIGURA 6 mostra o indivíduo posicionado para executar o TFMI. 


\subsubsection{AGACHAMENTO:}

Este exercício foi escolhido por envolver os membros inferiores (WARREN et al., 2010), para facilitar a comparação entre estudos (MARTORELLI et al., 2015; ROGATZKI et al., 2014). No presente estudo o agachamento foi executado na máquina Smith (barra guiada). A posição inicial do exercício foi com o indivíduo em pé, com a barra apoiada na região do trapézio, para iniciar o movimento, ele deve destravar o apoio de segurança da barra e então agachar até que sua coxa esteja paralela ao solo com ângulo de flexão de joelho de aproximadamente $80^{\circ}$ e então retornar a posição inicial em pé. Foi usada uma faixa elástica como referência para manter o exercício em uma mesma amplitude constante de movimento (MARTORELLI e cols., 2015). Este exercício foi utilizado para os testes de uma repetição máxima (1RM) e endurance muscular (TEM). A FIGURA 7 demonstra a execução do exercício e a FIGURA 8 demonstra o posicionamento da faixa elástica.

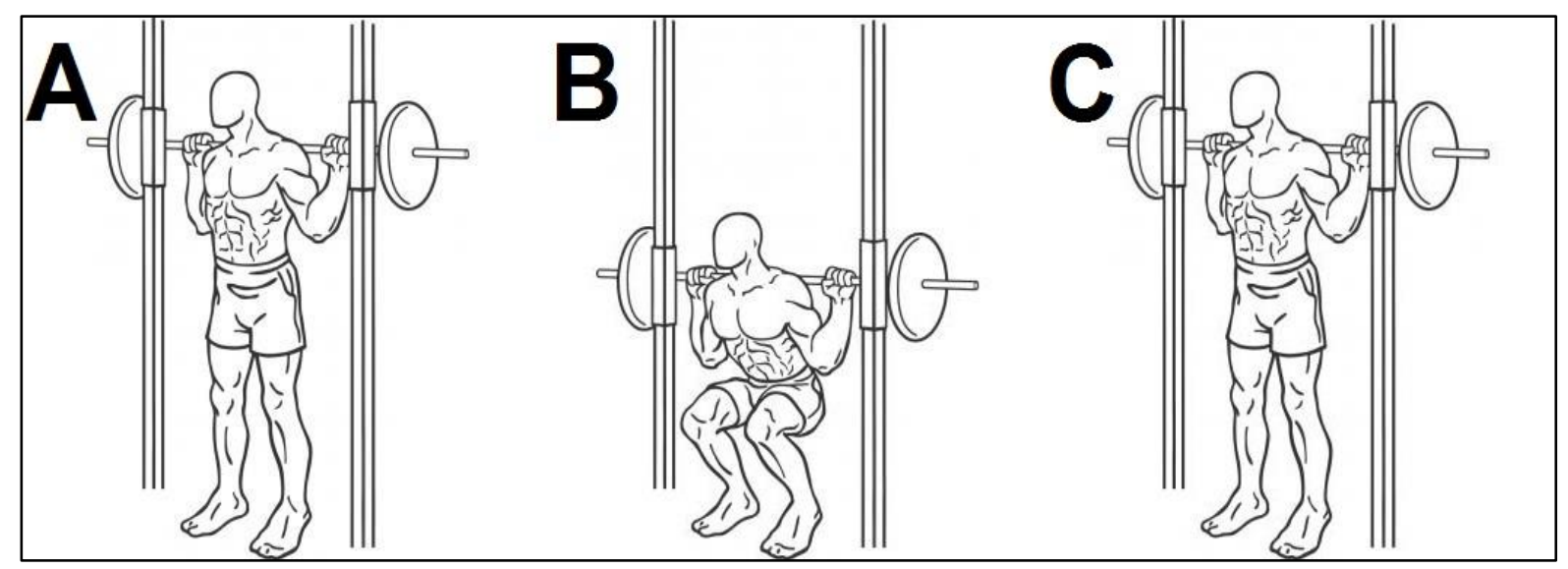

FIGURA 07 - Execução do agachamento: "A" posição inicial; "B" posição final; "C" retorno à posição inicial, completado este ciclo é então contabilizada uma repetição completa.

\subsubsection{TESTE DE 1 REPETIÇÃO MÁXIMA (1RM):}

O teste de 1RM é uma avaliação da força máxima concêntrica, tendo por base a maior carga que um indivíduo consegue levantar em uma única repetição completa em determinado exercício - no caso foi utilizado o agachamento. A realização do teste foi de acordo com (BROWN; WEIR, 2001; MARTORELLI et al., 2015). Foi realizado aquecimento de 8 repetições com a carga estimada de $50 \%$ de $1 \mathrm{RM}$, feito isso, foi dado um intervalo de um minuto para em seguida ser realizada uma série de três repetições com a carga estimada de $70 \%$ de 1 RM. Finalmente, após mais um intervalo de um minuto, foi dado um incremento de peso e então foram realizadas três a cinco tentativas, para determinação de $1 \mathrm{RM}$, com cinco minutos de intervalo entre elas, sendo registrado o valor da maior carga utilizada na última tentativa bem sucedida. 


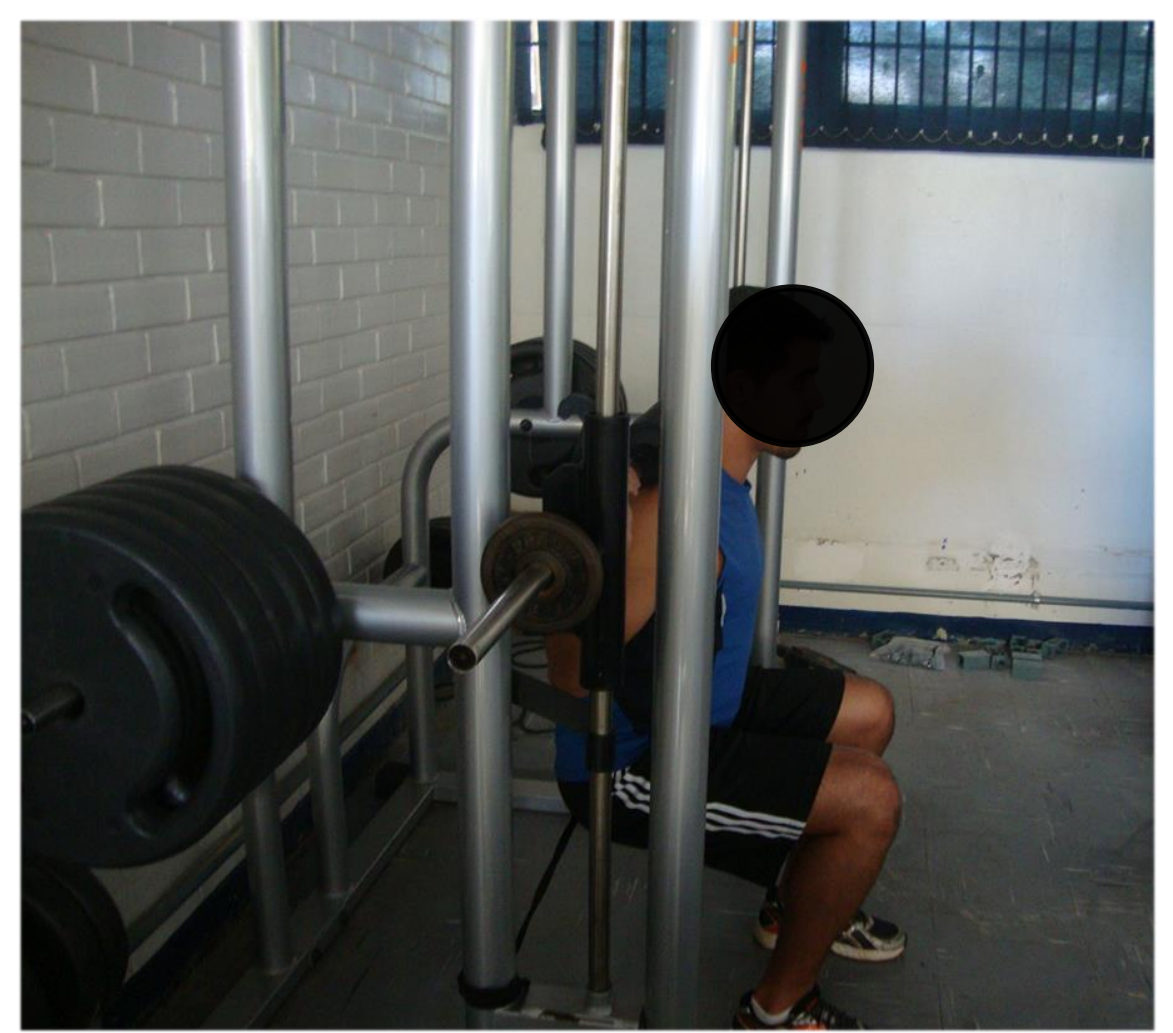

FIGURA 08 - Posicionamento da faixa elástica para que o voluntário mantivesse a mesma amplitude de movimento em todas as repetições.

\subsubsection{TESTE DE ENDURANCE MUSCULAR (TEM):}

O protocolo do teste de endurance muscular consistiu em três séries de repetições máximas até a fadiga realizadas no exercício de agachamento, executado na máquina Smith (barra guiada) utilizando a carga de $60 \% 1 \mathrm{RM}$ e intervalo entre cada série de três minutos sendo a recuperação passiva imediatamente após a série o voluntário ficava sentado em uma cadeira, com dois minutos e trinta segundos o voluntário era instruído a ficar de pé e se aproximar da barra, e com dois minutos e cinquenta segundas o voluntário era instruído a apoiar a barra nas costas e era iniciada a contagem regressiva para que o voluntário começasse o movimento exatamente com três minutos. O voluntário deveria executar a fase excêntrica e concêntrica em dois segundos - a cadência do movimento foi estabelecida utilizando um metrônomo digital (MetronomeFree, Geppo Production, Itália) no ritmo de 60 bpm. Para ajudar o avaliado a executar o movimento na cadência correta, o pesquisador contava os tempos do movimento (um, dois, três, quatro) informando o avaliado previamente que no "dois" ele deveria estar no final da fase excêntrica e no "quatro" ele deveria finalizar a fase concêntrica do movimento. Era dado um intervalo de 10 a 15 minutos entre o TFM e o TEM, para garantir um intervalo ótimo de recuperação.

O protocolo foi elaborado considerando os achados em dois estudos. Williams et al., (2008) não observaram efeito ergogênico da cafeína na realização de uma série única de exercício de força, contudo, Green et al., (2007) observaram efeito significativo da cafeína somente na terceira série de exercício de força, indicando assim que possivelmente o efeito da cafeína ocorre principalmente em 
estados de fadiga (MEYERS; CAFARELLI, 2005; MOHR; NIELSEN; BANGSBO, 2011). Assim, optou-se por utilizar um protocolo com no mínimo três séries de exercício resistido.

\subsubsection{LACTACIDEMIA E COLETA SANGUÍNEA:}

Tendo por objetivo analisar alguma possível influência da suplementação de CAF no metabolismo anaeróbio, foram realizadas medidas de lactato sanguíneo no período de repouso antes dos testes e no $2^{\circ}, 4^{\circ}$ e $6^{\circ}$ minuto após o TEM. Wirtz et al., (2014) observaram que o pico de lactacidemia ocorria no $2^{\circ}$ minuto após exercício, com o valor do sexto minuto sendo menor que o do $4^{\circ}$, por isso, foram utilizados os mesmos intervalos de tempo. Tanto a coleta no período de repouso quanto após o TEM, o individuo se encontrava sentado em uma cadeira.

Para a coleta, realizava-se a assepsia do lobo da orelha com álcool e em seguida a punção com lanceta descartável, sendo que o avaliador usando luvas cirúrgicas descartáveis. Para cada amostra, a superfície lancetada era limpa por gases com álcool para retirada de possíveis gotas de suor, as quais poderiam contaminar as amostras. Um volume de $25 \mu \mathrm{L}$ (micro-litros) de sangue arterializado era retirado por pressão no local e coletado em tubos capilares calibrados e heparinizados e a seguir colocado em tubos Eppendorff com $50 \mu \mathrm{L}$ de fluoreto de sódio a $1 \%$ para posterior análise. A lactacidemia foi determinada utilizando-se um analisador de lactato, modelo YSI 2300 Sport (Yellow Springs Inc, EUA) que opera pelo método eletro-enzimático e a cada dez medidas, para maior precisão, foi calibrado utilizando um padrão de $5 \mathrm{mmol} / \mathrm{L}$. Os valores de lactacidemia foram expressos em $\mathrm{mmol} / \mathrm{L}$. Todas as amostras de sangue coletadas foram analisadas pelo menos duas vezes. Por serem medidas muito estáveis e que sofrem menor variação quando mensuradas pelo lactímetro, as amostras de repouso foram analisadas normalmente uma vez (51,6\% dos casos), em alguns casos foi feita uma segunda medida para confirmação do valor da primera. Caso houvesse alguma variação expressiva entre as duas medidas era feita uma terceira medida de lactato $(10,9 \%$ dos casos).

\subsubsection{ESCALA DE PERCEPÇÃO DO ESTADO DE RECUPERAÇÃO (EPER):}

Foi utilizada a escala de percepção do estado de recuperação proposta por Laurent et al., (2011) para avaliar a recuperação entre as sessões de exercício e inferir se o voluntário encontra-se suficientemente recuperado para realizar nova sessão de exercício. Trata-se de uma escala numerada de 0 a 10, com números maiores indicando maior recuperação. Alguns números da escala estão acompanhados de frases norteadoras para ajudar na marcação. O participante indicava quão recuperado ele se sentia após realização do aquecimento, na segunda sessão de familiarização e em todas as sessões experimentais.

\subsubsection{QUESTIONÁRIO DE EFEITOS DA CAFEÍNA (QEC):}

Este questionário proposto por Del Coso et al., (2012) contém oito itens totais, sendo sete de efeitos ergolíticos relacionados ao consumo de cafeína e exercício (dor muscular, diurese, taquicardia, ansiedade ou nervosismo, cefaleia, desconforto gastrointestinais e insônia) e um efeito ergogênico 
(aumento da sensação de vigor físico) e ao ser apresentada para o avaliado, ele relatava, item por item, falando sim ou não, para cada um dos efeitos listados. A escala foi utilizada imediatamente após a suplementação e a cada 15 minutos subsequentes até completar uma hora, e também, ao comparecer à sessão seguinte.

O QEC foi traduzido através de uma parceria do pesquisador com um tradutor da língua inglesa que possui elevado domínio da língua (CPE CAMBRIDGE). A mesma não foi validade em português.

\subsubsection{ANÁLISE DO CONSUMO DE CAFEÍNA:}

Para quantificar o consumo diário de cafeína do participante, foram utilizadas as tabelas fornecidas por Altimari et al., (2006a, 2006b) - Anexo III e Anexo IV, respectivamente. O avaliador perguntava ao participante sobre o seu consumo de café, chá, bebida energética, refrigerante ou chocolate. Quando o avaliado informava que consumia um dos itens, o avaliador perguntava a quantidade e a frequência semanal e diária. Para o cálculo da quantidade de cafeína ingerida por semana, foi levado em consideração primeiramente os valores de cafeína nos alimentos apresentados por Altimari et al., (2006b), feito isso, a quantidade de cafeína no alimento foi multiplicada pela frequência do consumo - por exemplo, hipoteticamente o avaliado consome uma xícara de café de $150 \mathrm{ml}$ todos os dias da semana, consumindo assim $85 \mathrm{mg}$ de cafeína por dia e, consequentemente, um valor médio de $595 \mathrm{mg}$ de cafeína por semana. Utilizou-se a média dos valores apresentados na tabela de referência de Altimari et al., (2006a).

\subsection{PROCEDIMENTO ESTATÍSTICO}

Para a análise estatística foi utilizado o software Microsoft Excel 2014 versão 14.0 para tabulação dos dados e o software GraphPad Prism versão 7.0. A hipótese de normalidade dos dados foi testada por meio do teste de Shapiro-Wilk, atualmente considerado um dos testes de normalidade mais poderosos, mesmo em amostras pequenas (GHASEMI; ZAHEDIASL, 2012; RAZALI; WAH, 2011). Os dados foram descritos em termo de média e desvio padrão. Para análise inferencial, quando comparada as diferentes sessões experimentais (C/C vs C/P vs P/C vs P/P) foi utilizado ANOVA $2 \times 2$ (Informado $x$ Recebido) utilizando como variáveis dependentes os resultados dos testes de força, TEND e lactacidemia. Foi utilizada uma ANOVA one-way (um fator) para comparar os valores de repouso de lactato e para comparar o efeito da CAF na amostra subdividida em relação ao seu consumo habitual de CAF. Para as análises de post-hoc foi utilizado o teste de Bonferroni por ser um teste conservador e manter um controle adequado do erro tipo I (FIELD, 2005). O nível de significância adotado foi de $\mathrm{p}<0.05$. 


\section{RESULTADOS}

\subsection{CARACTERIZAÇÃO DA AMOSTRA:}

Ao analisar o tipo de distribuição dos dados da pesquisa, alguns dados apresentaram distribuição não normal $(p<0,05)$. Foram então traçados histogramas e diagramas de caixas para a observação desses dados. Foi notada a presença de valores extremos nos grupos supracitados, que certamente seriam responsáveis pelo comportamento não paramétrico naquele grupo de dados. Foi utilizado em conjunto com a inspeção visual, o método matemático proposto por MOTULSKY; BROWN, (2006) para confirmação da presença de valores extremos, utilizando um $Q$ de $1 \%$ conforme recomendado pelos autores. Confirmada presença de valores extremos, os mesmos foram substituídos pelo valor da média mais duas vezes o desvio padrão ou menos duas vezes, conforme a posição do dado no grupo (FIELD, 2005). Foi necessário a normalização dos resultados de dois voluntários nos valores de pico de torque absoluto isométrico e na velocidade de $60 \% \mathrm{~s}$, bem como no total de repetições de um voluntário no teste de endurance muscular (TEM) e na lactacidemia de outro voluntário.

A homogeneidade das variâncias foi confirmada pelo teste de Levene $(p>0,99)$ e a esfericidade foi assumida - isso foi feito pois cada fator da ANOVA apresenta apenas dois níveis (FIELD, 2005). Não foi possível realizar o exame de percentual de gordura em dois voluntários, por isso, eles não foram considerados no cálculo da média e desvio padrão do percentual de gordura do grupo, participando normalmente dos outros cálculos do estudo. A TABELA 1 apresenta as características da amostra.

TABELA 1 - Características antropométricas, força e consumo de cafeína da amostra.

\begin{tabular}{ccccccccc}
\hline & IDADE & MC & EST & IMC & $\% G^{*}$ & CAF/SEM & 1RM & 1RM/MC \\
& $($ anos $)$ & $(\mathrm{kg})$ & $(\mathrm{cm})$ & $\left(\mathrm{kg} / \mathrm{m}^{2}\right)$ & & $(\mathrm{mg} / \mathrm{semana})$ & $(\mathrm{kg})$ & \\
\hline Média & 21,4 & 81,8 & 177,4 & 25,9 & 17,6 & 657,2 & 134,7 & 1,7 \\
DP & 2,9 & 11,1 & 6,2 & 2,6 & 4,0 & 617,2 & 24,1 & 0,3 \\
\hline
\end{tabular}

DP: Desvio padrão; MC: Massa corporal; EST: Estatura; \%G: Percentual de gordura; CC/SEM: Consumo de cafeína semanal; 1RM: 1 repetição máxima.*: 14 voluntários.

Os dados se encontram dentro do esperado para homens jovens treinados. Reforçamos a importância da avaliação do percentual de gordura, pois, pelo índice de massa corporal eles poderiam ser classificados como indivíduos com sobrepeso, contudo, é possível observar que na verdade sua massa corporal elevada está ligada a uma massa muscular elevada, os dados estão similares a outros estudos envolvendo suplementação de CAF (ASTORINO et al., 2010; BEHRENS et al., 2015a; TIMMINS; SAUNDERS, 2014).

Em relação ao consumo de CAF, o grupo é bem heterogêneo, possuindo alguns que não consumiam CAF e outros com elevado consumo, nota-se a média acompanahada de elevado desvio padrão (TABELA 1). O critério para definição de alto ou baixo consumidor, muda muito entre estudos sem a utilização de referências bibliográficas que possam justificar sua definição. 
Quanto aos dados obtidos através da anamnese, os voluntários apresentaram tempo de treinamento de 2,8 $\pm 2,0$ anos, treinando $4 \pm 1$ dias por semana com a duração da sessão de 53,8 $\pm 16,8$ minutos. A maioria fazia outras atividades além de musculação $(81,3 \%)$. Eles foram orientados a evitarem fazer atividades físicas paralelas no período da pesquisa, A maioria já havia utilizado alguma forma de suplemento alimentar $(93,8 \%)$ e alguns especificamente suplementos pré-treino $(43,8 \%)$, dos que utilizaram este tipo de suplemento, a maioria $(87,5 \%)$ tiveram uma percepção positiva sobre o mesmo. Quando perguntados se eles acreditavam que a suplementação de cafeína (CAF) exercia efeito ergogênico a grande maioria disse que $\operatorname{sim}(87,5 \%)$ e o restante disse não trazia efeito nenhum $(12,5 \%)$.

\subsection{ESCALA DE PERCEPÇÃO DO ESTADO DE RECUPERAÇÃO - EPER:}

Como esperado, o intervalo entre as sessões foi suficiente para que a recuperação entre as sessões fosse adequada. Somente foi registrado uma ocorrência de um valor menor que 6 (5), porém, foi na sessão controle. Ao investigar os resultados do voluntário, não houve indícios que seu desempenho tenha sido prejudicado naquele dia, ao comparar com as outras sessões, dando assim confiança para o prosseguimento das análises. A FIGURA 9 apresenta os resultados da EPER em cada sessão.

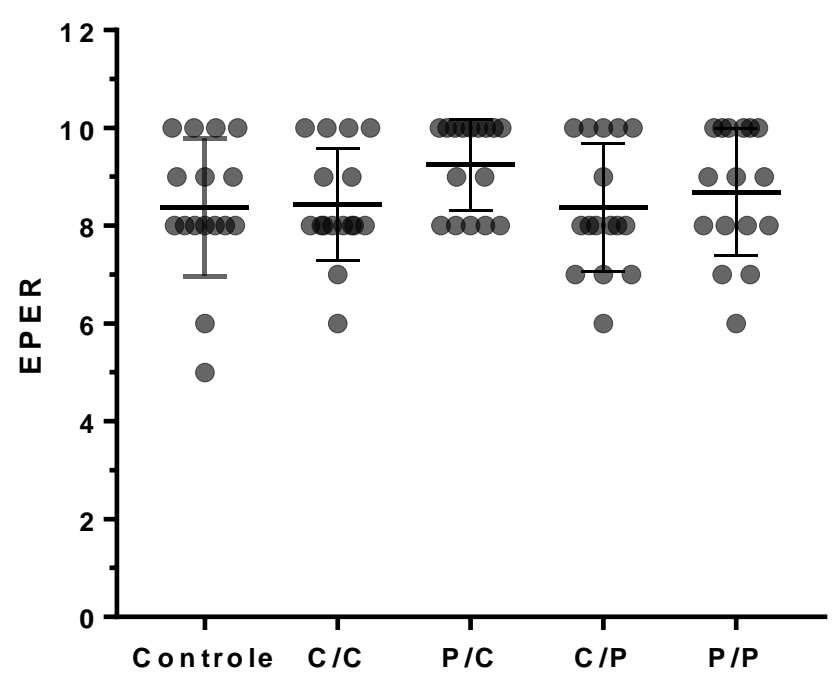

FIGURA 09 - Resultado da EPER em cada sessão experimental.

\subsection{TESTE DE FORÇA MÁXIMA - TFM:}

Foram observados efeitos significativos da ingestão de CAF no TFM $(p<0,05)$, sem qualquer efeito da expectativa de receber $C A F$, também não houve interação entre ingestão de CAF e expectativa de receber CAF $(p>0,05)$. Foram analisadas três variáveis: pico de torque (PT), pico de torque relativo à massa corporal (PT/MC) e trabalho máximo (TM). As duas primeiras variáveis foram analisadas nas quatro velocidades $(0,60 \%, 180 \%$ e $300 \%$ s), já a última somente em velocidades de contrações concêntricas, pois a ausência de deslocamento impede o cálculo de trabalho na contração isométrica $(0 \%$ s). 


\subsubsection{PICO DE TORQUE (PT):}

Foram observados efeitos significativos da ingestão de CAF no PT a $60 \%$ s e a $0 \%$ s e neste último, a análise de post-hoc apontou uma diferença significativa entre as sessões C/C e P/P. A FIGURA 10 apresenta o PT nas diferentes velocidades.
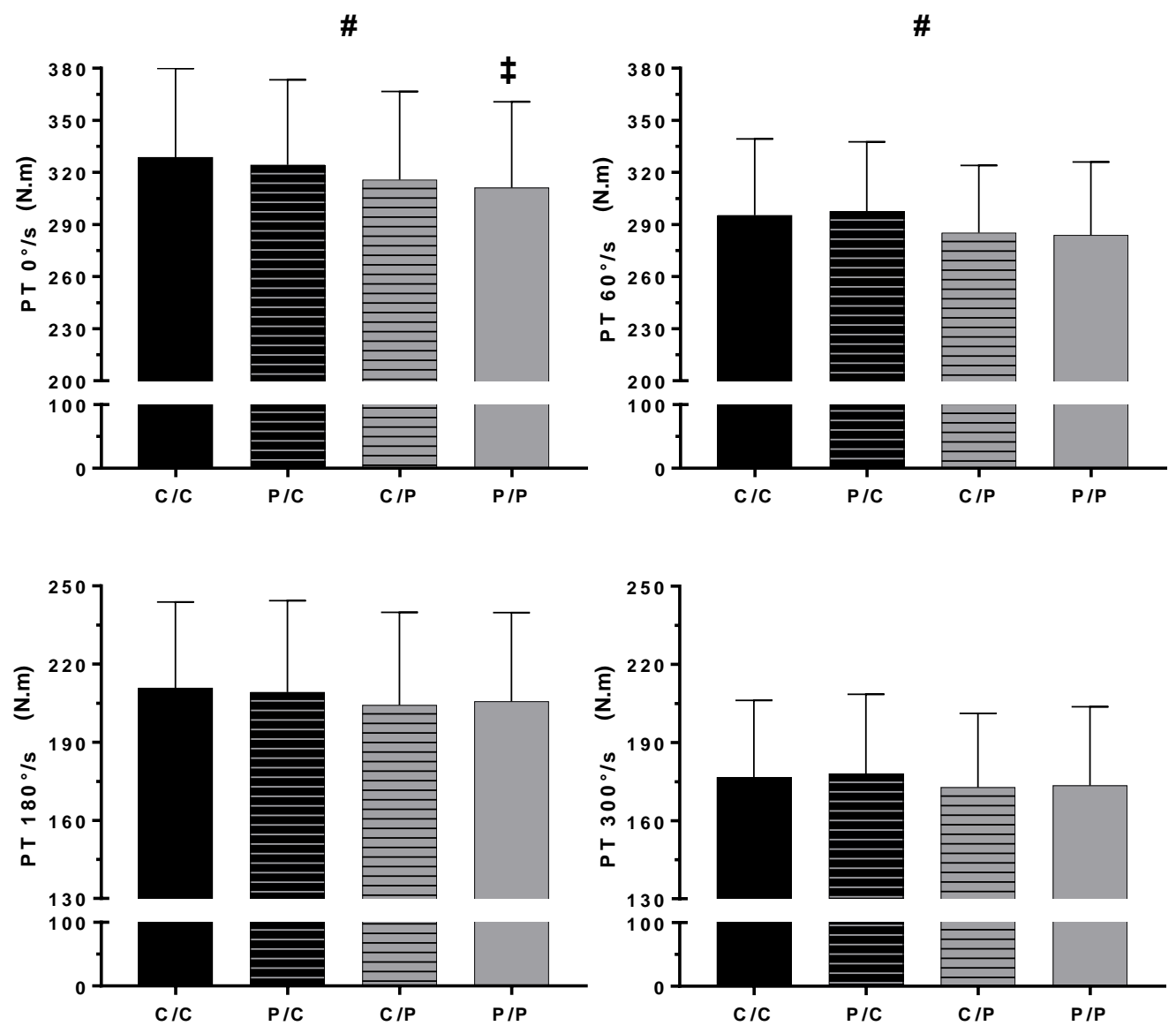

FIGURA 10 - Pico de Torque (PT) nas diferentes velocidades $\left(0,60^{\circ}, 180^{\circ}\right.$ e $\left.300^{\circ} / \mathrm{s}\right)$, $\mathrm{O}$ \# representa 0 feito significativo de usar CAF, e $\ddagger$ a diferença significativa com a sessão $C / C$.

\subsubsection{PICO DE TORQUE RELATIVO A MASSA CORPORAL (PT/MC):}

A CAF mostrou efeito significativo em todas as velocidades quanto ao pico de torque relativo $\mathrm{PT} / \mathrm{MC}$, exceto para a velocidade de $300 \% \mathrm{~s}$. Na velocidade $0 \% \mathrm{~s}$ foi possível observar uma diferença significativa entre $\mathrm{C} / \mathrm{C}$ e $\mathrm{P} / \mathrm{C}$, bem como C/C e P/P. A FIGURA 11 mostra esses resultados. 
\#
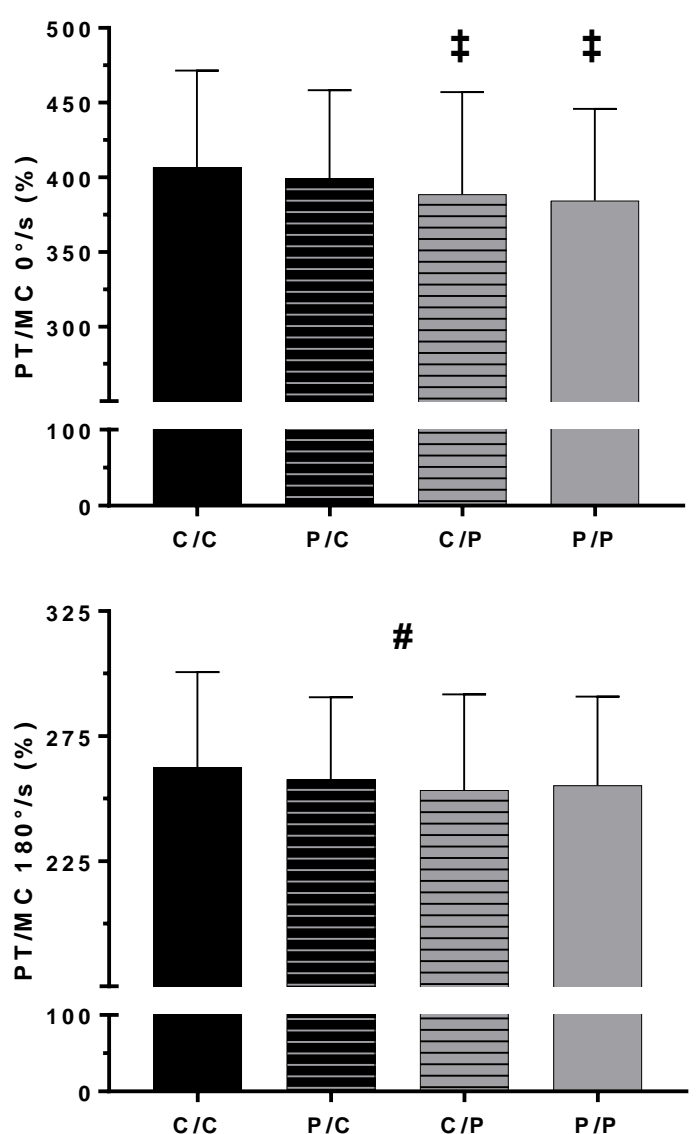

\#
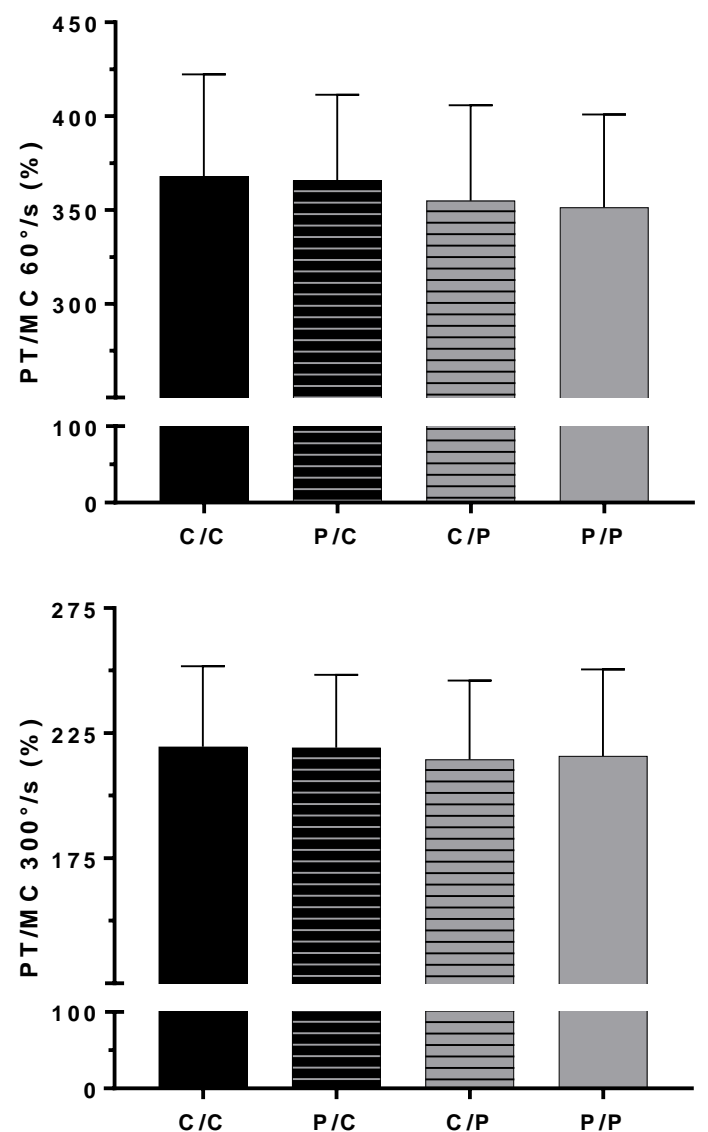

FIGURA 11 - Pico de Torque relativo à massa corporal nas diferentes velocidades $\left(0^{\circ}, 60^{\circ}, 180^{\circ} \mathrm{e}\right.$ $300 \%$ s), O \# representa o feito significativo de usar CAF, e $\ddagger$ a diferença significativa com a sessão C/C.

\subsubsection{TRABALHO MÁXIMO - (TM):}

A CAF mostrou efeito significativo em todas no máximo trabalho realizado em todas as velocidades Na velocidade $180^{\circ}$ s foi possível observar uma diferença significativa entre $\mathrm{C} / \mathrm{C}$ e $\mathrm{P} / \mathrm{C}$, bem como C/C e P/P. A FIGURA 12 mostra esses resultados. 

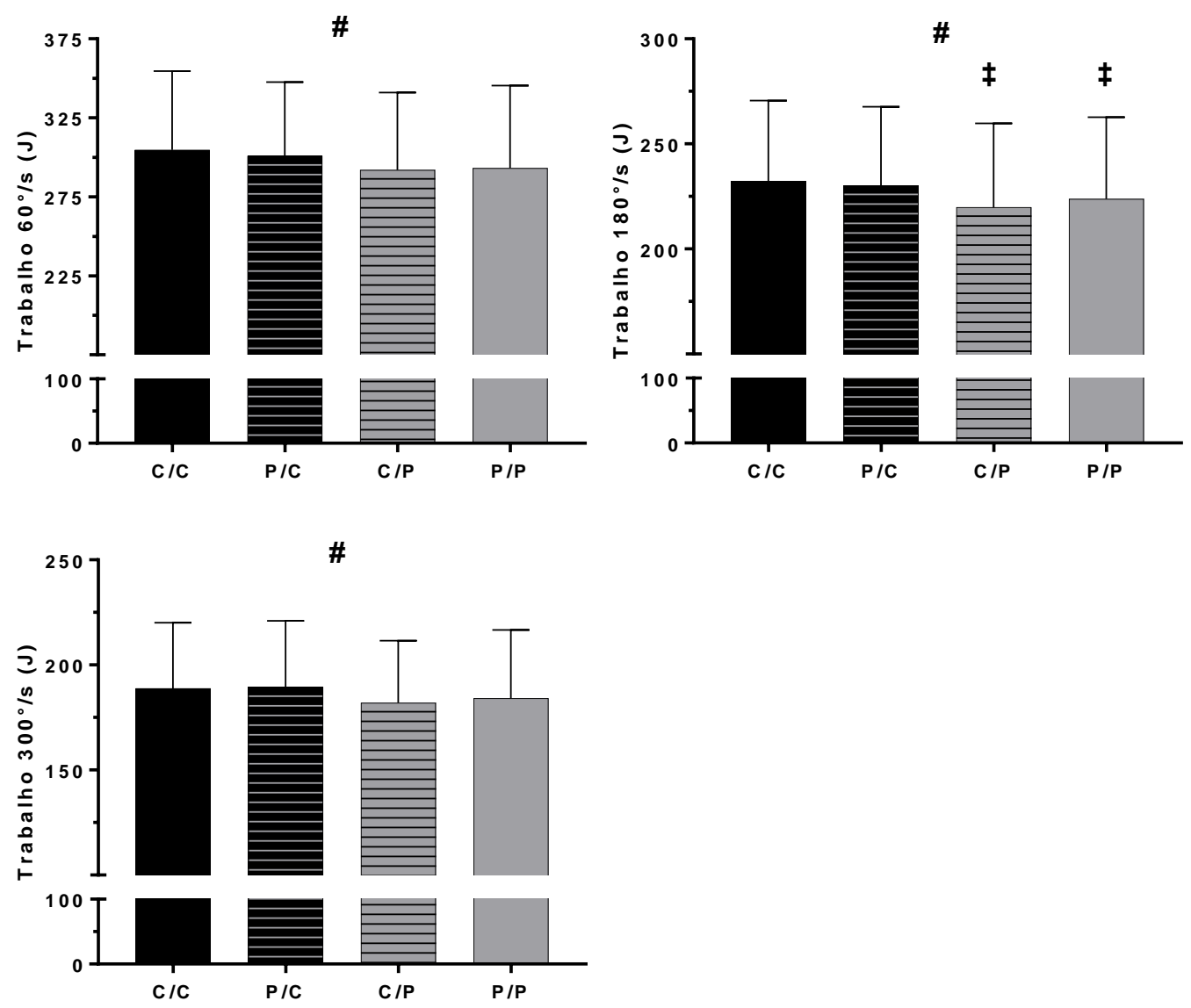

FIGURA 12 - Trabalho máximo realizado nas diferentes velocidades $\left(0^{\circ}, 60^{\circ}, 180^{\circ}\right.$ e $\left.300^{\circ} / \mathrm{s}\right), 0$ \# representa o feito significativo de usar $C A F, e ~ \ddagger$ a diferença significativa com a sessão C/C.

\subsection{TESTE DE ENDURANCE MUSCULAR (TEM):}

Não foi observado efeito significativo da ingestão de CAF no TEM, nem em ser informado que receberia $\mathrm{CAF}$, considerando tanto o número total de repetições, quanto analisado isoladamente a primeira, a segunda e a terceira séries $(p>0,05)$ - o mesmo resultado foi obtido quando analisado 0 volume total, e isoladamente o volume da primeira, segunda e terceira séries, a FIGURA 13 apresenta os resultados dos testes. 

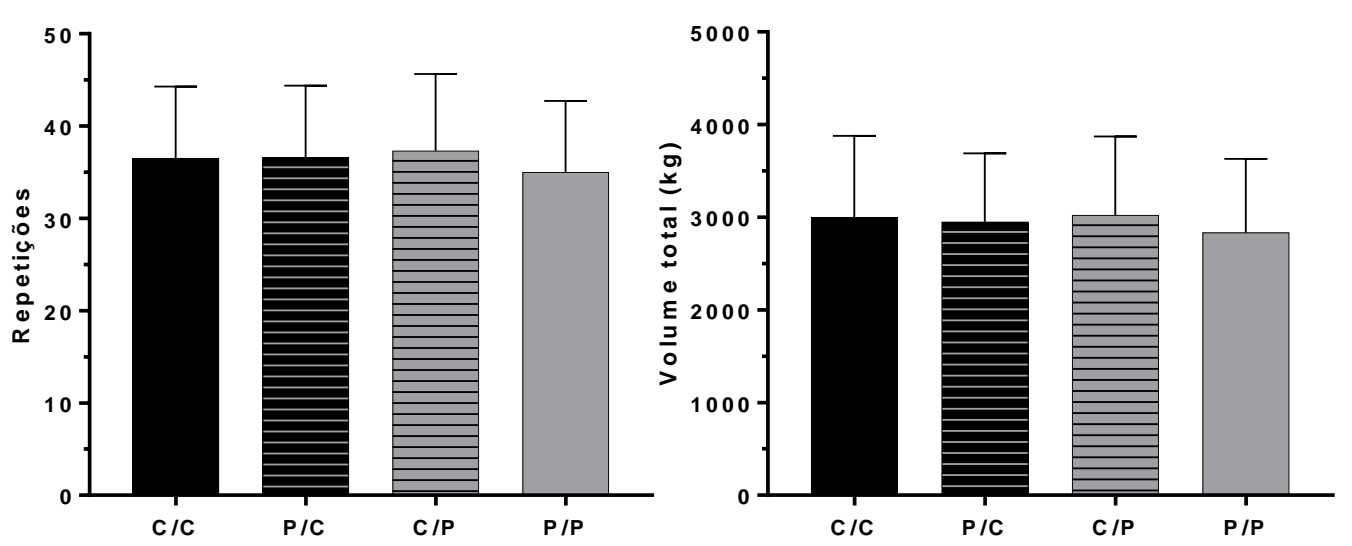

FIGURA 13 - Resultados do TEM quanto ao total de repetições realizados no treino e o volume total de cada sessão experimental.

Quanto aos valores de lactacidemia no repouso, não foram observadas diferenças significativas entre as sessões, contudo, eles parecem estar dentro da normalidade de valores esperados na literatura entre 0,7 e $1,4 \mathrm{mmol} / \mathrm{L}$.

O lactato sanguíneo sofreu efeito significativo do uso de CAF, como também de informar o uso da CAF $(p<0,05)$, mas sem interação entre os dois fatores, no segundo minuto, quarto e sexto minuto após o exercício. A FIGURA 14 apresenta a lactacidemia nos diferentes espaços de tempo. Não houve diferença significativa entre os valores de repouso nos diferentes dias.

A análise post-hoc observou algumas diferenças significativas. O lactato produzido na sessão $\mathrm{C} / \mathrm{C}$ foi significativamente maior que na sessão $P / P$ no segundo, quarto e sexto minuto $-10,9 \pm 1,7$ vs $8,8 \pm 1,2 ; 11,6 \pm 1,6$ vs $9,7 \pm 1,8 ; 11,8 \pm 1,9$ vs $9,5 \pm 1,7 \mathrm{mmol} / \mathrm{L}$ - respectivamente. No segundo minuto, o lactato produzido na condição $C / C(10,9 \pm 1,7 \mathrm{mmol} / \mathrm{L})$ foi maior que na condição $P / C(9,9 \pm 1,7$ $\mathrm{mmol} / \mathrm{L})$ e $\mathrm{C} / \mathrm{P}(9,7 \pm 1,9 \mathrm{mmol} / \mathrm{L})$. A condição $\mathrm{P} / \mathrm{C}$ foi significativamente maior que a condição $\mathrm{P} / \mathrm{P}$ no segundo e sexto minuto $-9,9 \pm 1,7$ vs $8,8 \pm 1,2 ; 11,2 \pm 1,9$ vs $9,5 \pm 1,7 \mathrm{mmol} / \mathrm{L}$ - respectivamente. Tendo por objetivo investigar mais essas relações, executou-se uma análise de correlação entre o número de repetições, o volume total e a lactacidemia nos diferentes minutos. 


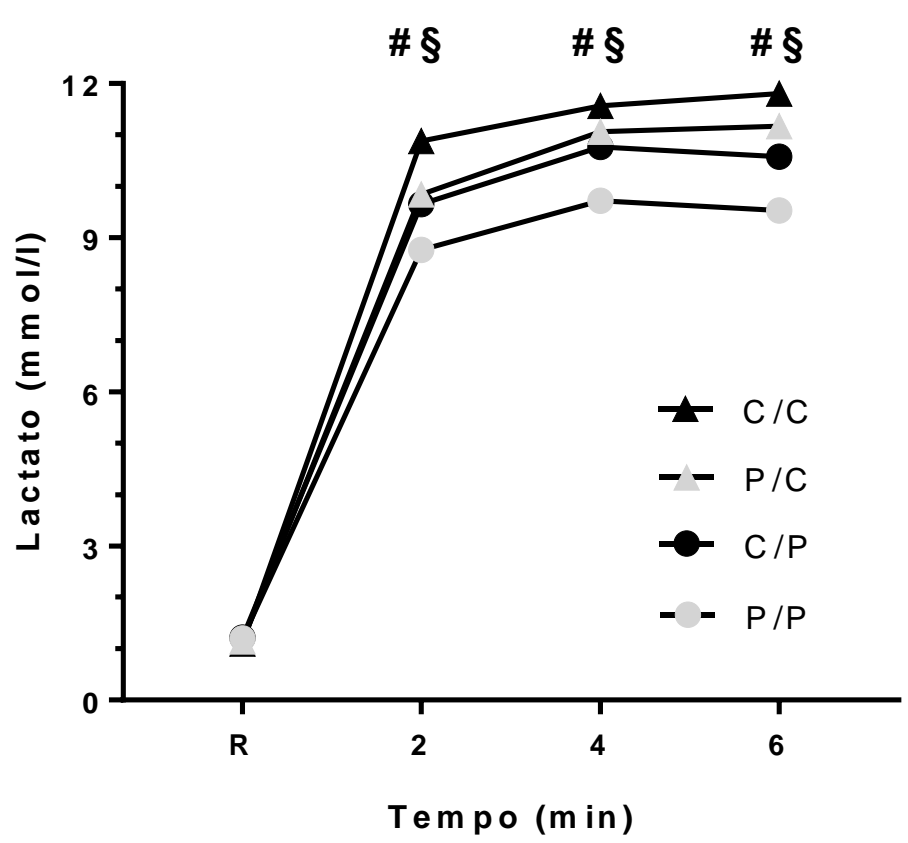

FIGURA 14 - Concentração de lactato sanguíneo no repouso, no $2^{\circ}, 4^{\circ}$ e $6^{\circ}$ minutos após o TEM. O \# representa o feito significativo do uso de CAF, e $\S$ o efeito significativo da expectativa da CAF.

TABELA 2 - Correlações de Pearson entre lactacidemia e as repetições e volume total do teste de endurance muscular (TEM).

\begin{tabular}{|c|c|c|c|c|c|c|c|}
\hline \multirow{2}{*}{ Sessão } & \multirow{2}{*}{ Variável } & \multicolumn{2}{|c|}{$\mathrm{L}^{\circ}{ }^{\mathrm{o}}$} & \multicolumn{2}{|c|}{$\mathrm{L}^{\circ} \stackrel{\circ}{ }$} & \multicolumn{2}{|c|}{ L6 ${ }^{\circ}$} \\
\hline & & $\mathrm{R}$ & $p$ & $R$ & $p$ & $R$ & $p$ \\
\hline \multirow{2}{*}{$\mathrm{C} / \mathrm{C}$} & Repetições & 0,58 & $0,02^{*}$ & 0,49 & 0,06 & 0,42 & 0,11 \\
\hline & Volume Total & 0,62 & $0,01^{*}$ & 0,53 & $0,03^{*}$ & 0,34 & 0,20 \\
\hline \multirow{2}{*}{$\mathrm{C} / \mathrm{P}$} & Repetições & 0,53 & $0,03^{\star}$ & 0,49 & 0,06 & 0,50 & 0,05 \\
\hline & Volume Total & 0,57 & $0,02^{*}$ & 0,65 & $0,01^{*}$ & 0,59 & $0,02^{*}$ \\
\hline \multirow{2}{*}{$\mathrm{P} / \mathrm{C}$} & Repetições & $-0,02$ & 0,94 & 0,49 & 0,06 & 0,30 & 0,25 \\
\hline & Volume Total & 0,16 & 0,57 & 0,34 & 0,20 & 0,21 & 0,44 \\
\hline \multirow{2}{*}{$\mathrm{P} / \mathrm{P}$} & Repetições & 0,10 & 0,73 & 0,05 & 0,85 & 0,28 & 0,30 \\
\hline & Volume Total & 0,27 & 0,32 & 0,37 & 0,15 & 0,38 & 0,15 \\
\hline
\end{tabular}

L2: Lactato no $2^{\circ}$ minuto; L4: Lactato no $4^{\circ}$ minuto; L6: Lactato no $6^{\circ}$ minuto; ${ }^{*}$; significativo $(p<0,05)$.

Quando analisadas todas as sessões ao mesmo tempo, observou-se uma fraca, porém, significativa $(p<0,01)$ correlação entre o lactato no $2^{\circ}, 4^{\circ}$ e $6^{\circ}$ minutos, $r=0,384, r=0,433, r=0,349$, respectivamente. Contudo as correlações entre lactacidemia no $2^{\circ}, 4^{\circ}$ e $6^{\circ}$ minutos e total de repetições 
foram insignificantes $(p>0,05)(r=0,100 ; r=-0,121 ; r=-0,041$, respectivamente). Considerando $o$ achado da ANOVA quanto ao efeito do uso da CAF e da expectativa de CAF sobre a lactacidemia, decidiu-se então analisar as sessões separadamente. Os resultados podem ser vistos na TABELA 2.

\subsection{QUESTIONÁRIO DE EFEITOS DA CAFEÍNA - QEC:}

Ocorreram efeitos associadas ao uso de CAF em todas as sessões, independente do uso de $\mathrm{CAF}$, havendo uma elevada variação nas respostas do questionário entre as sessões. Os efeitos associados diretamente ao consumo de CAF foram respondidos em 7 itens, com perguntas de sim e não, coletados de 15 em 15 minutos. Houve um total de 51 marcações positivas, porém, cinco foram excluídas, pois, se tratava de uma dor de cabeça não relacionada ao exercício, nem a suplementação, nem a expectativa (era a sessão P/P), o avaliado relatou que já chegou com uma leve dor de cabeça restando então 46 marcações positivas. Não houve relato de nenhum efeito imediatamente após o consumo da suplementação (tempo 0). Em relação às sessões e o tempo em que os efeitos ocorreram, foi possível, notar diferenças expressivas entre elas, conforme demonstra a FIGURA 15.

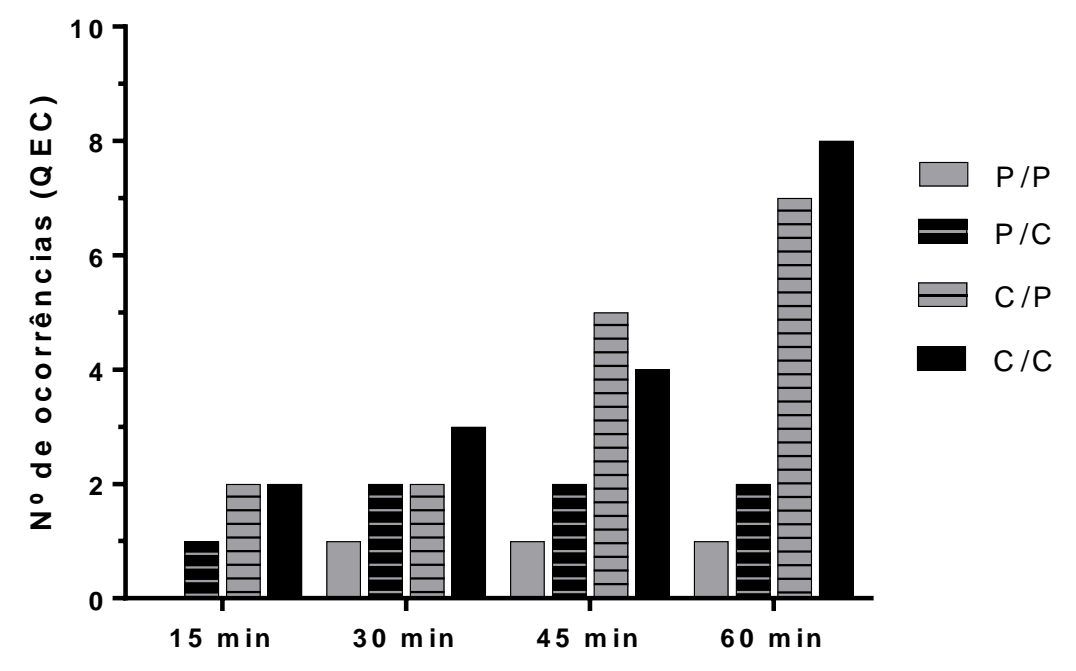

FIGURA 15 - Frequência absoluta de ocorrência de efeito associados a CAF.

A TABELA 3 mostra quais foram os efeitos associados ao uso de CAF que ocorreram no $60^{\circ}$ minuto nas diferentes sessões. 
TABELA 3 - Efeitos associados ao uso de CAF relatados no $60^{\circ}$ min nas diferentes sessões.

\begin{tabular}{|c|c|c|c|c|c|c|c|c|}
\hline \multirow{2}{*}{ Efeitos } & \multicolumn{2}{|c|}{$\mathrm{C} / \mathrm{C}$} & \multicolumn{2}{|c|}{$\mathrm{C} / \mathrm{P}$} & \multicolumn{2}{|c|}{$\mathrm{P} / \mathrm{C}$} & \multicolumn{2}{|c|}{$\mathrm{P} / \mathrm{P}$} \\
\hline & Abs & $\operatorname{Rel}(\%)$ & Abs & $\operatorname{Rel}(\%)$ & Abs & $\operatorname{Rel}(\%)$ & Abs & $\operatorname{Rel}(\%)$ \\
\hline Dor de cabeça & 1 & 6,3 & 1 & 6,3 & 0 & 0 & 0 & 0 \\
\hline $\begin{array}{c}\text { Desconforto abdominal ou na } \\
\text { barriga }\end{array}$ & 0 & 0 & 0 & 0 & 0 & 0 & 0 & 0 \\
\hline Aumento no Vigor/Disposição & 2 & 12,5 & 2 & 12,5 & 0 & 0 & 1 & 6,3 \\
\hline Taquicardia e palpitação & 1 & 6,3 & 1 & 6,3 & 0 & 0 & 0 & 0 \\
\hline Aumento na produção de urina & 1 & 6,3 & 1 & 6,3 & 0 & 0 & 1 & 6,3 \\
\hline Aumento na ansiedade & 4 & 25 & 2 & 12,5 & 2 & 12,5 & 0 & 0 \\
\hline
\end{tabular}

Abs: Frequência absoluta de ocorrência; Rel(\%): Frequência relativa de ocorrência

No ínicio de cada sessão experimental, a partir da segunda, foi apresentado o questionário ao avaliado para que ele relatasse a ocorrência dos efeitos associados à cafeína ao longo do dia e no período noturno - da sessão anterior. Neste contexto, houve baixa ocorrência de efeitos, sendo que os seis itens seguintes foram citados uma vez por algum voluntário (6,3\%): dor de cabeça, desconforto abdominal ou na barriga, dor muscular, aumento no vigor/disposição, taquicardia e palpitação, insônia. $O$ aumento na produção de urina foi relatado três vezes por três voluntários distintos (18,8\%) enquanto que o aumento de ansiedade não foi citado. Curiosamente o aumento no vigor/disposição foi citado pelo voluntário após uma sessão C/P, ou seja, foi um efeito PLA. As outras oito ocorrências foram após sessões C/C (50\%) e P/C (50\%) indicando a existência de efeitos fisiológicos associados ao uso de CAF.

\subsubsection{QUESTIONÁRIO DE EFEITOS DA CAFEÍNA - DOR MUSCULAR:}

Quando Del Coso et al., (2012) e Pallarés et al., (2013) utilizaram o item dor muscular no QEC, foi uma tentativa de examinar a hipótese de que a CAF pudesse atenuar a dor muscular tardia. Devido ao intervalo entre as sessões, houve poucos casos de relato de dor muscular. Foram duas, depois quatro, depois quatro, depois três, depois três marcações nos tempos zero, 15 minutos, 30 minutos, 45 minutos e 60 minutos respectivamente. Foi checado o desempenho dos voluntários nos dias que relataram a dor muscular e não houve qualquer indício de que o desempenho tenha sido menor naqueles dias apesar da dor muscular estar presente, e um determinado caso um voluntário, registrou que a dor sumiu com o tempo - por isso diminuiu o registro na marcação do $45^{\circ}$ e $60^{\circ}$ minutos.

\subsection{EFEITO DA CAFEÍNA E EXPECTATIVA - EFF E EXP:}

Individualmente, houve grande variação no efeito da CAF e na expectativa de receber CAF. $O$ efeito do uso de CAF (EFF) e o efeito da expectativa do uso de CAF (EXP) foram calculados conforme proposto por Foad; Beedie; Coleman (2008), levando em consideração a mudança (variação percentual) das sessões em relação a sessão controle - isso, em cada indivíduo. Interessantemente, o EFF 
apresentou uma distribuição paramétrica em todos os EFF, exceto no TEM. Na EXP os efeitos também apresentaram distribuição paramétrica exceto no TM à 300\%. Nesses casos optou-se por não realizar a correção, por se tratar da real natureza dos dados, realizou-se então uma ANOVA não-paramétrica pareada (Teste de Friedman). Não houve diferenças significativas entre o EFF $(p>0,05)$. A TABELA 4 apresenta o EFF em cada sujeito e a TABELA 5 apresenta o EXP.

TABELA 4 - Efeito individual da CAF(\%) (EFF) nas variáveis do teste de força máxima.

\begin{tabular}{|c|c|c|c|c|c|c|c|}
\hline \multirow[b]{2}{*}{ Sujeito } & \multicolumn{4}{|c|}{ PT } & \multicolumn{3}{|c|}{ TM } \\
\hline & 0 & $60 \% / \mathrm{s}$ & $180^{\circ} / \mathrm{s}$ & $300 \% / s$ & $60 \% / \mathrm{s}$ & $180^{\circ} / \mathrm{s}$ & $300 \% / \mathrm{s}$ \\
\hline 1 & 8,1 & 2,6 & 0,3 & $-7,1$ & 3,3 & 1,6 & $-5,5$ \\
\hline 2 & 9,5 & 6,6 & 4,4 & 6,3 & 4,6 & 6,6 & 7,4 \\
\hline 3 & 5,8 & 3,6 & 5,0 & 5,5 & 3,1 & 8,6 & 6,9 \\
\hline 4 & $-1,4$ & 0,2 & 3,0 & 5,0 & 0,9 & 6,4 & 5,4 \\
\hline 5 & 13,4 & 11,8 & 10,3 & 2,8 & 10,6 & 13,7 & 7,1 \\
\hline 6 & 6,8 & 4,1 & $-2,2$ & $-1,3$ & 0,5 & $-1,8$ & $-0,1$ \\
\hline 7 & $-0,1$ & $-0,6$ & 2,3 & $-0,6$ & 0,7 & 2,4 & $-1,6$ \\
\hline 8 & $-1,5$ & 5,6 & 4,5 & $-1,0$ & 5,5 & 5,0 & 3,6 \\
\hline 9 & 5,5 & 3,6 & 9,1 & 8,6 & $-0,7$ & 8,0 & 10,9 \\
\hline 10 & 5,3 & 4,1 & 1,8 & $-4,9$ & 2,2 & $-0,9$ & $-2,6$ \\
\hline 11 & $-0,8$ & 1,8 & $-2,4$ & 11,1 & 0,4 & 2,2 & 6,2 \\
\hline 12 & $-3,2$ & 4,4 & $-6,5$ & $-0,7$ & 4,0 & $-4,8$ & $-1,2$ \\
\hline 13 & 15,8 & 5,3 & 7,0 & 5,8 & 9,3 & 13,5 & 7,5 \\
\hline 14 & 3,7 & 2,3 & $-3,5$ & $-0,5$ & 6,8 & 3,6 & 0,0 \\
\hline 15 & 0,6 & 3,5 & 6,1 & 9,4 & 3,1 & 5,7 & 6,9 \\
\hline 16 & 7,8 & 8,9 & 1,5 & $-1,2$ & 6,7 & 1,3 & 0,5 \\
\hline Média & 4,7 & 4,2 & 2,5 & 2,3 & 3,8 & 4,4 & 3,2 \\
\hline DP & 5,5 & 3,1 & 4,6 & 5,3 & 3,3 & 5,1 & 4,7 \\
\hline
\end{tabular}

PT: Pico de torque; TM: Trabalho máximo; DP: Desvio padrão. 
TABELA 5 - Efeito individual da expectativa de CAF(\%) nas variáveis do teste de força máxima.

\begin{tabular}{|c|c|c|c|c|c|c|c|}
\hline \multirow[b]{2}{*}{ Sujeito } & \multicolumn{4}{|c|}{ PT } & \multicolumn{3}{|c|}{ TM } \\
\hline & 0 & $60 \% / \mathrm{s}$ & $180^{\circ} / \mathrm{s}$ & $300 \% / s$ & $60 \% / \mathrm{s}$ & $180^{\circ} / \mathrm{s}$ & $300 \% / \mathrm{s}$ \\
\hline 1 & $-1,3$ & 2,4 & $-1,9$ & $-13,2$ & 1,1 & $-2,1$ & $-13,2$ \\
\hline 2 & $-10,4$ & $-4,4$ & 2,3 & 3,0 & $-6,1$ & 0,5 & 1,4 \\
\hline 3 & 4,1 & 5,8 & 2,4 & 1,7 & 5,9 & 7,1 & 3,0 \\
\hline 4 & 8,6 & 5,4 & 1,0 & $-4,9$ & 3,9 & 0,2 & $-3,7$ \\
\hline 5 & $-10,9$ & $-16,1$ & $-12,8$ & $-9,7$ & $-12,4$ & $-15,1$ & $-11,1$ \\
\hline 6 & 9,0 & 1,8 & 0,3 & 2,1 & 2,4 & 0,6 & 0,8 \\
\hline 7 & 3,7 & $-4,8$ & 0,5 & 5,0 & $-3,6$ & $-3,4$ & 3,0 \\
\hline 8 & 5,9 & 6,9 & 7,6 & 11,2 & 4,1 & 7,2 & 15,1 \\
\hline 9 & 4,3 & 3,5 & $-1,8$ & $-3,5$ & 5,7 & 2,5 & 0,1 \\
\hline 10 & 2,3 & 0,8 & 3,2 & 4,8 & 4,1 & 2,9 & 3,1 \\
\hline 11 & 13,0 & 6,9 & 6,3 & $-1,1$ & 7,4 & 4,3 & 1,0 \\
\hline 12 & $-3,2$ & $-5,8$ & $-0,8$ & $-1,6$ & $-7,4$ & $-5,8$ & $-11,4$ \\
\hline 13 & 9,2 & 8,6 & 5,5 & 0,3 & 5,6 & 6,5 & 1,1 \\
\hline 14 & 5,1 & 7,1 & 1,1 & $-6,7$ & 9,2 & 1,0 & $-2,1$ \\
\hline 15 & $-3,4$ & $-3,2$ & $-2,2$ & 1,1 & $-3,4$ & $-2,3$ & 1,8 \\
\hline 16 & $-15,1$ & $-7,9$ & $-7,1$ & 4,4 & $-7,7$ & $-9,9$ & 2,6 \\
\hline Média & 1,3 & 0,4 & 0,2 & $-0,4$ & 0,5 & $-0,4$ & $-0,5$ \\
\hline DP & 8,1 & 6,9 & 5,0 & 6,1 & 6,4 & 6,1 & 6,9 \\
\hline
\end{tabular}

PT: Pico de torque; TM: Trabalho máximo; DP: Desvio padrão.

A variabilidade das respostas foi no TEM expressiva, assim, provavelmente não é que a CAF não faça efeito, mas, que em alguns casos ela não gera melhora e em outros piora o desempenho resultando em uma média zero ou muito baixa próxima desse valor. A FIGURA 16 ilustra o EFF e a EXP no resultado do TEM.

Observa-se claramente que a média na FIGURA 16 (linha pontilhada) não expressa o comportamento individual, no caso do EFF da CAF no TEM, ficou nítido que temos um grupo de respondedores e outro de não respondedores. Foi montado então um histograma para ilustrar essa questão (FIGURA 17). O histograma é um gráfico de frequências absolutas, ou seja, os valores do EFF são divididos em classes (no caso, foi feito de dois em dois) e ele apresenta quantas ocorrências (frequências) existem em cada classe (barra vertical). Interessantemente os voluntários apresentaram somente respostas extremas, isto é, é nítido um grupo de pessoas que a CAFF teve efeito positivo (aumento no desempenho de 6 a 14\%) ou efeito negativo (redução no desempenho de -6 a $-12 \%$ ). 


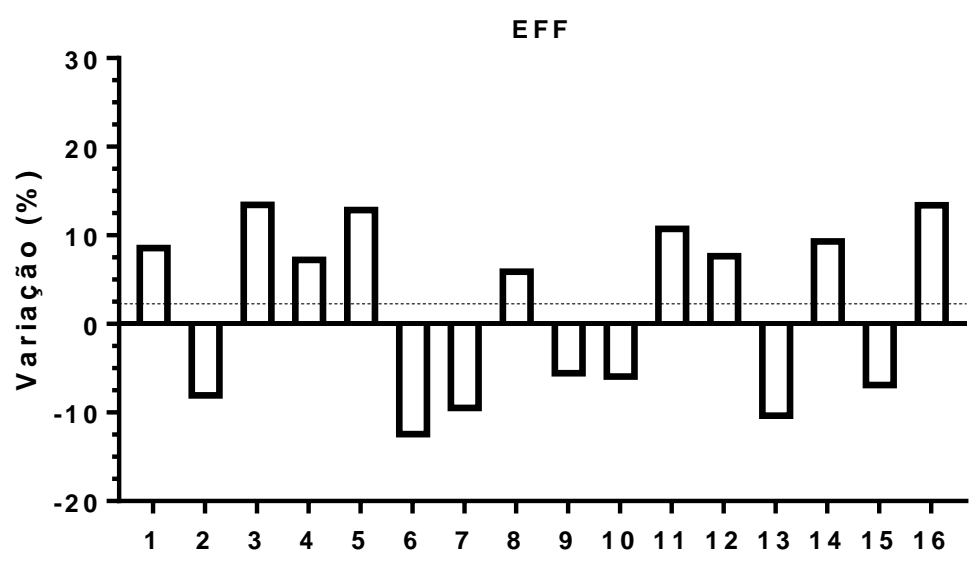

In divíduo

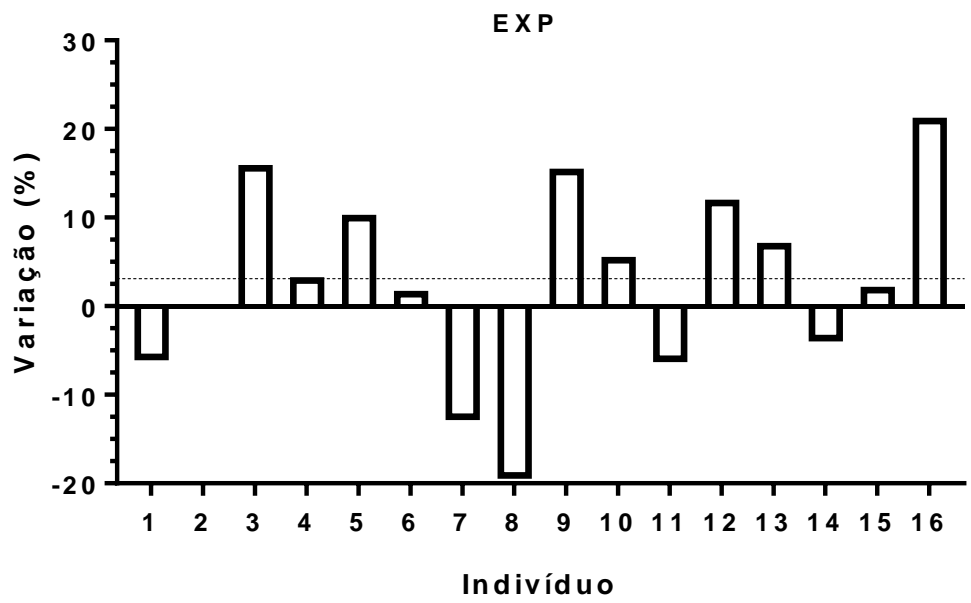

FIGURA 16 - Variação percentual do desempenho devido ao efeito da CAF (EFF) e da expectativa (EXP) em cada indivíduo. A linha pontilhada representa a média dos resultados. A expectativa de CAF apresentou efeito zero no indivíduo dois.

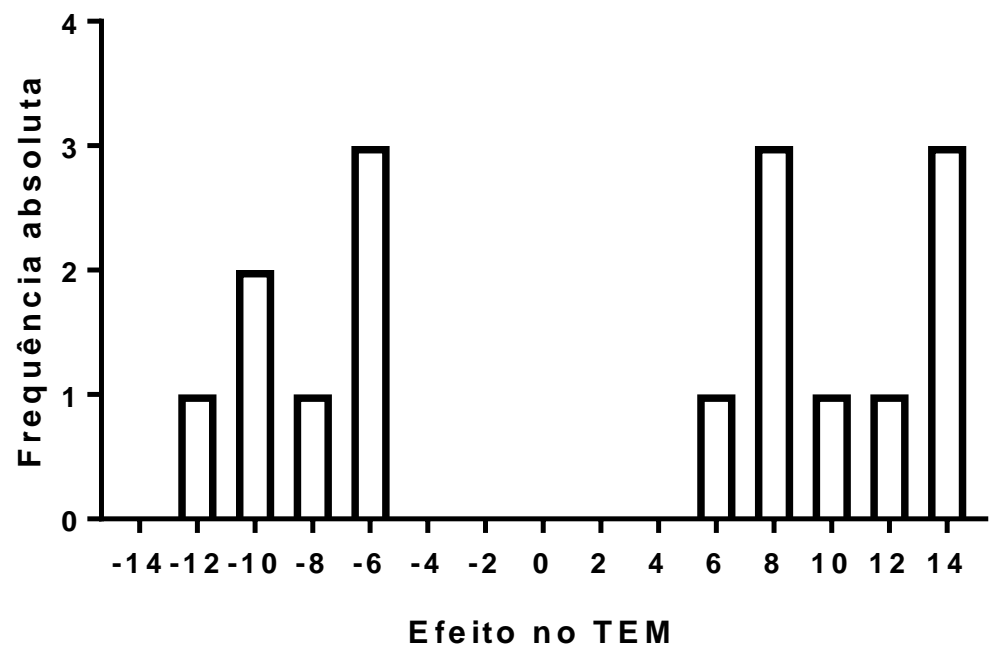

FIGURA 17 - Histograma de efeitos da CAF no TEM 


\subsubsection{RESPONDEDORES E NÃO RESPONDEDORES}

Considerando a presença de respondedores e não respondedores à suplementação de CAF, buscou-se então analisar se eles seriam os mesmos nos diferentes testes, para isso, fez-se uma correlação entre os efeitos. Assim sendo, foi utilizada a correlação de Pearson nos dados paramétricos (resultados do teste de TFM) e de Spearman quando os dados foram comparados ao EFF no TEM. A TABELA 6 apresenta esses resultados.

TABELA 6 - Matriz de correlação (R) entre os EFF nos diferentes testes.

\begin{tabular}{|c|c|c|c|c|c|c|c|c|}
\hline & \multirow{2}{*}{$\begin{array}{l}\text { Velocidade } \\
\qquad(\% / s)\end{array}$} & \multicolumn{4}{|c|}{ PT } & \multicolumn{3}{|c|}{ TM } \\
\hline & & 0 & $60 \% / \mathrm{s}$ & $180^{\circ} / \mathrm{s}$ & $300 \% / \mathrm{s}$ & $60 \% / \mathrm{s}$ & $180^{\circ} / \mathrm{s}$ & $300 \% / \mathrm{s}$ \\
\hline \multirow{4}{*}{ PT } & 0 & 1 & & & & & & \\
\hline & 60 & $0,60^{*}$ & 1 & & & & & \\
\hline & 180 & 0,49 & 0,39 & 1 & & & & \\
\hline & 300 & $-0,04$ & $-0,05$ & 0,39 & 1 & & & \\
\hline \multirow{3}{*}{ TM } & 60 & $0,58^{*}$ & $0,72^{*}$ & 0,26 & $-0,14$ & 1 & & \\
\hline & 180 & $0,57^{*}$ & 0,34 & $0,85^{\star}$ & $0,51^{*}$ & 0,48 & 1 & \\
\hline & 300 & 0,19 & 0,23 & $0,67^{\star}$ & $0,89^{\star}$ & 0,08 & $0,74^{*}$ & 1 \\
\hline
\end{tabular}

PT: Pico de Torque; TM: Trabalho Máximo realizado; *: Estatisticamente significativo p<0,05.

É possível notar que as mais fortes correlações foram nas mesmas velocidades de variáveis diferentes (PT vs TM), indicando que provavelmente os indivíduos apresentaram EFF semelhantes quando avaliados na mesma velocidade, ainda que em variáveis distintas. Observando as diferentes velocidades, as correlações foram mais fortes e frequentes entre as velocidades 0 e $60 \%$, enquanto que as velocidades 180 e $300 \%$ só se correlacionaram significativamente entre si. Possivelmente os mecanismos relacionados a ergogenia da CAF em menores velocidades sejam distintos daqueles das velocidades maiores. Não foram encontradas correlações importantes entre o EFF no TEM em nenhuma das variáveis ( $\rho$ entre $-0,13$ e 0,$27 ; p>0,31$ ) provavelmente também as vias fisiológicas afetadas pela CAF na produção de força máxima sejam distintas das que aumentam a endurance muscular, assim possivelmente um indivíduo pode ter sua força aumentada pela ação da CAF, contudo, não aumentar sua endurance muscular.

Buscou-se também encontrar alguma associação entre o consumo habitual de CAF e os EFF nos testes, porém, todas as correlações foram desprezíveis - $R$ entre $-0,08$ e $0,02(p>0,64)$ e $\rho=0,2$; $(p=0,44)$, para confirmar este achado, a amostra foi subdividida em dois grupos com base na mediana do consumo habitual e foi utilizada uma ANOVA de um fator para comparar os grupos e foi não foi observado nenhuma diferença nos efeitos entre os grupos $(p=0,99)$. 


\section{DISCUSSÃO}

\subsection{FORÇA MÁXIMA}

Nesse trabalho a CAF apresentou efeito ergogênico independente do que foi informado ao voluntário. A hipótese de que o efeito da CAF, por ser pequeno (WARREN et al., 2010), poderia ser semelhante a um efeito PLA não se confirmou.

A CAF atuou sistematicamente aumentando a força nas contrações isométricas e concêntricas a $60 \%$ em todas as variáveis analisadas. $\mathrm{O}$ pico de toque relativo à massa corporal (PT/MC) e o trabalho máximo (TM) realizado a 180\% s também aumentaram. Entretanto, a força não foi afetada em nenhuma das variáveis estudadas quando as contrações musculares foram realizadas a $300 \%$ exceto no TM. Uma possível explicação para a menor atuação da CAF nas contrações musculares realizadas a $180 \%$ e principalmente a $300 \%$ seria uma menor atuação da CAF sobre as fibras musculares do tipo II (rápidas), conforme sugerido por Wondmikun; Soukup; Asmussen (2006). Eles observaram claramente que a CAF aumentou a força em fibras musculares de contração lenta mais do que na fibras de contração rápida em ratos (in vitro). Tallis et al. (2012) observaram o mesmo fenômeno, ou seja, aumento significativo de força após a administração de CAF em músculos de ratos (in vitro), demonstrando efeito significativamente maior nos músculos com predominância de fibras de contração lenta. O estudo de Tallis et al., (2012) se destaca por ter usado doses fisiológicas de CAF, enquanto que o de Wondmikun; Soukup; Asmussen (2006) usou doses que seriam tóxicas in vivo. Embora essa relação não tenha ainda sido observada diretamente em humanos, os nossos resultados vão ao encontro dessa hipótese, uma vez que, se o efeito da CAF for menor nas fibras musculares de contração rápida, seria de se esperar menores efeitos da CAF em atividades que exigem maior participação desse tipo de fibras, como as contrações à $300 \%$ s. Sabe-se que há uma associação entre a predominância de fibras musculares rápidas e o torque produzido em velocidades angulares maiores no isocinético (FITTS; WIDRICK, 1996).

Em um trabalho muito elegante, Maclntosh et al., (1993) utilizando dois modelos teóricos e um experimental, demonstraram que conforme a velocidade de contração aumenta também aumenta a contribuição das fibras de contração rápida, particularmente quando se observa a variável potência muscular - força muscular relativa à uma unidade de tempo. Gür et al., (2003) observaram uma associação significativa entre o torque produzido a $240 \%$ e a área relativa de fibras de contração rápida. Mais recentemente, Metaxas et al. (2014) observaram uma correlação significativa entre o percentual de distribuição de fibras tipo I e o torque produzido na velocidade de $60 \%$ s.

É possível relacionar esses achados com o que foi observado nos efeitos da CAFF. O efeito do uso (EFF) da CAF nas contrações a $300 \%$ s se relacionavam melhor com o EFF nas contrações à $180 \%$ do que com o EFF nas realizadas a $60 \%$ e isométricas. É interessante notar que o pico de torque absoluto (PT) e relativo à massa corporal (PT/MC) a $300 \%$ s não aumentaram, enquanto que o TM aumentou com o uso de CAF.

O TM é considerado por alguns como uma medida representativa da função muscular, tendo em vista que ele representa a força exercida por toda amplitude de movimento (Trabalho = Força $x$ Deslocamento), foi calculado pelo isocinético usando a área sob a curva da força e amplitude de 
movimento (BASTIANI et al., 2012). É interessante comparar nossos resultados com os obtidos por Tallis et al., (2012) quanto a ação da CAF nas fibras de contração rápida. Os aumentos de força foram pequenos ao longo dos diversos comprimentos em que a fibra muscular foi testada, talvez assim, também tenha sido com as contrações a $300 \%$ ao se analisar conjuntamente todos os pequenos aumentos de força ao longo do movimento (área sob a curva), desta forma a ação da CAF no músculo pode ser observada.

A relação entre a ergogenia da CAF e o tipo de fibra muscular é um fator que pode ajudar a explicar a ausência de efeitos positivos da CAF em diversos trabalhos que utilizaram testes de potência anaeróbia que exigem elevada participação de fibras de contração rápida (DAVIS; GREEN, 2009). Especialmente no que se refere a pessoas treinadas, cujo desempenho em testes com predominância do metabolismo anaeróbio, parecem estar mais relacionadas a fibras de contração rápida (INBAR; KAISER; TESCH, 1981). Também leva a uma reflexão de porque a ergogenia da CAF está tão bem estabelecida em exercícios de longa duração - favorecem fibras de contração lenta - enquanto há tanta disparidade nas pesquisas utilizando exercícios de curta duração e alta intensidade (ALTIMARI et al., 2006a; AMERICAN DIETETIC ASSOCIATION et al., 2009; GOLDSTEIN et al., 2010).

É importante lembrar que a CAF não tem um mecanismo de atuação único, nem ainda bem definido, e normalmente, os efeitos da CAF são atribuídos a ações no SNC, dessa forma, é provável que a CAF atue tanto nos mecanismos centrais como nos periféricos, e que ambos possam resultar em ergogenia. Desta forma é possível entender porque em alguns indivíduos a CAF aumentou a força somente em contrações realizadas a $300 \%$ s, enquanto que alguns outros obtiveram aumentos em todas as velocidades. Essa variação dentro de um grupo, com a inclusão de indivíduos respondedores e não respondedores acaba induzindo o observador que se atenta apenas às tendências de medida central a subestimar o efeito da CAF, pois, quanto mais ausências de respostas, mais a medida tende a zero. Contudo, porque algumas pessoas não respondem a suplementação não significa que CAF não seja eficaz - basta olhar para a FIGURA 17, alguma pessoas responderam bem à suplementação de CAF outras apresentaram menor desempenho, isso é diferente de ausência de efeito. Nesses casos, é importante e necessário observar separadamente aqueles que respondem e aqueles que não respondem - essa variabilidade da resposta a CAF não é novidade, Kalmar (2005) em sua revisão aponta isso muito claramente, contudo, sugere trabalhar com grupos maiores, ao invés de analisar separadamente respondedores e não respondedores.

Nossos resultados vão ao encontro com o que tem sido mais observado na literatura recente sobre o efeito da CAF na força muscular. Estudos utilizando os extensores de joelho geralmente observam efeitos significativos da CAF na força (BEHRENS et al., 2015a; BLACK; WADDELL; GONGLACH, 2015; DUNCAN; THAKE; DOWNS, 2014; TIMMINS; SAUNDERS, 2014), enquanto que estudos que utilizam outros grupamentos musculares apresentam resultados variados ora aumentando (BAZZUCCHI et al., 2011; TIMMINS; SAUNDERS, 2014), ora não apresentando efeito (BEHRENS et al., 2015b; BLACK; WADDELL; GONGLACH, 2015; TREVINO et al., 2015).

Quanto ao tipo de contração, a CAF atuou de modo semelhante entre as contrações concêntricas e isométricas, conforme o achado de Warren et al., (2010). Contudo, o tema está longe de ser esgotado, Behrens et al., (2015a) analisando o tamanho do efeito, observaram que a CAF aumentou mais a força da contração isométrica e aumentou a ativação muscular significativamente mais nas 
contrações concêntricas. Não observamos qualquer tendência nesse sentido, a não ser pelo falta de associação entre os EFF da CAFF nas velocidades maiores com a contração isométrica, indicando que as mesmas pessoas se comportam de forma diferente em resposta a CAF nas distintas velocidades, não significando que o efeito foi maior em uma frente a outra.

Em relação a ação da CAF em diferentes velocidades de contração, Bond et al., (1986) não observaram efeito da CAF em nenhuma velocidade estudada (30, 150 e 300\%s), sem nenhum viés aparente que pudesse explicar a ausência de efeitos exceto pelo fato dos autores não mencionarem se o estudo foi cego. Jacobson et al., (1992) suplementaram $7 \mathrm{mg} / \mathrm{kg}$ de CAF em atletas de futebol americano e observaram aumento significativo da força somente nas velocidades 30 e $300 \%$, os autores não forneceram explicação para uma possível ação diferenciada da CAF no PT nas diferentes velocidades eles somente atribuíram o efeito a uma dose maior que estudos anteriores. Infelizmente, este estudo possui um potencial limitador nos resultados, ele não comparou os valores de força nas sessões CAF e PLA diretamente, mas, sim a variação da força em cada sessão, realizando um pré-teste na sessão CAF e PLA. Nos testes de extensão de joelho a 30 e a $300 \%$ s as sessões PLA variaram negativamente do pré para o pós enquanto a CAF positivamente. A dose elevada de CAF dificultou esconder seus efeitos associados, facilitando perceber quando se está na sessão CAF ou na sessão PLA (ausência de efeitos associados), desta forma é possível que os avaliados tenham reconhecido que não estavam usando CAF e acabaram inconscientemente tendo um desempenho pior, por acharem que não estavam utilizando uma substância que seria ergogênica (FOAD; BEEDIE; COLEMAN, 2008; POLLO et al., 2012).

Bazzucchi et al., (2011) também avaliaram o PT em diferentes velocidades, e observaram efeitos significativos da CAF em todas as velocidades, contudo, este trabalho possui as mesmas limitações do estudo de Jacobson et al., (1992) tendo em vista que a o variação pré e pós PLA geralmente era negativa, enquanto que no caso da CAF era similar, somente o pré e pós da contração a $250 \%$ s foi significativa. Duncan; Thake; Downs, (2014) utilizaram três velocidades (30, 150 e 300\%s) para avaliar o efeito da suplementação de $6 \mathrm{mg} / \mathrm{kg}$ de CAFF, com sua análise estatística, eles observaram que a CAF aumenta a força de uma forma geral, sem conseguir discernir e observar nenhuma interação com a velocidade.

Em sua meta análise, Warren et al. (2010) observaram que a cafeína aumentou a força muscular em 4\% em média e em nosso estudo a CAF foi responsável pelo aumento a força muscular da ordem de 2,3 a 4,7\%, esses efeitos (menor e maior) estão relacionados à sessão controle. Para ilustrar a importância deste achado vamos observar os resultados da Olímpiada de 2012 realizada em Londres, no levantamento de peso olímpico da categoria de até $105 \mathrm{~kg}$ masculino. O pódio dessa categoria teve a diferença de apenas $1,0 \mathrm{~kg}$ da primeira para a segunda posição e 1,0 kg, novamente, de diferença da segunda para terceira posição, ou seja, na ordem do $1^{\circ}$ para o $3^{\circ}$. - 412, 411 e $410 \mathrm{~kg}$ (INTERNATIONAL OLYMPIC COMITEE, 2016). Observa-se nessa modalidade de força a variação de apenas $0,49 \%$ entre as cargas levantadas, permitindo dessa forma, que o percentual de efeito da CAF pudesse fazer com que um atleta dessa prova conseguisse subir da terceira para primeira posição. $O$ aumento de $4 \%$ no desempenho de um atleta posicionado em sexto lugar poderia levá-lo para o primeiro lugar. Tendo em vista números como esses, não surpreende o grande interesse de atletas e treinadores no uso da CAF como recurso ergogênico (SÖKMEN et al., 2008; STEAR et al., 2010). Desta forma 
reforçamos a importâncias dos achados do presente trabalho, ainda que seja necessário saber o quanto de aumento de força medido em laboratório pode ser extrapolado para o desempenho atlético.

\subsection{ENDURANCE MUSCULAR}

No presente estudo não observamos efeito significativo da CAF no teste de endurance muscular (TEM) utilizado, contudo, analisando as respostas individuais - FIGURA 17 - foi possível perceber que houve um grupo nítido de respondedores e não respondedores, por isso, em média o efeito foi nulo. Analisando o resultado geral, contraria o observado por Warren et al., (2010) no que tange o efeito da CAF na endurance muscular.

Diversos estudos não observam efeito da CAF na endurance muscular (ASTORINO; ROHMANN; FIRTH, 2008; BECK et al., 2006; JACOBS; PASTERNAK; BELL, 2003; WILLIAMS et al., 2008; WOOLF; BIDWELL; CARLSON, 2009), enquanto outros sim (ASTORINO et al., 2011; GREEN et al., 2007; HUDSON et al., 2008; WOOLF; BIDWELL; CARLSON, 2008), sem que haja nenhuma diferença metodológica expressiva, dosagens, tipo de amostra e exercícios foram semelhantes, contudo os resultados divergem. Mesmo dentro dos estudos que observaram resultados positivos, há incongruências, Woolf; Bidwell e Carlson (2008) observaram efeito da CAF no volume da sessão (séries $x$ repetições $x$ carga) somente no exercício supino reto e não no leg press, enquanto que Green et al., (2007) observaram efeito da CAF somente na terceira série de exercícios, aumentando o número de repetições e não observaram efeito algum para o supino, já no estudo de Hudson et al., (2008), a CAF exerceu efeito ergogênico somente na extensão de joelho, aumentando o número de repetições totais e na primeira série de exercícios, não havendo efeito da CAF na "rosca bíceps" (flexão de cotovelo). Astorino et al., (2011) comparam quatro exercícios diferentes - supino reto, leg press, puxada (extensão de ombro somada a flexão de cotovelo) e desenvolvimento (abdução de ombro somada a extensão de cotovelo) e observaram somente efeito da CAF no número de repetições realizadas na primeira série do leg press - não houve efeito quando algum quando os exercícios foram comparados os volumes das sessões. Assim, quais seriam as razões para tanta divergências nos resultados?

Uma primeira hipótese é que na verdade eles tenham resultados semelhantes aos nossos, possuindo respondedores e não respondedores, ainda que nem sempre explícitos. Alguns estudos relatam a variabilidade de respostas frente a suplementação de CAF em seus estudos, havendo bastante variação, geralmente os que obtiveram maior percentual são os que observaram diferenças significativas, há casos em que 59\% dos participantes melhoraram seu desempenho (WOOLF; BIDWELL; CARLSON, 2009), 67\% (WOOLF; BIDWELL; CARLSON, 2008), 47\% (HUDSON et al., 2008), 72\% (ASTORINO et al., 2011), curioso pensar a respeito do restante da amostra, eles tiveram um desempenho igual, ou eles pioraram? Poucos relataram se houve piora de desempenho com o uso da CAF e quantos casos foram, Hudson et al., (2008) informou que $13 \%$ da amostra pioraram seu desempenho - o que para eles significava fazer cinco repetições a mais (considerando o total de repetições) na sessão PLA em relação a sessão CAF. Assim, a falta de efeito observado nos estudos estaria ligada a presença de respondedores e não respondedores a CAF fazendo a média tender a zero. Uma observação interessante que pode indicar a presença de respondedores e não respondedores é o aumento da dispersão em torno da média (coeficiente de variação), isso fica bem aparente em dois 
estudos (ASTORINO; ROHMANN; FIRTH, 2008; JACOBS; PASTERNAK; BELL, 2003), que, ao observar o volume da sessão, é possível notar um aumento no coeficiente de variação (razão entre o desvio padrão e a média multiplicada por 100 ) passando de $40,1 \%$ para $55,1 \%$ e de $39,8 \%$ para 52,7 , indicando um aumento na dispersão dos dados - possivelmente uns melhoraram mais, outros pioraram o desempenho, assim a média fica semelhante mas a dispersão aumenta.

A segunda hipótese seria mais simples, o efeito da CAF não pode ser avaliado adequadamente por falta de reprodutibilidade do protocolo, ou seja, de uma sessão para a outra os resultados variam tanto que fica impossível distinguir o que é ergogênico o que é variação natural. A maioria dos estudos por avaliar pessoas treinadas, parte do pressuposto empírico que por eles fazerem aquele atividade frequentemente o desempenho seria "igual" entre os dias e qualquer diferença seria ergogênica. Jacobs; Pasternak e Bell (2003) observaram o efeito da CAF e efedrina (combinados ou não) na endurance muscular, para equilibrar seu desenho experimental, utilizaram duas sessões PLA que aproveitaram para tentar avaliar a reprodutibilidade. Eles observaram ótima reprodutibilidade no leg press e boa no supino através de uma regressão linear, contudo, é possível observar nos gráficos que existem alguns indivíduos que variam consideravelmente entre sessões, no leg press, por exemplo, quatro indivíduos realizaram cinco repetições na primeira série da primeira sessão PLA, na segunda sessão PLA um desses indivíduos realizou cinco repetições novamente, outro sete, outro nove e outro dez. Um problema desta análise é que voluntários podem ter tido seu desempenho afetado pela condição experimental, achando que receberam um suplemento, podem ter se esforçado mais (POLLO; CARLINO; BENEDETTI, 2008). Outro ponto importante é que os estudos supracitados não comentam qual foi o tempo de execução de cada repetição em seus protocolos, algo que é importante para que os resultados possam ser comparados entre estudos.

Desta forma destacamos a importância de se saber a reprodutibilidade do protocolo previamente ao estudo, para que, sabendo a variação normal para aquele protocolo, possa se determinar que variação, seja melhora ou piora de desempenho é significativa e distinto de uma variação normal entre dias distintos de teste.

\subsubsection{LACTACIDEMIA}

Os nossos resultados demonstraram um efeito significativo da ingestão da CAF, ou seja, a CAF agiu diretamente nas vias metabólicas que interferiam na lactacidemia - sessões $C / C$ e $P / C$ vs $C / P$ e P/P - no $2^{\circ}, 4^{\circ}$ e $6^{\circ}$ minutos de recuperação após o TEM $(p<0,05)$. É possível que as células humanas em contato com a CAF aumentem a produção de lactato independente de estimulação endócrina, conforme o estudo de Dias et al., (2015) que observou aumento da produção de lactato em células Sértoli humanas (células somáticas dos testículos) in vitro, contudo não se pode extrapolar isso para todas as células, nem em situações in vivo.

Foi observado também, efeito significativo ao informar (expectativa) o uso de CAF na lactacidemia - sessões C/C e C/P vs P/C e P/P - significando que, só o fato de informar que CAF seria usada aumentou o valor do lactato sanguíneo nos $2^{\circ}, 4^{\circ}$ e $6^{\circ}$ minutos $(p<0,05)$ comparada à informação de que o PLA seria usado. 
Em relação aos valores de lactato em si, os nossos valores estão maiores que o reportado normalmente na literatura, contudo, sabe-se que o tipo de protocolo de exercício pode influenciar, mesmo tendo um volume da sessão igual (ROGATZKI et al., 2014), a massa muscular utilizada (WIRTZ et al., 2014), com maiores massas musculares resultando em um maior valor de lactato sanguíneo, além do mais. Considerando que a lactacidemia resultante parece ser protocolo dependente, fica difícil comparar com outros achados que utilizaram diferentes protocolos, ainda mais sendo observada a interação entre uso de suplementação e a informação dada. Hunter; Seelhorst e Snyder (2003) utilizando repetições máximas com cargas de 65\% de 1RM observaram um valor de lactato similar após uma sessão de treino com dez exercícios (sendo o último agachamento) encontraram valores semelhantes aos nossos na sessão P/P.

Estudos que tratam da ação da CAF na lactacidemia de uma forma geral apontam que a CAF aumenta a lactacidemia (DAVIS; GREEN, 2009), ora em conjunto com melhor desempenho (RIBEIRO et al., 2016; SANTOS et al., 2014), ora não (LOPES-SILVA et al., 2015). Existem evidências de uma relação entre o aumento de lactato sanguíneo com a atuação do sistema nervoso simpático, em especial uma relação entre lactato sanguíneo e catecolaminas circulantes (GLADDEN, 2004; KUBERA et al., 2012; PHILP; MACDONALD; WATT, 2005). Parece haver também uma associação entre CAF e o aumento de catecolaminas (DAVIS; GREEN, 2009; SÖKMEN et al., 2008), bem como indícios de associação entre consumo de CAF e maior atividade simpática após exercício (LOPES-SILVA et al., 2015; RISSARDI, 2010), o que poderia explicar nossos achados de que as sessões que receberam CAF apresentaram maior lactacidemia, mesmo sem ergogenia significativa para 0 teste de endurance muscular. Graham et al., (2000) observaram um aumento no lactato medido em sangue arterial durante exercício após suplementação de CAF, contudo, não observaram alterações significativas no conteúdo intramuscular de lactato nem consumo/liberação de lactato durante exercício.

Sabe-se que é possível melhorar o desempenho físico através de manipulações psicológicas (WILLIAMS et al., 2014), e muitas vezes isso pode influenciar as variáveis fisiológicas como no caso do estudo de Foad; Beedie; Coleman, (2008) onde foi observado uma maior produção de lactato quando comparadas duas situações, informar que foi dado CAF e dar, na verdade, PLA em relação a não informar nenhum tratamento e não administrar tratamento algum. Isso considerando os intervalos de confiança, pois a grande variação dos dados provavelmente tenha impedido a obtenção de valor significativo $(p<0,05)$. Em sequência do estudo anterior eles realizaram entrevistas com o objetivo de encontrar pessoas que apresentassem um efeito PLA. Três sujeitos foram considerados como respondedores ao PLA, seu valor de lactato foi em média 16,7\% maior do que o restante do grupo na sessão que Ihes foi informado terem recebido CAF e receberam na verdade PLA (BEEDIE; FOAD; COLEMAN, 2008). Os mecanismos fisiológicos exatos que podem estar por trás desses aumentos ainda são desconhecidos.

Provavelmente, as vias fisiológicas estão ligadas à mecanismos antecipatórios do SNC, por exemplo, o soar da sirene em um quartel de bombeiros leva a uma hiperatividade simpática, podendo em alguns casos resultar em óbito, pelo simples ouvir de uma sirene (SMITH; BARR; KALES, 2013), assim, os mecanismos que resultam em uma maior produção de lactato devido a um efeito placebo (expectativa de CAF) são desconhecidos, mas, o aumento da atividade simpática é uma possibilidade (MEISSNER, 2011). 
Sabe-se que há um elo entre o efeito PLA e o SNA, ainda que não se saiba por quais vias essas interações ocorrem. Em um estudo realizado em pessoas com Mal de Parkinson foi observado que quando era aplicado um estímulo elétrico na região subtalâmica as respostas autonômicas (aumento de frequência cardíaca, pressão arterial e frequência respiratória) eram menores quando os pacientes não eram avisados do estímulo, sugerindo que o contexto envolvido pode aumentar a excitabilidade de algumas regiões cerebrais (BENEDETTI et al., 2004; POLLO; CARLINO; BENEDETTI, 2011).

Kubera et al., (2012) observaram o efeito de estresse psicossocial (simular uma entrevista de emprego seguida de operações aritméticas) na produção de lactato e observou aumento significativa em relação a situação controle, mostrando também que o contexto pode influenciar a produção de lactato. Possivelmente informar que Ihe seria dado CAF agiu de forma a produzir algum tipo de estresse, o que refletiu em efeito no lactato para as condições onde foi informado o uso de CAF.

\subsection{EFEITOS ASSOCIADOS À CAFEÍNA}

Os resultados de questionário de efeitos associados a cafeína (QEC) observados são semelhantes com o reportado na literatura (DEL COSO et al., 2012; PALLARÉS et al., 2013). Del Coso et al., (2012) observaram que entre 8 a 23\% da amostra (1 a 3 pessoas) apresentaram pelo menos um dos efeitos mencionados no questionário de efeitos associados enquanto que no nosso trabalho, 6 a $25 \%$ da amostra (1 a 4 pessoas) relataram pelo menos um efeito associado à CAF (TABELA Z). Mesmo considerando as diferenças entre os tempos de mensuração - o presente estudo fez o registro logo após a suplementação enquanto que eles registraram somente no dia seguinte ao teste, os resultados estão muito semelhantes.

A exceção se dá quanto à percepção de maior vigor/disposição, pois foi achado um efeito dependente da dose de CAF com elevado percentual da amostra reportando esse sentimento (58\%), enquanto que no nosso estudo a porcentagem foi baixa, mais semelhante às doses placebo e $3 \mathrm{mg} / \mathrm{kg}$ (DEL COSO et al., 2012). Outros estudos utilizando praticamente o mesmo questionário observaram frequências muito semelhantes, geralmente com um a três voluntários relatando algum efeito, exceto na percepção de maior vigor/disposição, onde os outros estudos mostraram uma frequência consideravelmente maior que o presente trabalho (MORA-RODRíGUEZ et al., 2015; PALLARÉS et al., 2013). Infelizmente, esses estudos não fizeram, ou não reportam uma análise de vendamento, isto é, a verificação após os testes se o voluntário foi de fato "enganado". Considerando em especial o estudo que utilizou diferentes dosagens (PALLARÉS et al., 2013), foi realizada somente uma sessão PLA, ou seja, o voluntário facilmente deduziria quais eram as sessões com CAF, especialmente se o voluntário foi informado que receberia diferentes dosagens de CAF, e, provavelmente foi, pois, o desenho metodológico não informava nada sobre "enganar" os participantes.

O desenho experimental realizado neste trabalho fornece informações muito interessantes quando comparamos as diferentes sessões, havendo mais relatos de efeitos associados nos dias $\mathrm{C} / \mathrm{C} \mathrm{e}$ $\mathrm{C} / \mathrm{P}$ do que nos dia P/C. Portanto, ainda que a CAF realmente cause alguns efeitos, a expectativa deles parece ter grande influência (efeito PLA). A incidência de aumento na ansiedade foi $50 \%$ menor na sessão $\mathrm{P} / \mathrm{C}$ quando comparada a sessão $\mathrm{C} / \mathrm{C}$, mostrando claramente a influência da expectativa. 
A análise da ocorrência de efeitos ao longo do tempo desse trabalho provavelmente é inédita. Como a CAF é rapidamente absorvido pelo trato gastrointestinal e em 45 minutos $99 \%$ já foram absorvidos (MAGKOS; KAVOURAS, 2005), é plenamente possível que alguns efeitos se manifestem antes de 60 minutos. Na sessão $\mathrm{P} / \mathrm{C}$, ocorreu um caso aos 15 minutos e outro aos 30 minutos (aumento na ansiedade) que permaneceram constantes até o final. Um comportamento claro de aumento dos efeitos associados ao uso de CAF ao longo do tempo só ficou demonstrado nas sessões C/C e C/P, podendo ser um efeito na verdade relacionado às expectativas dos participantes da pesquisa.

\subsection{FATORES INTERVENIENTES}

\subsubsection{DOSAGEM}

Não se sabe ainda se os efeitos da CAF são dose dependente. A maioria dos estudos in vitro, em células musculares animais, indicariam que a ergogenia da CAF pode ser dependente da dose, contudo, estudos que afirmam isso geralmente usam dosagens tóxicas in vivo, um dos poucos estudos com dosagens fisiológicas (para humanos) encontrou um efeito "tudo ou nada", a partir do momento em que havia ergogenia, não havia benefícios adicionais com maiores dosagens (TALLIS; DUNCAN; JAMES, 2015). Contudo, em outro estudo recente (DIAS et al., 2015), foi observado que a CAF exercia efeitos distintos e dependentes da dosagem, mesmos em valores fisiológicos. A limitação deste estudo foi ter usado células de Sértoli, células somáticas dos testículos, assim, não se sabe se o mesmo vale para células musculares humanas.

Utilizando modelo animal o efeito da dosagem foi demonstrado, sendo que com dosagens baixas e moderadas de CAF houve aumento da atividade locomotora - bloqueio dos receptores $A_{2 A}$ de adenosina - e com dosagens altas diminuíram a atividade locomotora - provavelmente pelo bloqueio dos receptores $A_{1}$ de adenosina (EL YACOUBI et al., 2000). Entretanto, no que se refere a humanos, isto não está claro, parece não haver efeito dose resposta no exercício de longa duração (SPRIET, 2014). Contudo, há relatos de dose resposta, quanto a redução da dor muscular (O'CONNOR et al., 2004), a diminuição a sensibilidade a insulina (BEAUDOIN et al., 2013), a diminuição do risco de fibrilação atrial (CHENG et al., 2014) e a incidência de efeitos diversos associados ao uso de CAF como insônia e agitação (PALLARÉS et al., 2013).

Tratando-se especificamente de exercícios de curta duração e alta intensidade há somente indícios. Warren et al., (2010) observaram que quanto maior a dosagem, maior o tamanho do efeito da CAF, contudo isso não foi testado diretamente - essa mesma relação não foi observada para a força muscular. Pallarés et al., (2013) analisaram o efeito de doses crescentes de CAF na força muscular, contudo, sua variável dependente foi a velocidade de deslocamento da barra, que está mais próxima de uma variável relacionada a potência muscular, trabalho (deslocamento) realizado por unidade de tempo, do que a força per si. Eles investigaram o efeito de três dosagens de CAF (3, 6 e $9 \mathrm{mg} / \mathrm{kg})$ em dois exercícios com quatro cargas diferentes - 25\%,50\%,75\% e 90\% de uma repetição máxima (1RM). Eles observaram que nas cargas mais leves (25 e 50\% de $1 \mathrm{RM}$ ), todas as dosagens de CAF foram ergogências, contudo na carga mais alta (90\% de 1RM) somente a suplementação com $9 \mathrm{mg} / \mathrm{kg}$ obteve efeito nos dois exercícios. Del Coso et al., (2012) observaram duas doses de CAF (1 e $3 \mathrm{mg} / \mathrm{kg}$ ) e 
notaram efeitos ergogênicos na velocidade de propulsão da barra no meio-agachamento e supino somente na a maior dose. Já outro estudo não observou efeito da CAF na força muscular isométrica utilizando dosagens moderadas (5 mg/kg) e grandes (10 mg/kg) (TREVINO et al., 2015). Astorino et al., (2010) também não observaram efeito de duas doses de CAF (2 e $5 \mathrm{mg} / \mathrm{kg}$ ) na força de extensão de joelhos porém a dose maior aumentou a força dos flexores de joelho. Assim, não está claro qual seria a dose ideal para aumentar a força muscular e a endurance muscular.

Considerando em especial o desenho experimental desta pesquisa e para manter o cegamento dos voluntários, foi necessário escolher uma dose que não fosse alta o suficiente para que os efeitos da CAF fossem muito evidentes (PALLARÉS et al., 2013), nem também baixa, a ponto de não exercerem efeito ergogênico (ASTORINO et al., 2010). Dessa forma, optou-se por uma dosagem de $5 \mathrm{mg} / \mathrm{kg}$ de CAF, considerando que essa dosagem apresentou efeito no estudo de Black; Waddell e Gonglach (2015). Além disso, a dosagem deveria estar também, dentro da quantidade de CAF recomendada pela ANVISA (ANVISA, 2010). Tendo em vista que conseguimos observar de modo muito interessante a ergogenia da CAF, não consideramos que a dosagem do presente estudo seja uma limitação, mas, reconhecemos a necessidade de se continuar investigando o tema em relação à força máxima e endurance muscular.

\subsubsection{HORÁRIO DO DIA}

Todos os testes do presente estudo foram realizados no período da manhã (8 - 12h), pouco se sabe sobre a interação entre o horário de execução dos testes e a ação da CAF. Quando analisada a potência muscular, observou-se que 0 aumento na velocidade de deslocamento da barra ocorria somente com o uso de CAF pela manhã, com os valores vespertinos de PLA e CAF iguais aos valores de CAF pela manhã (MORA-RODRíGUEZ et al., 2015). Em relação à força muscular, alguns anos antes, o mesmo grupo não conseguiu comprovar sua hipótese (MORA-RODRÍGUEZ et al., 2012), pois não observou ergogenia da CAF na força muscular em nenhuma condição, nem de manhã, nem de tarde, nem nos extensores de joelho nem na dinamometria manual. A única exceção foi um aumento na força de extensores de joelho estimulado eletricamente pela manhã, se igualando aos valores da tarde e ficando maior que na sessão sem CAF. Este fato indica que, possivelmente, haja algum efeito do ciclo circadiano na configuração intramuscular, contudo, sem um aumento na força muscular voluntária, perde-se o sentido prático deste achado.

Assim sendo, mesmo não havendo consenso sobre o efeito de diferentes horários de testes ao longo do dia na ergogenicidade da CAF, em nosso trabalho todos os testes foram realizados pela manhã e o horário dos testes de cada voluntário foram mantidos constantes ao longo das sessões, evitando assim um possível fator de influência, também não é possível afirmar que os resultados seriam iguais se realizados o estudo fosse realizado no período vespertino. A mudança de horário afetaria os resultados do QEC, pois, há indícios que quando a CAF é consumida à tarde, os efeitos associados são mais intensos, especialmente o de insônia (MORA-RODRíGUEZ et al., 2015). 


\subsubsection{CONSUMO HABITUAL DE CAFEÍNA}

O consumo habitual de CAF tem sido utilizado para tentar observar alguma associação entre a ergogenia da CAF e o fato da pessoa consumir CAF regularmente ou não. Contudo, a forma de classificar entre alto e baixo consumidor de CAF não possui qualquer padrão entre os estudos, sendo os critérios extremamente subjetivos. Por exemplo, para classificar o baixo consumo de CAF alguns estudos consideram um consumo menor que $100 \mathrm{mg} / \mathrm{dia}$, ou seja, deve ser consumido menos de 700 $\mathrm{mg} / \mathrm{semana}$ (ASTORINO et al., 2010), enquanto que outro estudo chega a falar em menos de $200 \mathrm{mg} / \mathrm{dia}$ (menos de 1400 mg/semana) para essa classificação (ATTWOOD; TERRY; HIGGS, 2006). Sem falar em várias outras classificações como: $\leq 70 \mathrm{mg} / \mathrm{dia}$ (DUNCAN; THAKE; DOWNS, 2014), $\leq 60 \mathrm{mg} / \mathrm{dia}$ (MORARODRíGUEZ et al., 2012), < $50 \mathrm{mg} /$ dia (TARNOPOLSKY; CUPIDO, 2000), 8 a $33 \mathrm{mg} / \mathrm{dia}$ (FIMLAND et al., 2010).

A classificação de usuários intensos de CAF também não é padronizada, alguns estudos consideram um consumo intenso de CAF > 500mg/dia (TARNOPOLSKY; CUPIDO, 2000), enquanto outros usam > $300 \mathrm{mg} / \mathrm{dia}$ (TIMMINS; SAUNDERS, 2014), assim, não é tarefa fácil distinguir um consumidor intenso de um moderado de CAF - a preocupação se volta para a possível adaptação dos receptores de adenosina que poderiam influenciar a ação ergogênica da CAF (ZHANG; WELLS, 1990). É importante também mencionar que são poucos os estudos que relatam qual foi o critério utilizado para determinar o consumo habitual de CAF (TARNOPOLSKY; CUPIDO, 2000), sem contar que existem diferenças nos diversos países quanto aos níveis de CAF presentes nos alimentos (BURKE, 2008; CAMARGO; TOLEDO, 1998).

Os nossos resultados, ainda que com grupos pequenos, indicam que provavelmente não existe interação entre consumo habitual de CAF e efeito na força e endurance muscular. Rogers et al., (2013) observaram diferenças nas respostas de ansiedade e tremor entre alto consumidores e médio consumidores de CAF, contudo, ao olhar os dados do nosso estudo sobre efeitos associados a CAF, salta aos olhos a necessidade de futuros estudos trabalharem com um desenho balanceado por placebo, pois, se a mera expectativa pode fazer uma pessoa sentir dor (BENEDETTI, 2013), quanto mais pode se esperar no que se refere a expectativa de tremor e sensação de ansiedade? Interessantemente, Rogers et al., (2013) observaram que ambos os grupos apresentaram desempenho motor melhorado. Semelhantemente outro estudo também observou maior presença de efeitos benéficos do consumo da CAF em pessoas que consumiam mais CAF (ATTWOOD; HIGGS; TERRY, 2007).

Resultados como esses tem levado autores a se preocuparem quanto ao efeito diferenciado da CAF entre pessoas com diferentes níveis de consumo, bem como quanto ao protocolo de abstenção de CAF, a ponto de levantaram a possibilidade de que esses efeitos maiores em consumidores intensos de CAF se tratem na realidade de um falso positivo, isto é, na sessão PLA o voluntário está sem CAF e acaba sofrendo sintomas de abstinência, enquanto que no teste utilizando CAF ele apresenta seu desempenho normal (ASTORINO; ROBERSON, 2010). No caso do presente estudo optou-se por não restringir o consumo de CAF, justamente para evitar esse tipo de situação, parece que a CAF agiu independente de sua restrição e independe da habito do voluntário. Não é possível saber se os efeitos teriam sido maiores caso tivesse sido realizada a restrição de consumo de CAF, o presente autor 
também desconhece trabalhos que tenham comparado o efeito de diferentes protocolos de restrição ao consumo da CAF nos efeitos ergogênicos.

Indo ao encontro da opinião do pesquisador, Tarnopolsky e Cupido (2000) utilizaram contrações eletricamente induzidas para avaliar o efeito da CAF em não usuários e usuários intensos - estratégia interessante uma vez que não depende da expectativa do sujeito (contração involuntária), contudo, negligencia os efeitos centrais da CAF - foi observada ergogenia da CAF independente do nível de consumo dos participantes. Provavelmente, a CAF pode aumentar o desempenho de modo semelhante em pessoas com níveis distintos de consumo de CAF.

\subsubsection{RESPONDEDORES E NÃO RESPONDEDORES}

Surpreendentemente apenas há pouco tempo autores tem se preocupado com a questão de que algumas pessoas responderam a suplementação de CAF e outros não, havendo inclusive relatos de piora de desempenho, (ASTORINO; ROHMANN; FIRTH, 2008; HUDSON et al., 2008). Astorino e Roberson, (2010) levantaram a hipótese de que isso estaria relacionado à capacidade de metabolização de CAF que cada um apresenta (CYP450 1A2), sua hipótese está baseada nos achados de estudos epidemiológicos que observaram associações entre consumo de CAF e danos a saúde (infarto do miocárdio, hipertensão arterial) somente em metabolizadores lentos de CAF (CORNELIS et al., 2006; PALATINI et al., 2009).

No campo da ergogenia, os resultados são contraditórios, Womack et al., (2012) deram o ponto de partida nas pesquisas sobre o assunto, observaram efeito maior da CAF em metabolizadores rápidos que pedalaram $40 \mathrm{~km}$. Contraditoriamente, outro estudo observou que a suplementação de CAF melhorou mais o desempenho de metabolizadores lentos que pedalaram uma distância de $3 \mathrm{~km}$ (PATAKY et al., 2016). Thomas et al., (2016) observaram que durante a recuperação após teste de esforço, um marcador de influência vagal medido por meio da variabilidade da frequência cardíaca (RMSSD) foi afetado pelo consumo de CAF somente nos metabolizadores lentos. Assim na área do desempenho físico, os resultados ainda são contraditórios. Outra boa opção pode ser analisar os genes ligados aos receptores de adenosina, estudos recentes analisando as variações genéticas (Homozigotos e Heterozigotos) obtiveram bons resultados em associá-los com a ocorrência de insónia ligada ao consumo de CAF (LANDOLT, 2012; RÉTEY et al., 2007). No campo do exercício físico, Loy et al., (2015) provavelmente foram os primeiros a examinarem a relação entre esses genes, suplementação de CAF e desempenho físico. Eles observaram que a CAF foi ergogênica naqueles indivíduos que possuíam os alelos que predispõe a apresentarem maior sensibilidade a CAF (insônia). Não se sabe como esses achados se reproduziriam no campo da força e endurance muscular.

Considerando que a CAF pode agir tanto em mecanismos centrais quanto periféricos, fica difícil saber a real causa da resposta ou não resposta. Nosso estudo observou mais associação do efeito da CAF na força muscular quando comparadas entre si as contrações em baixa velocidade ( 0 e $60 \%$ s) e as rápidas (180\% e $300 \%$ s ) - TABELA 6 . Não houve associação significativa com os resultados do teste de endurance muscular. Assim sendo, nosso estudo parece estar dentro do normal no que tange a respondedores e não respondedores, e se mesmo em estudos com células existem não respondedores 
(TALLIS et al., 2012), ainda há muito para se avançar na entendimento desse fenômeno na suplementação de CAF.

\subsubsection{NÍVEL DE TREINAMENTO}

Em sua meta-análise, Warren et al., (2010) não observou diferença da ação da CAF em treinados e destreinados. A despeito disso, especialistas na área ainda entendem que a CAF age predominantemente em pessoas treinadas (ASTORINO; ROBERSON, 2010; GOLDSTEIN et al., 2010). Estudos recentes utilizaram somente homens treinados ou ativos (ASTORINO et al., 2010; BLACK; WADDELL; GONGLACH, 2015; DUNCAN; THAKE; DOWNS, 2014; MORA-RODRÍGUEZ et al., 2012; TIMMINS; SAUNDERS, 2014; TREVINO et al., 2015). Desta forma, não há indícios que a amostra seja um fator limitante ou confundidor para o presente trabalho.

\subsection{LIMITAÇÕES}

Em nosso estudo não foi realizada medida a ativação muscular, nem outras medidas relacionadas que pudessem fornecer mais informações a respeito dos mecanismos da atuação da CAF, o que é uma limitação, contudo, devido à necessidade de se investigar a interrelação entre o efeito PLA e o efeito da CAF, é compreensível que se tenha focado mais na avaliação do efeito per si do que os mecanismos por trás do efeito que poderia não existir.

A amostra do presente estudo foi pequena $(n=16)$ apesar de ser semelhante a diversos estudos recentes envolvendo CAF (BEHRENS et al., 2015a; BLACK; WADDELL; GONGLACH, 2015; DUNCAN; THAKE; DOWNS, 2014; TIMMINS; SAUNDERS, 2014). Nosso estudo utilizou métodos estatísticos robustos que analisam bem amostras pequenas (ANOVA de medidas repetidas $2 \times 2$ ). Sabe-se que há uma grande variabilidade de respostas a CAF, portanto, o estudo estaria mais consistente caso tivessemos utilizado uma amostra ainda maior (KALMAR, 2005).

Não se conhece a reprodutibilidade do protocolo utilizado para mensurar a endurance muscular, apesar de que outros estudos já utilizaram a mesma carga relativa ( $60 \%$ de uma repetição máxima), não se sabe até que ponto alterações no intervalo de recuperação e tempo de execução da repetição podem influenciar nos resultados.

O estudo foi realizado com homens jovens treinados, não sendo possível extrapolar seus resultados para mulheres, homens mais velhos e sedentários.

A escala de percepção do estado de recuperação não teve sua tradução validada, mas, devido a sua objetividade e pelo fato de usar números aliados as frases, é improvável que esse fato tenha trazido prejuízo significativo para a aplicação do instrumento.

O questionário de efeitos da cafeína (QEC) não teve sua tradução validada também. Considerando a semelhança com os resultados na literatura, provavelmente não houve prejuízos para os resultados da presente pesquisa. Não foi realizada também uma análise de vendamento, mas, considerando os resultados do QEC, parecem ter sido suficientemente cegados a ponto de não interferir na pesquisa. 
Foi utilizado o método de Foad; Beedie e Coleman, (2008) para calcular o efeito da CAF e da expectativa de CAF, ele é um método aritmético simples e possui suas limitações. Contudo, considerando a falta comparações e um padrão ouro para calcular esse efeito e determinar se 0 voluntário é responsivo à CAF, justifica-se o uso do mesmo. Em um experimento duplo-cego "simples" saber se a CAF é benéfico no indivíduo seria simplesmente comparar o resultado de uma sessão utilizando CAF com uma usando PLA. Contudo o modelo balanceado por PLA oferece informações muito ricas, pois, se um indivíduo aumenta sua força - em relação à sessão controle - na sessão $C / C$ e na sessão $C / P$, mas, não nas sessões $P / C$ e $P / P$, torna-se evidente que o aumento é um efeito PLA e não fisiológico, assim, o método supracitado - ainda que com suas limitações - mostra-se adequado para calcular o efeito da CAF e identificar se ele respondeu ao uso da CAF ou não. 


\section{CONCLUSÕES}

1. A cafeína (CAF) aumenta a força muscular independende da expectativa de receber CAF, isso, considerando o pico de torque absoluto e relativo à massa corporal, bem como 0 trabalho máximo. A expectativa de receber CAF não aumenta força muscular.

2. Foi possível observar, em alguns casos, diferenças significativas na força muscular entre as sessões experimentais. $\mathrm{Na}$ sessão $\mathrm{C} / \mathrm{C}$ o voluntário realizou a maior que as sessões $\mathrm{C} / \mathrm{P}$ e $P / P$. Não houve diferenças significativas entre as sessões $C / C$ e $P / C$, nem $P / C$ e $C / P$.

3. A CAF parece agir de modo distinto nas diferentes velocidades de contração muscular. A $\mathrm{CAF}$ aumentou a força muscular de modo marcante principalmente na contração isométrica e a $60 \%$ s. A ação ergogênica da CAF na contração a $300 \%$ s só foi observada quando avaliado o trabalho máximo.

4. A CAF possui efeito ergogênico importante na força muscular na maioria dos voluntários, havendo baixo índice de não respondedores. A velocidade de contração parece influenciar a resposta, sendo que um indivíduo em que a CAF aumenta força muscular na contração a $300 \%$, não necessariamente apresenta aumento da força muscular na contração isométrica e a $60 \%$ s.

5. A expectativa de receber CAF geralmente não aumenta a força muscular.

6. A CAF e a expectativa de receber CAF não aumentam a endurance muscular, isso, considerando o número total de repetições e o volume total da sessão, bem como o número de repetições e o volume da primeira, segunda e terceira série de exercício.

7. Não foram observadas diferenças significativas na endurance muscular entre as sessões experimentais.

8. Foi observado um grupo bem distinto de respondedores e não respondedores a CAF. Alguns melhoraram sua endurance muscular e outros pioraram com o uso de CAF.

9. A expectativa de CAF pode aumentar endurance muscular em alguns indivíduos.

10. O uso de CAF e a expectativa de receber CAF aumentam significativamente a lactacidemia após teste de endurance muscular.

11. Não foi observada associação entre o efeito da cafeína na força e endurance muscular, possivelmente mecanismos distintos estejam por trás da ação da CAF nestas capacidades físicas, assim, um indivíduo que a CAF exerce efeito ergogênico na força muscular não necessariamente apresentará efeito na endurance muscular.

12. A expectativa de receber CAF influência expressivamente a ocorrência de efeitos associados ao uso da CAF como aumento na ansiedade e sensação de taquicardia e palpitação.

\subsection{CONSIDERAÇÕES FINAIS}

Novos estudos devem ser feitos para verificar o efeito da CAF em situações menos laboratoriais, verificando se a suplementação aumenta o desempenho esportivo, naqueles atletas que podem se beneficiar de um aumento de força muscular. 
Recomenda-se que novos estudos continuem utilizando o desenho balanceado por placebo ou, no mínimo, trabalhem com três sessões experimentais, controle, placebo e CAF, pois, a expectativa de CAF pode exercer efeito no desempenho físico, ainda que não seja predominantemente (BEEDIE, 2010; BEEDIE; FOAD, 2009).

Ressaltamos que em contraste com a força muscular onde a CAF aumentou a força independetemente da informação dada ao voluntário, na endurance muscular foi observado nitidamente um grupo de respondedores e não respondedores ao uso de CAF e isto deve ser levado em consideração em futuros trabalhos, pois a presença de ambos em um mesmo grupo pode distorcer a média dos resultados e levar a conclusões errôneas sobre o efeito da CAF.

Nossos achados indicam que devemos ter cuidado ao analisar o lactato sanguíneo para estimar a participação do metabolismo anaeróbio em estudos envolvendo a suplementação de CAF tendo em vista que a lactacidemia foi afetada de modo significativo pelo uso de CAF e também pela expectativa de CAF sem haver uma mudança no desempenho do teste de endurance muscular.

Em nosso estudo a CAF de forma geral não aumentou a endurance muscular, contudo, algumas pessoas ainda podem se beneficiar da CAF, pois existem pessoas que respondem a esse suplemento, 0 que deve ser testado individualmente e adequadamente, pois, algumas pessoas tiveram seu desempenho piorado como consequência do uso de CAF. 


\section{REFERÊNCIAS BIBLIOGRÁFICAS}

AHTIAINEN, J. P. et al. Recovery after heavy resistance exercise and skeletal muscle androgen receptor and insulin-like growth factor-I isoform expression in strength trained men. Journal of Strength and Conditioning Research / National Strength \& Conditioning Association, v. 25, n. 3, p. 767-777, mar. 2011.

ALTAMIRANO, K. M. et al. Effects of warm-up on peak torque, rate of torque development, and electromyographic and mechanomyographic signals. Journal of Strength and Conditioning Research / National Strength \& Conditioning Association, v. 26, n. 5, p. 1296-1301, maio 2012.

ALTIMARI, L. R. et al. Cafeína e exercício físico aeróbio. Nutrire Rev. Soc. Bras. Aliment. Nutr, v. 31, n. 1, p. 79-96, 2006a.

ALTIMARI, L. R. et al. Caffeine and performance in anaerobic exercise. Revista Brasileira de Ciências Farmacêuticas, v. 42, n. 1, p. 17-27, mar. 2006b.

ALVES, C.; LIMA, R. V. B. Dietary supplement use by adolescents. Jornal de Pediatria, v. 85, n. 4, p. 287-294, ago. 2009.

AMERICAN COLLEGE OF SPORTS MEDICINE. American College of Sports Medicine position stand. Progression models in resistance training for healthy adults. Medicine and Science in Sports and Exercise, v. 41, n. 3, p. 687-708, mar. 2009.

AMERICAN DIETETIC ASSOCIATION et al. American College of Sports Medicine position stand. Nutrition and athletic performance. Medicine and Science in Sports and Exercise, v. 41, n. 3, p. 709731, mar. 2009.

ANVISA. DIRETORIA COLEGIADA RESOLUÇÃO - RDC No - 18, DE 27 DE ABRIL DE 2010ANVISA, , $2010 . \quad$ Disponível em: <http://portal.anvisa.gov.br/documents/33916/394219/RDC\%2B18_2010.pdf/d6815465-e99a-477f-bb3548b1432b380e>. Acesso em: 31 jul. 2016

ARIEL, G.; SAVILLE, W. Anabolic steroids: the physiological effects of placebos. Medicine \& Science in Sports \& Exercise, v. 4, n. 2, p. 124-126, 1972.

ARNAUD, M. J. Pharmacokinetics and metabolism of natural methylxanthines in animal and man. Handbook of Experimental Pharmacology, n. 200, p. 33-91, 2011.

ASHIHARA, H.; KATO, M.; CROZIER, A. Distribution, biosynthesis and catabolism of methylxanthines in plants. Handbook of Experimental Pharmacology, n. 200, p. 11-31, 2011.

ASTORINO, T. A. et al. Effect of two doses of caffeine on muscular function during isokinetic exercise. Medicine and Science in Sports and Exercise, v. 42, n. 12, p. 2205-2210, dez. 2010.

ASTORINO, T. A. et al. Minimal effect of acute caffeine ingestion on intense resistance training performance. Journal of Strength and Conditioning Research / National Strength \& Conditioning Association, v. 25, n. 6, p. 1752-1758, jun. 2011.

ASTORINO, T. A. et al. Increases in cycling performance in response to caffeine ingestion are repeatable. Nutrition Research (New York, N.Y.), v. 32, n. 2, p. 78-84, fev. 2012.

ASTORINO, T. A.; ROBERSON, D. W. Efficacy of acute caffeine ingestion for short-term high-intensity exercise performance: a systematic review. Journal of Strength and Conditioning Research, v. 24, n. 1, p. 257-265, jan. 2010.

ASTORINO, T. A.; ROHMANN, R. L.; FIRTH, K. Effect of caffeine ingestion on one-repetition maximum muscular strength. European Journal of Applied Physiology, v. 102, n. 2, p. 127-132, jan. 2008. 
ATTWOOD, A. S.; HIGGS, S.; TERRY, P. Differential responsiveness to caffeine and perceived effects of caffeine in moderate and high regular caffeine consumers. Psychopharmacology, v. 190, n. 4, p. 469477, mar. 2007.

ATTWOOD, A. S.; TERRY, P.; HIGGS, S. Exploring factors that mediate responsiveness to caffeine. Appetite, v. 47, n. 2, p. 258, 2006.

BASTIANI, D. et al. Work and power of the knee flexor and extensor muscles in patients with osteoarthritis and after total knee arthroplasty. Revista Brasileira de Reumatologia, v. 52, n. 2, p. 195202, abr. 2012.

BAZZUCCHI, I. et al. Caffeine improves neuromuscular function during maximal dynamic exercise. Muscle \& Nerve, v. 43, n. 6, p. 839-844, jun. 2011.

BEAUDOIN, M.-S. et al. Caffeine ingestion impairs insulin sensitivity in a dose-dependent manner in both men and women. Applied Physiology, Nutrition, and Metabolism = Physiologie Appliquée, Nutrition Et Métabolisme, v. 38, n. 2, p. 140-147, fev. 2013.

BECK, T. W. et al. The acute effects of a caffeine-containing supplement on strength, muscular endurance, and anaerobic capabilities. Journal of Strength and Conditioning Research / National Strength \& Conditioning Association, v. 20, n. 3, p. 506-510, ago. 2006.

BEEDIE, C. J. et al. Placebo effects of caffeine on cycling performance. Medicine and Science in Sports and Exercise, v. 38, n. 12, p. 2159-2164, dez. 2006.

BEEDIE, C. J. All in the mind? Pain, placebo effect, and ergogenic effect of caffeine in sports performance. Open Access Journal of Sports Medicine, v. 1, p. 87-94, 2010.

BEEDIE, C. J.; FOAD, A. J. The placebo effect in sports performance: a brief review. Sports Medicine (Auckland, N.Z.), v. 39, n. 4, p. 313-329, 2009.

BEEDIE, C. J.; FOAD, A. J.; COLEMAN, D. A. Identification of placebo responsive participants in 40km laboratory cycling performance. Journal of Sports Science \& Medicine, v. 7, n. 1, p. 166-175, 2008.

BEHRENS, M. et al. Caffeine-induced increase in voluntary activation and strength of the quadriceps muscle during isometric, concentric and eccentric contractions. Scientific Reports, v. 5, p. 10209, 2015a.

BEHRENS, $M$. et al. Alteration in neuromuscular function of the plantar flexors following caffeine ingestion. Scandinavian Journal of Medicine \& Science in Sports, v. 25, n. 1, p. e50-58, fev. 2015b.

BELTMAN, J. G. M. et al. Voluntary activation level and muscle fiber recruitment of human quadriceps during lengthening contractions. Journal of Applied Physiology (Bethesda, Md.: 1985), v. 97, n. 2, p. 619-626, ago. 2004.

BENEDETTI, F. et al. Placebo-responsive Parkinson patients show decreased activity in single neurons of subthalamic nucleus. Nature Neuroscience, v. 7, n. 6, p. 587-588, jun. 2004.

BENEDETTI, F. Placebo and the new physiology of the doctor-patient relationship. Physiological Reviews, v. 93, n. 3, p. 1207-1246, jul. 2013.

BENEDETTI, F.; POLLO, A.; COLLOCA, L. Opioid-mediated placebo responses boost pain endurance and physical performance: is it doping in sport competitions? The Journal of Neuroscience: The Official Journal of the Society for Neuroscience, v. 27, n. 44, p. 11934-11939, 31 out. 2007.

BÉRDI, M. et al. Placebo Effects in Sport and Exercise: A Meta-Analysis. European Journal of Mental Health, v. 6, n. 2, p. 196-212, 31 dez. 2011.

BISHOP, D. Dietary supplements and team-sport performance. Sports Medicine (Auckland, N.Z.), v. 40, n. 12, p. 995-1017, 1 dez. 2010. 
BLACK, C. D.; WADDELL, D. E.; GONGLACH, A. R. Caffeine's Ergogenic Effects on Cycling: Neuromuscular and Perceptual Factors. Medicine and Science in Sports and Exercise, v. 47, n. 6, p. 1145-1158, jun. 2015.

BOND, V. et al. Caffeine ingestion and isokinetic strength. British Journal of Sports Medicine, v. 20, n. 3, p. 135-137, set. 1986.

BOTTARO, M. et al. Effects of age and rest interval on strength recovery. International Journal of Sports Medicine, v. 31, n. 1, p. 22-25, jan. 2010.

BRAULIO, V. B. et al. Comparison of body composition methods in overweight and obese Brazilian women. Arquivos Brasileiros De Endocrinologia E Metabologia, v. 54, n. 4, p. 398-405, jun. 2010.

BRILL, P. A. et al. Muscular strength and physical function. Medicine and Science in Sports and Exercise, v. 32, n. 2, p. 412-416, fev. 2000.

BROWN, L. E.; WEIR, J. P. ASEP Procedures Recommendation I: Accurate Assessment of Muscular Strength and Power. Journal of Exercise hysiology Online, v. 4, n. 3, 2001.

BURKE, L. M. Caffeine and sports performance. Applied Physiology, Nutrition, and Metabolism = Physiologie Appliquée, Nutrition Et Métabolisme, v. 33, n. 6, p. 1319-1334, dez. 2008.

CALEGARO, J. U. M. Baixos níveis de radiação ionizante causam câncer? Radiologia Brasileira, v. 40, n. 4, p. IX-X, ago. 2007.

CAMARGO, M. C. R.; TOLEDO, M. C. F. CAFFEINE CONTENT OF COMMERCIAL BRAZILIAN COFFEE. Food Science and Technology (Campinas), v. 18, n. 4, p. 421-424, out. 1998.

CHENG, M. et al. Caffeine intake and atrial fibrillation incidence: dose response meta-analysis of prospective cohort studies. The Canadian Journal of Cardiology, v. 30, n. 4, p. 448-454, abr. 2014.

CLARK, V. R. et al. Placebo effect of carbohydrate feedings during a 40-km cycling time trial. Medicine and Science in Sports and Exercise, v. 32, n. 9, p. 1642-1647, 2000.

CORNELIS, M. C. et al. Coffee, CYP1A2 genotype, and risk of myocardial infarction. JAMA, v. 295, n. 10, p. 1135-1141, 8 mar. 2006.

CORNISH, R. S.; BOLAM, K. A.; SKINNER, T. L. Effect of caffeine on exercise capacity and function in prostate cancer survivors. Medicine and Science in Sports and Exercise, v. 47, n. 3, p. 468-475, mar. 2015.

DAVIS, J. K.; GREEN, J. M. Caffeine and anaerobic performance: ergogenic value and mechanisms of action. Sports Medicine (Auckland, N.Z.), v. 39, n. 10, p. 813-832, 2009.

DAVIS, J. M. et al. Central nervous system effects of caffeine and adenosine on fatigue. American Journal of Physiology. Regulatory, Integrative and Comparative Physiology, v. 284, n. 2, p. R399404, fev. 2003.

DEL COSO, J. et al. Dose response effects of a caffeine-containing energy drink on muscle performance: a repeated measures design. Journal of the International Society of Sports Nutrition, v. 9, n. 1, p. 21, 2012.

DEL COSO, J.; MUÑOZ, G.; MUÑOZ-GUERRA, J. Prevalence of caffeine use in elite athletes following its removal from the World Anti-Doping Agency list of banned substances. Applied Physiology, Nutrition, and Metabolism $=$ Physiologie Appliquée, Nutrition Et Métabolisme, v. 36, n. 4, p. 555561, ago. 2011.

DESBROW, B.; LEVERITT, M. Well-trained endurance athletes' knowledge, insight, and experience of caffeine use. International Journal of Sport Nutrition and Exercise Metabolism, v. 17, n. 4, p. 328339, ago. 2007. 
DIAS, T. R. et al. Dose-dependent effects of caffeine in human Sertoli cells metabolism and oxidative profile: relevance for male fertility. Toxicology, v. 328, p. 12-20, 3 fev. 2015.

DING, M. et al. Caffeinated and decaffeinated coffee consumption and risk of type 2 diabetes: a systematic review and a dose-response meta-analysis. Diabetes Care, v. 37, n. 2, p. 569-586, fev. 2014.

DOHERTY, M.; SMITH, P. M. Effects of caffeine ingestion on exercise testing: a meta-analysis. International Journal of Sport Nutrition and Exercise Metabolism, v. 14, n. 6, p. 626-646, dez. 2004.

DOHERTY, M.; SMITH, P. M. Effects of caffeine ingestion on rating of perceived exertion during and after exercise: a meta-analysis. Scandinavian Journal of Medicine \& Science in Sports, v. 15, n. 2, p. 6978, abr. 2005.

DUNCAN, M. J.; LYONS, M.; HANKEY, J. Placebo effects of caffeine on short-term resistance exercise to failure. International Journal of Sports Physiology and Performance, v. 4, n. 2, p. 244-253, jun. 2009.

DUNCAN, M. J.; OXFORD, S. W. Acute caffeine ingestion enhances performance and dampens muscle pain following resistance exercise to failure. The Journal of Sports Medicine and Physical Fitness, v. 52, n. 3, p. 280-285, jun. 2012.

DUNCAN, M. J.; THAKE, C. D.; DOWNS, P. J. Effect of caffeine ingestion on torque and muscle activity during resistance exercise in men. Muscle \& Nerve, v. 50, n. 4, p. 523-527, out. 2014.

DUNWIDDIE, T. V.; MASINO, S. A. The role and regulation of adenosine in the central nervous system. Annual Review of Neuroscience, v. 24, p. 31-55, 2001.

EL YACOUBI, M. et al. The stimulant effects of caffeine on locomotor behaviour in mice are mediated through its blockade of adenosine $\mathrm{A}(2 \mathrm{~A})$ receptors. British Journal of Pharmacology, v. 129, n. 7, p. 1465-1473, abr. 2000.

EUDY, A. E. et al. Efficacy and safety of ingredients found in preworkout supplements. American journal of health-system pharmacy: AJHP: official journal of the American Society of Health-System Pharmacists, v. 70, n. 7, p. 577-588, 1 abr. 2013.

FERREIRA, D. V. Comparação de dano muscular induzido pelo exercício resistido entre uma sessão de treinamento de força com pesos livres e máquinas. Dissertação / Dissertation—-[s.l: s.n.].

FERREIRA-JÚNIOR, J. B. et al. Effects of different isokinetic knee extension warm-up protocols on muscle performance. The Journal of Sports Medicine and Physical Fitness, v. 53, n. (Suppl. 1 to No. 3), p. 25-29, 2013.

FIELD, A. Discovering statistics using SPSS. [s.I.] Sage Publications, 2005.

FIMLAND, M. S. et al. No effect of prior caffeine ingestion on neuromuscular recovery after maximal fatiguing contractions. European Journal of Applied Physiology, v. 108, n. 1, p. 123-130, jan. 2010.

FITTS, R. H.; WIDRICK, J. J. Muscle mechanics: adaptations with exercise-training. Exercise and Sport Sciences Reviews, v. 24, p. 427-473, 1996.

FOAD, A. J.; BEEDIE, C. J.; COLEMAN, D. A. Pharmacological and psychological effects of caffeine ingestion in 40-km cycling performance. Medicine and Science in Sports and Exercise, v. 40, n. 1, p. 158-165, jan. 2008.

FREDHOLM, B. B. et al. Actions of caffeine in the brain with special reference to factors that contribute to its widespread use. Pharmacological Reviews, v. 51, n. 1, p. 83-133, mar. 1999.

GANIO, M. S. et al. Effect of caffeine on sport-specific endurance performance: a systematic review. Journal of Strength and Conditioning Research / National Strength \& Conditioning Association, v. 23, n. 1, p. 315-324, jan. 2009. 
GARBER, C. E. et al. Quantity and Quality of Exercise for Developing and Maintaining Cardiorespiratory, Musculoskeletal, and Neuromotor Fitness in Apparently Healthy Adults: Guidance for Prescribing Exercise. Medicine \& Science in Sports \& Exercise, v. 43, n. 7, p. 1334-1359, jul. 2011.

GHASEMI, A.; ZAHEDIASL, S. Normality tests for statistical analysis: a guide for non-statisticians. International Journal of Endocrinology and Metabolism, v. 10, n. 2, p. 486-489, 2012.

GILES, G. E. et al. Differential cognitive effects of energy drink ingredients: caffeine, taurine, and glucose. Pharmacology, Biochemistry, and Behavior, v. 102, n. 4, p. 569-577, out. 2012.

GLADDEN, L. B. Lactate metabolism: a new paradigm for the third millennium. The Journal of Physiology, v. 558, n. Pt 1, p. 5-30, 1 jul. 2004.

GLADE, M. J. Caffeine-Not just a stimulant. Nutrition, v. 26, n. 10, p. 932-938, out. 2010.

GOLDSTEIN, E. R. et al. International society of sports nutrition position stand: caffeine and performance. Journal of the International Society of Sports Nutrition, v. 7, n. 1, p. 5, 2010.

GRAHAM, T. E. et al. Caffeine ingestion does not alter carbohydrate or fat metabolism in human skeletal muscle during exercise. The Journal of Physiology, v. 529 Pt 3, p. 837-847, 15 dez. 2000.

GREEN, J. M. et al. Effects of caffeine on repetitions to failure and ratings of perceived exertion during resistance training. International Journal of Sports Physiology and Performance, v. 2, n. 3, p. 250259, set. 2007.

GÜR, H. et al. Relationship between in vivo muscle force at different speeds of isokinetic movements and myosin isoform expression in men and women. European Journal of Applied Physiology, v. 88, n. 6, p. 487-496, fev. 2003.

HICKS, A. L.; KENT-BRAUN, J.; DITOR, D. S. Sex differences in human skeletal muscle fatigue. Exercise and Sport Sciences Reviews, v. 29, n. 3, p. 109-112, jul. 2001.

HUDSON, G. M. et al. Effects of caffeine and aspirin on light resistance training performance, perceived exertion, and pain perception. Journal of Strength and Conditioning Research / National Strength \& Conditioning Association, v. 22, n. 6, p. 1950-1957, nov. 2008.

HUNTER, G. R.; SEELHORST, D.; SNYDER, S. Comparison of metabolic and heart rate responses to super slow vs. traditional resistance training. Journal of Strength and Conditioning Research $/$ National Strength \& Conditioning Association, v. 17, n. 1, p. 76-81, fev. 2003.

INBAR, O.; KAISER, P.; TESCH, P. Relationships between leg muscle fiber type distribution and leg exercise performance. International Journal of Sports Medicine, v. 2, n. 3, p. 154-159, ago. 1981.

INTERNATIONAL OLYMPIC COMITEE. London 2012 105kg heavyweight men - Olympic Weightlifting. Disponível em: <https://www.olympic.org/london-2012/weightlifting/105kg-heavyweightmen>. Acesso em: 20 jul. 2016.

JACOBS, I.; PASTERNAK, H.; BELL, D. G. Effects of ephedrine, caffeine, and their combination on muscular endurance. Medicine and Science in Sports and Exercise, v. 35, n. 6, p. 987-994, jun. 2003.

JACOBSON, B. H. et al. Effect of caffeine on maximal strength and power in élite male athletes. British Journal of Sports Medicine, v. 26, n. 4, p. 276-280, dez. 1992.

JACOBSON, B. H.; EDWARDS, S. W. Influence of two levels of caffeine on maximal torque at selected angular velocities. The Journal of Sports Medicine and Physical Fitness, v. 31, n. 2, p. 147-153, jun. 1991.

JE, Y.; GIOVANNUCCI, E. Coffee consumption and total mortality: a meta-analysis of twenty prospective cohort studies. The British Journal of Nutrition, v. 111, n. 7, p. 1162-1173, 14 abr. 2014. 
KALMAR, J. M. The influence of caffeine on voluntary muscle activation. Medicine and Science in Sports and Exercise, v. 37, n. 12, p. 2113-2119, dez. 2005.

KEATING, J. L.; MATYAS, T. A. The influence of subject and test design on dynamometric measurements of extremity muscles. Physical Therapy, v. 76, n. 8, p. 866-889, ago. 1996.

KIM, B. et al. Coffee Consumption and Stroke Risk: A Meta-analysis of Epidemiologic Studies. Korean Journal of Family Medicine, v. 33, n. 6, p. 356-365, nov. 2012.

KRISHNAN, C.; WILLIAMS, G. N. Effect of knee joint angle on side-to-side strength ratios. Journal of Strength and Conditioning Research / National Strength \& Conditioning Association, v. 28, n. 10, p. 2981-2987, out. 2014.

KUBERA, B. et al. Rise in plasma lactate concentrations with psychosocial stress: a possible sign of cerebral energy demand. Obesity Facts, v. 5, n. 3, p. 384-392, 2012.

LANDOLT, H.-P. "No Thanks, Coffee Keeps Me Awake": Individual Caffeine Sensitivity Depends on ADORA2A Genotype. Sleep, v. 35, n. 7, p. 899-900, 1 jul. 2012.

LAURENT, C. M. et al. A practical approach to monitoring recovery: development of a perceived recovery status scale. Journal of Strength and Conditioning Research / National Strength \& Conditioning Association, v. 25, n. 3, p. 620-628, mar. 2011.

LIMA, R. M. et al. Fat-free mass, strength, and sarcopenia are related to bone mineral density in older women. Journal of Clinical Densitometry: The Official Journal of the International Society for Clinical Densitometry, v. 12, n. 1, p. 35-41, mar. 2009.

LOPES-SILVA, J. P. et al. Caffeine Ingestion Increases Estimated Glycolytic Metabolism during Taekwondo Combat Simulation but Does Not Improve Performance or Parasympathetic Reactivation. PloS One, v. 10, n. 11, p. e0142078, 2015.

LORENZ, D. S.; REIMAN, M. P.; WALKER, J. C. Periodization: current review and suggested implementation for athletic rehabilitation. Sports Health, v. 2, n. 6, p. 509-518, nov. 2010.

LOY, B. D. et al. Caffeine is ergogenic for adenosine A2A receptor gene (ADORA2A) T allele homozygotes: a pilot study. Journal of Caffeine Research, v. 5, n. 2, p. 73-81, 2015.

MACINTOSH, B. R. et al. Human skeletal muscle fibre types and force: velocity properties. European Journal of Applied Physiology and Occupational Physiology, v. 67, n. 6, p. 499-506, 1993.

MAGANARIS, C. N.; COLLINS, D.; SHARP, M. Expectancy effects and strength training: do steroids make a difference? Sport Psychologist, v. 14, n. 3, p. 272-278, 2000.

MAGKOS, F.; KAVOURAS, S. A. Caffeine use in sports, pharmacokinetics in man, and cellular mechanisms of action. Critical Reviews in Food Science and Nutrition, v. 45, n. 7-8, p. 535-562, 2005.

MARTORELLI, A. et al. Neuromuscular and blood lactate responses to squat power training with different rest intervals between sets. Journal of Sports Science \& Medicine, v. 14, n. 2, p. 269-275, jun. 2015.

MATTOS, F. DE O. et al. Ergogenic efficacy of caffeine supplementation on strength performance? a critical analysis. Revista da Educação Física / UEM, v. 25, n. 3, p. 501-511, set. 2014.

MCBRIDE, J. M. et al. Comparison of methods to quantify volume during resistance exercise. Journal of Strength and Conditioning Research / National Strength \& Conditioning Association, v. 23, n. 1, p. 106-110, jan. 2009.

MCCLUNG, M.; COLLINS, D. "Because I know it will!": placebo effects of an ergogenic aid on athletic performance. Journal of Sport \& Exercise Psychology, v. 29, n. 3, p. 382-394, jun. 2007. 
MEISSNER, K. The placebo effect and the autonomic nervous system: evidence for an intimate relationship. Philosophical Transactions of the Royal Society of London. Series B, Biological Sciences, v. 366, n. 1572, p. 1808-1817, 27 jun. 2011.

METAXAS, T. I. et al. Muscle fiber characteristics, satellite cells and soccer performance in young athletes. Journal of Sports Science \& Medicine, v. 13, n. 3, p. 493-501, set. 2014.

MEYERS, B. M.; CAFARELLI, E. Caffeine increases time to fatigue by maintaining force and not by altering firing rates during submaximal isometric contractions. Journal of Applied Physiology (Bethesda, Md.: 1985), v. 99, n. 3, p. 1056-1063, set. 2005.

MIZUNO, $M$. et al. Greater adenosine $A(2 A)$ receptor densities in cardiac and skeletal muscle in endurance-trained men: a [11C]TMSX PET study. Nuclear Medicine and Biology, v. 32, n. 8, p. 831836, nov. 2005.

MOHR, M.; NIELSEN, J. J.; BANGSBO, J. Caffeine intake improves intense intermittent exercise performance and reduces muscle interstitial potassium accumulation. Journal of Applied Physiology (Bethesda, Md.: 1985), v. 111, n. 5, p. 1372-1379, nov. 2011.

MOHR, T. et al. Caffeine ingestion and metabolic responses of tetraplegic humans during electrical cycling. Journal of Applied Physiology (Bethesda, Md.: 1985), v. 85, n. 3, p. 979-985, set. 1998.

MORA-RODRÍGUEZ, R. et al. Caffeine ingestion reverses the circadian rhythm effects on neuromuscular performance in highly resistance-trained men. PloS One, v. 7, n. 4, p. e33807, 2012.

MORA-RODRÍGUEZ, R. et al. Improvements on neuromuscular performance with caffeine ingestion depend on the time-of-day. Journal of Science and Medicine in Sport / Sports Medicine Australia, v. 18, n. 3, p. 338-342, maio 2015.

MORA-RODRIGUEZ, R.; PALLARÉS, J. G. Performance outcomes and unwanted side effects associated with energy drinks. Nutrition Reviews, v. 72 Suppl 1, p. 108-120, out. 2014.

MOTULSKY, H. J.; BROWN, R. E. Detecting outliers when fitting data with nonlinear regression - a new method based on robust nonlinear regression and the false discovery rate. BMC bioinformatics, v. 7, p. 123, 2006.

O'CONNOR, P. J. et al. Dose-dependent effect of caffeine on reducing leg muscle pain during cycling exercise is unrelated to systolic blood pressure. Pain, v. 109, n. 3, p. 291-298, jun. 2004.

PALATINI, P. et al. CYP1A2 genotype modifies the association between coffee intake and the risk of hypertension. Journal of Hypertension, v. 27, n. 8, p. 1594-1601, ago. 2009.

PALLARÉS, J. G. et al. Neuromuscular responses to incremental caffeine doses: performance and side effects. Medicine and Science in Sports and Exercise, v. 45, n. 11, p. 2184-2192, nov. 2013.

PATAKY, M. W. et al. Caffeine and 3-km cycling performance: Effects of mouth rinsing, genotype, and time of day. Scandinavian Journal of Medicine \& Science in Sports, v. 26, n. 6, p. 613-619, jun. 2016.

PEARCE, J. et al. A-Z of nutritional supplements: dietary supplements, sports nutrition foods and ergogenic aids for health and performance-Part 37. British Journal of Sports Medicine, v. 46, n. 13, p. 954-956, 10 jan. 2012.

PETERSON, M. D. et al. Progression of volume load and muscular adaptation during resistance exercise. European Journal of Applied Physiology, v. 111, n. 6, p. 1063-1071, jun. 2011.

PETERSON, M. D.; RHEA, M. R.; ALVAR, B. A. Maximizing strength development in athletes: a metaanalysis to determine the dose-response relationship. Journal of Strength and Conditioning Research / National Strength \& Conditioning Association, v. 18, n. 2, p. 377-382, maio 2004.

PHILIPPE, A. G. et al. Modeling the responses to resistance training in an animal experiment study. BioMed Research International, v. 2015, p. 914860, 2015. 
PHILP, A.; MACDONALD, A. L.; WATT, P. W. Lactate--a signal coordinating cell and systemic function. The Journal of Experimental Biology, v. 208, n. Pt 24, p. 4561-4575, dez. 2005.

POLLO, A. et al. Response expectancies in placebo analgesia and their clinical relevance. Pain, v. 93, n. 1, p. 77-84, jul. 2001.

POLLO, A. et al. Preventing motor training through nocebo suggestions. European Journal of Applied Physiology, v. 112, n. 11, p. 3893-3903, nov. 2012.

POLLO, A.; CARLINO, E.; BENEDETTI, F. The top-down influence of ergogenic placebos on muscle work and fatigue. The European Journal of Neuroscience, v. 28, n. 2, p. 379-388, jul. 2008.

POLLO, A.; CARLINO, E.; BENEDETTI, F. Placebo mechanisms across different conditions: from the clinical setting to physical performance. Philosophical Transactions of the Royal Society of London. Series B, Biological Sciences, v. 366, n. 1572, p. 1790-1798, 27 jun. 2011.

POUSSEL, M. et al. Fatal cardiac arrhythmia following voluntary caffeine overdose in an amateur bodybuilder athlete. International Journal of Cardiology, v. 166, n. 3, p. e41-42, 1 jul. 2013.

RAZALI, N. M.; WAH, Y. B. Power comparisons of Shapiro-Wilk, Kolmogorov-Smirnov, Lilliefors and Anderson-Darling tests. Journal of Statistical Modeling and Analytics, v. 2, n. 1, p. 21-33, 2011.

RÉTEY, J. V. et al. A genetic variation in the adenosine A2A receptor gene (ADORA2A) contributes to individual sensitivity to caffeine effects on sleep. Clinical Pharmacology and Therapeutics, v. 81, n. 5 , p. 692-698, maio 2007.

RHEA, M. R. et al. A meta-analysis to determine the dose response for strength development. Medicine and Science in Sports and Exercise, v. 35, n. 3, p. 456-464, mar. 2003.

RIBEIRO, B. G. et al. Caffeine Attenuates Decreases in Leg Power Without Increased Muscle Damage. Journal of Strength and Conditioning Research / National Strength \& Conditioning Association, v. 30, n. 8, p. 2354-2360, ago. 2016.

RISSARDI, L. F. Efeitos da ingestão de cafeína na resposta autonômica pós-exercício anaeróbico. Dissertação / Dissertation—Paraná: Universidade Estadual de Londrina, 2010.

RIVERS, W. H.; WEBBER, H. N. The action of caffeine on the capacity for muscular work. The Journal of Physiology, v. 36, n. 1, p. 33-47, 27 ago. 1907.

ROGATZKI, M. J. et al. Blood ammonium and lactate accumulation response to different training protocols using the parallel squat exercise. Journal of Strength and Conditioning Research / National Strength \& Conditioning Association, v. 28, n. 4, p. 1113-1118, abr. 2014.

ROGERS, P. J. et al. Faster but not smarter: effects of caffeine and caffeine withdrawal on alertness and performance. Psychopharmacology, v. 226, n. 2, p. 229-240, mar. 2013.

RUIZ, J. R. et al. Association between muscular strength and mortality in men: prospective cohort study. BMJ (Clinical research ed.), v. 337, p. a439, 2008.

RUIZ, J. R. et al. Muscular strength and adiposity as predictors of adulthood cancer mortality in men. Cancer Epidemiology, Biomarkers \& Prevention: A Publication of the American Association for Cancer Research, Cosponsored by the American Society of Preventive Oncology, v. 18, n. 5, p. 1468-1476, maio 2009.

SANTOS, V. G. F. et al. Caffeine reduces reaction time and improves performance in simulated-contest of taekwondo. Nutrients, v. 6, n. 2, p. 637-649, 2014.

SEBASTIÃO, A. M.; RIBEIRO, J. A. Fine-tuning neuromodulation by adenosine. Trends in Pharmacological Sciences, v. 21, n. 9, p. 341-346, set. 2000. 
SENCHINA, D. S. et al. Alkaloids and endurance athletes: a research review and some demonstrations using bloodroot extracts and white blood cells from cyclists and runners. Track \& Cross Country Journal, v. 2, n. 1, p. 2-18, 2012.

SHEPHARD, R. J. Qualified Fitness and Exercise as Professionals and Exercise Prescription: Evolution of the PAR-Q and Canadian Aerobic Fitness Test. Journal of Physical Activity \& Health, v. 12, n. 4, p. 454-461, abr. 2015.

SIKORSKI, E. M. et al. Changes in perceived recovery status scale following high-volume muscle damaging resistance exercise. Journal of Strength and Conditioning Research / National Strength \& Conditioning Association, v. 27, n. 8, p. 2079-2085, ago. 2013.

SIM, Y.-J.; BYUN, Y.-H.; YOO, J. Comparison of isokinetic muscle strength and muscle power by types of warm-up. Journal of Physical Therapy Science, v. 27, n. 5, p. 1491-1494, maio 2015.

SKINNER, T. L. et al. Factors influencing serum caffeine concentrations following caffeine ingestion. Journal of Science and Medicine in Sport / Sports Medicine Australia, v. 17, n. 5, p. 516-520, set. 2014.

SMITH, A. Effects of caffeine on human behavior. Food and Chemical Toxicology: An International Journal Published for the British Industrial Biological Research Association, v. 40, n. 9, p. 12431255, set. 2002.

SÖKMEN, B. et al. Caffeine use in sports: considerations for the athlete. Journal of Strength and Conditioning Research / National Strength \& Conditioning Association, v. 22, n. 3, p. 978-986, maio 2008.

SPRIET, L. L. Exercise and sport performance with low doses of caffeine. Sports Medicine (Auckland, N.Z.), v. 44 Suppl 2, p. S175-184, nov. 2014.

STEAR, S. J. et al. BJSM reviews: A-Z of nutritional supplements: dietary supplements, sports nutrition foods and ergogenic aids for health and performance Part 6. British Journal of Sports Medicine, v. 44, n. 4, p. 297-298, 3 jan. 2010.

TALLIS, J. et al. The effect of physiological concentrations of caffeine on the power output of maximally and submaximally stimulated mouse EDL (fast) and soleus (slow) muscle. Journal of Applied Physiology (Bethesda, Md.: 1985), v. 112, n. 1, p. 64-71, jan. 2012.

TALLIS, J.; DUNCAN, M. J.; JAMES, R. S. What can isolated skeletal muscle experiments tell us about the effects of caffeine on exercise performance? British Journal of Pharmacology, v. 172, n. 15, p. 3703-3713, ago. 2015.

TARNOPOLSKY, M. A. et al. Physiological responses to caffeine during endurance running in habitual caffeine users. Medicine and Science in Sports and Exercise, v. 21, n. 4, p. 418-424, ago. 1989.

TARNOPOLSKY, M.; CUPIDO, C. Caffeine potentiates low frequency skeletal muscle force in habitual and nonhabitual caffeine consumers. Journal of Applied Physiology (Bethesda, Md.: 1985), v. 89, $n$. 5, p. 1719-1724, nov. 2000.

THOMAS, R. M. et al. Influence of a CYP1A2 polymorphism on post-exercise heart rate variability in response to caffeine intake: a double-blind, placebo-controlled trial. Irish Journal of Medical Science, 1 jul. 2016.

TIMMINS, T. D.; SAUNDERS, D. H. Effect of caffeine ingestion on maximal voluntary contraction strength in upper- and lower-body muscle groups. Journal of Strength and Conditioning Research / National Strength \& Conditioning Association, v. 28, n. 11, p. 3239-3244, nov. 2014.

TREVINO, M. A. et al. Acute effects of caffeine on strength and muscle activation of the elbow flexors. Journal of Strength and Conditioning Research / National Strength \& Conditioning Association, v. 29, n. 2, p. 513-520, fev. 2015. 
WARREN, G. L. et al. Effect of caffeine ingestion on muscular strength and endurance: a meta-analysis. Medicine and Science in Sports and Exercise, v. 42, n. 7, p. 1375-1387, jul. 2010.

WILLIAMS, A. D. et al. The effect of ephedra and caffeine on maximal strength and power in resistancetrained athletes. Journal of Strength and Conditioning Research / National Strength \& Conditioning Association, v. 22, n. 2, p. 464-470, mar. 2008.

WILSON, J. M. et al. $\beta$-Hydroxy- $\beta$-methylbutyrate free acid reduces markers of exercise-induced muscle damage and improves recovery in resistance-trained men. The British Journal of Nutrition, v. 110, n. 3 , p. 538-544, 28 ago. 2013.

WIRTZ, N. et al. Lactate Kinetics during Multiple Set Resistance Exercise. Journal of Sports Science \& Medicine, v. 13, n. 1, p. 73-77, jan. 2014.

WOMACK, C. J. et al. The influence of a CYP1A2 polymorphism on the ergogenic effects of caffeine. Journal of the International Society of Sports Nutrition, v. 9, n. 1, p. 7, 2012.

WONDMIKUN, Y.; SOUKUP, T.; ASMUSSEN, G. Effects of caffeine at different temperatures on contractile properties of slow-twitch and fast-twitch rat muscles. Physiological Research / Academia Scientiarum Bohemoslovaca, v. 55, n. 6, p. 641-652, 2006.

WOOLF, K.; BIDWELL, W. K.; CARLSON, A. G. The effect of caffeine as an ergogenic aid in anaerobic exercise. International Journal of Sport Nutrition and Exercise Metabolism, v. 18, n. 4, p. 412-429, ago. 2008.

WOOLF, K.; BIDWELL, W. K.; CARLSON, A. G. Effect of caffeine as an ergogenic aid during anaerobic exercise performance in caffeine naive collegiate football players. The Journal of Strength \& Conditioning Research, v. 23, n. 5, p. 1363-1369, 2009.

ZHANG, Y.; WELLS, J. N. The effects of chronic caffeine administration on peripheral adenosine receptors. The Journal of Pharmacology and Experimental Therapeutics, v. 254, n. 3, p. 757-763, set. 1990.

ZIEMANN, E. et al. Exercise training-induced changes in inflammatory mediators and heat shock proteins in young tennis players. Journal of Sports Science \& Medicine, v. 12, n. 2, p. 282-289, 2013. 


\title{
APÊNDICE I
}

\author{
Universidade de Brasília \\ Faculdade de Educação Física \\ Programa de Pós-Graduação em Educação Física
}

\section{Termo de Consentimento Livre e Esclarecido - TCLE}

Convidamos o Senhor a participar do projeto de pesquisa "Suplementação aguda de cafeína versus placebo semelhante à cafeína na força muscular", sob a responsabilidade do pesquisador Edgard de Melo Keene von Koenig Soares. Esta pesquisa pretende analisar o efeito da suplementação de cafeína na força muscular. O senhor receberá todos os esclarecimentos necessários antes e no decorrer da pesquisa e lhe asseguramos que seu nome não aparecerá sendo mantido o mais rigoroso sigilo pela omissão total de quaisquer informações que permitam identificá-lo.

A sua participação se dará por meio de no mínimo seis comparecimentos aos laboratórios da Faculdade de Educação Física da Universidade de Brasília, nas quais você terá sua força muscular medida em um teste realizado em uma máquina de alta tecnologia e a resistência de força medida no exercício de agachamento, você receberá uma suplementação de cafeína (5 miligramas de cafeína a cada quilograma de peso corporal) ou então uma substância inerte conforme a indicação do pesquisador. Você terá seu peso e estatura medidos, bem como sua gordura corporal em uma máquina de alta tecnologia que usa uma forma muito leve de radiação (6000 vezes menos que uma tomografia computadorizada). Serão feitas também algumas perguntas em relação há quanto tempo você faz exercício físico, o tipo, a duração, sua alimentação atual, como você está se sentindo antes de treinar e o que sentiu a cada 15 minutos após o uso de cafeína. Todos os testes físicos serão realizados no Laboratório de Treinamento de Força da Faculdade de Educação Física da Universidade de Brasília. O senhor deve comparecer nas datas combinada com cada visita tendo um tempo máximo estimado de duas horas para sua realização.

Os riscos decorrentes de sua participação na pesquisa são os naturais da prática de atividade física - dor muscular devido aos exercícios realizados - que serão sempre executados na presença de um avaliador experiente garantindo sua segurança. A suplementação aguda de cafeína é segura na dosagem usada, mas poderá provocar sintomas leves como: desconforto intestinal, aumento da frequência cardíaca e calor, que caso aconteçam, não irão prejudicar a realização dos testes e desaparecerão em torno de duas horas. Se você aceitar participar, receberá informações a respeito dos resultados dos testes de força e de sua composição corporal, se esses valores estão de acordo com os padrões esperados e receber indicações sobre exercício e sugestões de alterações nos programas de treinamento com base nos resultados quando for necessário.

O Senhor pode se recusar a responder qualquer questão que lhe traga constrangimento ou participar de qualquer procedimento, podendo desistir de participar da pesquisa em qualquer momento sem nenhum prejuízo para o senhor. Sua participação é voluntária, isto é, não há pagamento por sua colaboração. Todas as despesas que você tiver relacionadas ao projeto de pesquisa (passagem para o local da pesquisa, alimentação no local da pesquisa ou exames para realização da pesquisa) serão cobertas pelo pesquisador responsável. Caso haja algum dano direto ou indireto decorrente de sua participação na pesquisa, você poderá ser indenizado, obedecendo-se as disposições legais vigentes no Brasil.

Os resultados da pesquisa serão divulgados na Faculdade de Educação Física da Universidade de Brasília podendo ser publicados posteriormente. Os dados e materiais serão utilizados somente para esta pesquisa e ficarão sob a guarda do pesquisador por um período de cinco anos, após isso serão destruídos.

Se o Senhor tiver qualquer dúvida em relação à pesquisa, favor telefonar para: Edgard de Melo Keene von Koenig Soares, aluno de pós-graduação (mestrado acadêmico) da Faculdade de Educação Física - Universidade de Brasília no telefone (61) 3107-2519 ou (61) 8124-2036 no horário comercial (8 às 12 horas e 14 às 18 horas).

Este projeto foi Aprovado pelo Comitê de Ética em Pesquisa da Faculdade de Ciências da Saúde (CEP/FS) da Universidade de Brasília. O CEP é composto por profissionais de diferentes áreas cuja função é defender os interesses dos participantes da pesquisa em sua integridade e dignidade e contribuir no desenvolvimento da pesquisa dentro de padrões éticos. As dúvidas com relação à assinatura do TCLE ou os direitos do participante da pesquisa podem ser obtidos através do telefone: (61) 3107-1947 ou do e-mail cepfs@unb.br ou cepfsunb@gmail.com, horário de atendimento de 10:00hs às 12:00hs e de 13:30hs às $15: 30 \mathrm{hs}$, de segunda a sexta-feira.

Este documento foi elaborado em duas vias, uma ficará com o pesquisador responsável e a outra com o Senhor.

Nome / assinatura

Pesquisador Responsável

Edgard de Melo Keene von Koenig Soares

Brasília, de de 


\section{APÊNDICE II}

TABELA A1 - Características antropométricas, força e consumo de cafeína da amostra.

\begin{tabular}{|c|c|c|c|c|c|c|c|c|}
\hline Voluntário & $\begin{array}{l}\text { Idade } \\
\text { (anos) }\end{array}$ & $\begin{array}{l}\mathrm{MC} \\
(\mathrm{kg})\end{array}$ & $\begin{array}{l}\text { EST } \\
(\mathrm{cm})\end{array}$ & $\begin{array}{c}\text { IMC } \\
\left(\mathrm{kg} / \mathrm{m}^{2}\right)\end{array}$ & $\% G$ & $\begin{array}{l}\text { Consumo Caf } \\
\text { (mg/sem) }\end{array}$ & $\begin{array}{l}1 \mathrm{RM} \\
(\mathrm{kg})\end{array}$ & $1 \mathrm{RM} / \mathrm{kg}$ \\
\hline 1 & 22 & 77,9 & 182,7 & 23,3 & 14,9 & 1314,7 & 130 & 1,67 \\
\hline 2 & 21 & 82,3 & 179,8 & 25,5 & 12,6 & 69,75 & 156 & 1,90 \\
\hline 3 & 29 & 80,8 & 174,3 & 26,6 & 14,4 & 1207,7 & 134 & 1,66 \\
\hline 4 & 22 & 79,2 & 180,0 & 24,4 & 13,7 & 0 & 115 & 1,45 \\
\hline 5 & 24 & 90,1 & 183,7 & 26,7 & 14,0 & 484,7 & 164 & 1,82 \\
\hline 6 & 22 & 89,2 & 186,0 & 25,8 & 22,0 & 0 & 164 & 1,84 \\
\hline 7 & 19 & 75,7 & 174,0 & 25,0 & 21,0 & 776 & 145 & 1,92 \\
\hline 8 & 20 & 76,1 & 181,7 & 23,1 & 21,8 & 661,0 & 100 & 1,31 \\
\hline 9 & 19 & 88,0 & 180,2 & 27,1 & 18,0 & 1880 & 155 & 1,76 \\
\hline 10 & 20 & 74,7 & 173,7 & 24,7 & 10,8 & 470 & 165 & 2,21 \\
\hline 11 & 21 & 107,8 & 184,8 & 31,6 & - & 295,3 & 95 & 0,88 \\
\hline 12 & 19 & 83,3 & 176,3 & 26,8 & 19,8 & 1754,7 & 150 & 1,80 \\
\hline 13 & 20 & 54,0 & 161,5 & 20,7 & 19,4 & 897,0 & 105 & 1,94 \\
\hline 14 & 20 & 75,6 & 173,3 & 25,2 & 22,4 & 48,0 & 134 & 1,77 \\
\hline 15 & 26 & 87,8 & 175,1 & 28,6 & 21,2 & 0,0 & 136 & 1,55 \\
\hline 16 & 18 & 86,7 & 171,7 & 29,4 & - & 655,7 & 107 & 1,23 \\
\hline Média & 21,4 & 81,8 & 177,4 & 25,9 & 17,6 & 657,2 & 134,7 & 1,7 \\
\hline DP & 2,9 & 11,1 & 6,2 & 2,6 & 4,0 & 617,2 & 24,1 & 0,3 \\
\hline
\end{tabular}

DP: Desvio padrão; MC: Massa corporal; EST: Estatura; \%G: Percentual de gordura; CC/SEM: Consumo de cafeína semanal; 1RM: 1 repetição máxima. 
APÊNDICE III

TABELA A2 - Resultados do teste de força muscular em termos de pico de torque.

\begin{tabular}{|c|c|c|c|c|c|c|c|c|c|c|c|c|c|c|c|c|c|c|c|c|}
\hline \multirow{2}{*}{$\begin{array}{c}\text { Vel } \\
\text { Sessão }\end{array}$} & \multicolumn{5}{|c|}{0} & \multicolumn{5}{|c|}{$60 \% / \mathrm{s}$} & \multicolumn{5}{|c|}{$180^{\circ} / \mathrm{s}$} & \multicolumn{5}{|c|}{$300 \% / s$} \\
\hline & $\mathrm{CON}$ & $\mathrm{C} / \mathrm{C}$ & $\mathrm{C} / \mathrm{P}$ & $\mathrm{P} / \mathrm{C}$ & $\mathrm{P} / \mathrm{P}$ & $\mathrm{CON}$ & $\mathrm{C} / \mathrm{C}$ & $\mathrm{C} / \mathrm{P}$ & $\mathrm{P} / \mathrm{C}$ & $\mathrm{P} / \mathrm{P}$ & $\mathrm{CON}$ & $\mathrm{C} / \mathrm{C}$ & $\mathrm{C} / \mathrm{P}$ & $\mathrm{P} / \mathrm{C}$ & $\mathrm{P} / \mathrm{P}$ & $\mathrm{CON}$ & $\mathrm{C} / \mathrm{C}$ & $\mathrm{C} / \mathrm{P}$ & $\mathrm{P} / \mathrm{C}$ & $\mathrm{P} / \mathrm{P}$ \\
\hline & PT & PT & PT & PT & PT & PT & PT & PT & PT & PT & PT & PT & PT & PT & PT & $\mathrm{PT}$ & PT & PT & PT & PT \\
\hline Volun & (N.m) & (N.m) & (N.m) & (N.m) & (N.m) & (N.m) & (N.m) & (N.m) & (N.m) & (N.m) & (N.m) & (N.m) & $(\mathrm{N} . \mathrm{m})$ & (N.m) & (N.m) & (N.m) & (N.m) & (N.m) & (N.m) & (N.m) \\
\hline 1 & 305,1 & 303,6 & 304,2 & 332,9 & 282,8 & 282,8 & 296,2 & 291,4 & 292,0 & 282,3 & 225,3 & 215,5 & 214,8 & 219,8 & 219,2 & 186,7 & 174,9 & 174,7 & 186,2 & 212,8 \\
\hline 2 & 342,2 & 360,8 & 309,3 & 377,1 & 363,9 & 354,0 & 337,9 & 324,7 & 363,9 & 330,2 & 266,5 & 251,7 & 249,2 & 254,9 & 233,9 & 219,2 & 220,1 & 202,3 & 209,5 & 199,8 \\
\hline 3 & 294,1 & 337,9 & 312,9 & 318,0 & 308,9 & 274,8 & 294,8 & 287,4 & 281,4 & 269,0 & 190,9 & 204,4 & 186,9 & 192,0 & 190,3 & 172,9 & 175,6 & 163,8 & 170,3 & 163,2 \\
\hline 4 & 300,6 & 350,7 & 340,8 & 310,6 & 329,0 & 302,2 & 329,3 & 296,1 & 280,3 & 312,3 & 202,1 & 218,6 & 188,4 & 192,4 & 210,5 & 208,2 & 195,4 & 174,1 & 194,7 & 195,1 \\
\hline 5 & 345,5 & 345,9 & 299,7 & 383,7 & 337,5 & 309,0 & 284,3 & 233,2 & 319,7 & 297,6 & 216,7 & 203,3 & 168,2 & 218,3 & 208,8 & 179,9 & 158,1 & 149,0 & 171,5 & 170,6 \\
\hline 6 & 361,1 & 396,8 & 356,0 & 348,1 & 339,5 & 367,2 & 397,4 & 380,8 & 389,1 & 375,9 & 269,3 & 275,3 & 276,7 & 270,2 & 280,4 & 230,3 & 238,5 & 231,8 & 224,1 & 236,6 \\
\hline 7 & 287,2 & 299,1 & 307,5 & 296,8 & 288,8 & 264,8 & 275,6 & 280,5 & 291,6 & 290,0 & 191,0 & 192,9 & 185,7 & 189,1 & 187,5 & 152,5 & 163,5 & 166,3 & 157,7 & 156,8 \\
\hline 8 & 318,4 & 347,3 & 360,1 & 336,7 & 333,3 & 291,8 & 291,8 & 278,8 & 275,0 & 255,4 & 193,8 & 207,4 & 207,6 & 201,5 & 184,0 & 190,5 & 184,8 & 188,9 & 165,6 & 165,4 \\
\hline 9 & 332,8 & 363,1 & 354,2 & 358,1 & 330,5 & 316,4 & 343,3 & 316,0 & 316,2 & 320,8 & 244,1 & 267,5 & 244,6 & 271,1 & 249,7 & 184,9 & 208,3 & 197,1 & 219,4 & 198,8 \\
\hline 10 & 347,0 & 379,3 & 370,6 & 380,9 & 353,1 & 309,5 & 306,5 & 301,6 & 311,8 & 291,2 & 195,2 & 196,0 & 194,9 & 192,2 & 186,2 & 148,2 & 153,5 & 160,8 & 146,4 & 153,7 \\
\hline 11 & 268,3 & 327,3 & 348,2 & 311,3 & 294,7 & 254,8 & 294,3 & 284,8 & 271,8 & 271,9 & 180,0 & 212,7 & 216,8 & 201,1 & 205,8 & 181,0 & 185,4 & 176,1 & 198,2 & 167,4 \\
\hline 12 & 285,5 & 305,1 & 323,1 & 323,2 & 323,4 & 262,6 & 284,4 & 277,8 & 304,5 & 288,2 & 201,3 & 216,9 & 228,3 & 216,8 & 231,7 & 157,7 & 175,5 & 180,0 & 181,3 & 179,1 \\
\hline 13 & 161,8 & 191,2 & 164,5 & 175,1 & 150,7 & 172,3 & 195,7 & 185,3 & 179,7 & 171,7 & 120,7 & 146,0 & 125,7 & 127,5 & 130,9 & 120,7 & 119,1 & 100,6 & 107,2 & 111,8 \\
\hline 14 & 297,9 & 350,7 & 335,5 & 331,4 & 324,6 & 279,9 & 299,0 & 300,3 & 286,9 & 272,5 & 186,7 & 201,7 & 208,1 & 199,5 & 206,3 & 188,2 & 159,4 & 187,1 & 198,8 & 173,0 \\
\hline 15 & 312,7 & 359,3 & 333,8 & 346,2 & 368,1 & 278,9 & 275,4 & 282,3 & 300,8 & 274,5 & 191,7 & 199,0 & 195,6 & 211,5 & 191,5 & 163,6 & 171,5 & 160,4 & 174,0 & 154,2 \\
\hline 16 & 231,4 & 214,5 & 189,7 & 242,7 & 231,6 & 205,3 & 222,5 & 239,0 & 273,5 & 220,3 & 161,6 & 164,4 & 176,4 & 190,3 & 173,4 & 143,0 & 143,1 & 151,8 & 143,8 & 138,4 \\
\hline Média & 299,5 & 327,0 & 313,1 & 323,3 & 310,0 & 282,9 & 295,5 & 285,0 & 296,1 & 282,7 & 202,3 & 210,8 & 204,2 & 209,3 & 205,6 & 176,7 & 176,7 & 172,8 & 178,0 & 173,5 \\
\hline DP & 49,4 & 55,4 & 57,6 & 52,9 & 54,4 & 48,3 & 46,3 & 42,6 & 44,9 & 45,5 & 37,1 & 33,1 & 35,7 & 35,0 & 34,1 & 28,8 & 29,5 & 28,4 & 30,4 & 30,2 \\
\hline
\end{tabular}

Vel: Velocidade; Con: Controle; Volun: Voluntário; PT: Pico de torque; DP: Desvio Padrão. 
APÊNDICE IV

TABELA A3 - Resultados do teste de força muscular em termos de pico de torque relativo à massa corporal.

\begin{tabular}{|c|c|c|c|c|c|c|c|c|c|c|c|c|c|c|c|c|c|c|c|c|}
\hline \multirow{2}{*}{$\begin{array}{c}\text { Vel } \\
\text { Sessão }\end{array}$} & \multicolumn{5}{|c|}{0} & \multicolumn{5}{|c|}{$60 \% \mathrm{~s}$} & \multicolumn{5}{|c|}{$180 \% / \mathrm{s}$} & \multicolumn{5}{|c|}{$300 \% \mathrm{~s}$} \\
\hline & CON & $\mathrm{C} / \mathrm{C}$ & $\mathrm{C} / \mathrm{P}$ & $\mathrm{P} / \mathrm{C}$ & $\mathrm{P} / \mathrm{P}$ & CON & $\mathrm{C} / \mathrm{C}$ & $\mathrm{C} / \mathrm{P}$ & $\mathrm{P} / \mathrm{C}$ & $\mathrm{P} / \mathrm{P}$ & $\mathrm{CON}$ & $\mathrm{C} / \mathrm{C}$ & $\mathrm{C} / \mathrm{P}$ & $\mathrm{P} / \mathrm{C}$ & $\mathrm{P} / \mathrm{P}$ & CON & $\mathrm{C} / \mathrm{C}$ & $\mathrm{C} / \mathrm{P}$ & $P / C$ & $\mathrm{P} / \mathrm{P}$ \\
\hline & $\mathrm{PT} / \mathrm{MC}$ & PT/MC & PT/MC & PT/MC & $\mathrm{PT} / \mathrm{MC}$ & PT/MC & $\mathrm{PT} / \mathrm{MC}$ & PT/MC & PT/MC & $\mathrm{PT} / \mathrm{MC}$ & $\mathrm{PT} / \mathrm{MC}$ & $\mathrm{PT} / \mathrm{MC}$ & PT/MC & $\mathrm{PT} / \mathrm{MC}$ & $\mathrm{PT} / \mathrm{MC}$ & $\mathrm{PT} / \mathrm{MC}$ & $\mathrm{PT} / \mathrm{MC}$ & PT/MC & $\mathrm{PT} / \mathrm{MC}$ & PT/MC \\
\hline Volun & $\%$ & $\%$ & $\%$ & $\%$ & $\%$ & $\%$ & $\%$ & $\%$ & $\%$ & $\%$ & $\%$ & $\%$ & $\%$ & $\%$ & $\%$ & $\%$ & $\%$ & $\%$ & $\%$ & $\%$ \\
\hline 1 & 393,0 & 391,1 & 391,8 & 428,8 & 364,3 & 364,3 & 381,5 & 375,4 & 376,2 & 363,6 & 290,2 & 277,6 & 276,7 & 283,1 & 282,3 & 240,4 & 225,3 & 225 & 239,9 & 274 \\
\hline 2 & 416,4 & 439,1 & 376,4 & 459,0 & 442,9 & 430,8 & 411,2 & 395,1 & 442,9 & 401,9 & 324,3 & 306,3 & 303,2 & 310,1 & 284,7 & 266,7 & 267,9 & 246,1 & 254,9 & 243,1 \\
\hline 3 & 363,9 & 418,1 & 387,2 & 393,5 & 382,2 & 340,1 & 364,8 & 355,6 & 348,2 & 332,9 & 236,3 & 253 & 231,3 & 237,6 & 235,5 & 213,9 & 217,3 & 202,7 & 210,8 & 202 \\
\hline 4 & 380,5 & 443,9 & 431,4 & 393,2 & 416,5 & 382,5 & 416,8 & 374,9 & 354,8 & 395,4 & 255,8 & 276,8 & 238,5 & 243,5 & 266,4 & 263,6 & 247,4 & 220,4 & 246,5 & 247 \\
\hline 5 & 384,4 & 384,8 & 333,4 & 426,9 & 375,4 & 343,8 & 316,3 & 259,4 & 355,7 & 331,1 & 241 & 226,2 & 187,1 & 242,9 & 232,3 & 200,1 & 175,9 & 165,7 & 190,8 & 189,7 \\
\hline 6 & 405,8 & 445,9 & 400,1 & 391,2 & 381,5 & 412,7 & 446,6 & 427,9 & 437,3 & 422,4 & 302,6 & 309,4 & 311 & 303,7 & 315,1 & 258,8 & 268,1 & 260,4 & 251,9 & 265,8 \\
\hline 7 & 381,1 & 396,8 & 408,0 & 393,9 & 383,2 & 351,3 & 365,7 & 372,1 & 386,9 & 384,8 & 253,4 & 256 & 246,4 & 251 & 248,7 & 202,4 & 216,9 & 220,6 & 209,2 & 208 \\
\hline 8 & 419,9 & 458,0 & 475,0 & 444,1 & 439,6 & 384,9 & 384,8 & 367,7 & 362,7 & 336,8 & 255,6 & 273,5 & 273,7 & 265,7 & 242,7 & 251,2 & 243,8 & 249,2 & 218,5 & 218,2 \\
\hline 9 & 416,5 & 454,4 & 443,3 & 408,7 & 413,6 & 395,9 & 429,6 & 395,4 & 360,9 & 401,5 & 305,4 & 334,8 & 306,1 & 309,5 & 312,5 & 231,3 & 260,6 & 246,6 & 250,5 & 248,8 \\
\hline 10 & 466,0 & 509,4 & 497,7 & 511,6 & 474,3 & 415,7 & 411,7 & 405 & 418,7 & 391 & 262,1 & 263,3 & 261,8 & 258,2 & 250,1 & 199,1 & 206,2 & 216 & 196,6 & 206,5 \\
\hline 11 & 249,3 & 304,1 & 323,7 & 289,3 & 273,9 & 236,8 & 273,5 & 264,7 & 252,6 & 252,7 & 167,3 & 197,7 & 201,5 & 186,9 & 191,3 & 168,2 & 172,3 & 163,7 & 184,2 & 155,6 \\
\hline 12 & 345,5 & 369,2 & 388,9 & 391,1 & 391,4 & 317,8 & 344,2 & 334,4 & 368,6 & 348,8 & 243,7 & 262,5 & 274,8 & 262,4 & 280,4 & 190,8 & 212,4 & 216,6 & 219,5 & 216,7 \\
\hline 13 & 302,0 & 356,9 & 307,1 & 326,8 & 281,3 & 321,7 & 365,2 & 345,9 & 335,4 & 320,5 & 225,3 & 272,5 & 234,6 & 237,9 & 244,4 & 225,3 & 222,4 & 187,7 & 200,2 & 208,7 \\
\hline 14 & 397,7 & 468,2 & 447,8 & 442,4 & 433,3 & 373,7 & 399,2 & 400,9 & 383 & 363,7 & 249,2 & 269,2 & 277,8 & 266,4 & 275,4 & 251,2 & 212,8 & 249,8 & 265,4 & 231 \\
\hline 15 & 360,7 & 414,4 & 384,9 & 399,2 & 424,5 & 321,6 & 317,6 & 325,6 & 346,9 & 316,6 & 221,1 & 229,5 & 225,6 & 243,9 & 220,8 & 188,7 & 197,8 & 185 & 200,7 & 177,8 \\
\hline 16 & 269,7 & 250,0 & 221,1 & 282,8 & 269,9 & 239,3 & 259,3 & 278,6 & 318,7 & 256,8 & 188,3 & 191,6 & 205,5 & 221,8 & 202,1 & 166,6 & 166,7 & 176,9 & 167,6 & 161,3 \\
\hline Média & 372,0 & 406,5 & 388,6 & 398,9 & 384,2 & 352,1 & 368,0 & 354,9 & 365,6 & 351,3 & 251,4 & 262,5 & 253,5 & 257,8 & 255,3 & 219,9 & 219,6 & 214,5 & 219,2 & 215,9 \\
\hline DP & 57,1 & 64,9 & 68,5 & 59,4 & 61,6 & 56,4 & 54,2 & 50,9 & 45,9 & 49,6 & 41,3 & 38,1 & 38,2 & 32,8 & 35,6 & 33,3 & 32,1 & 31,5 & 29,1 & 34,7 \\
\hline
\end{tabular}

Vel: Velocidade; Con: Controle; Volun: Voluntário; PT/MC: Pico de torque relativo à massa corporal; DP: Desvio Padrão. 
APÊNDICE V

TABELA A4 - Resultados do teste de força muscular em termos de pico de trabalho máximo realizado.

\begin{tabular}{|c|c|c|c|c|c|c|c|c|c|c|c|c|c|c|c|}
\hline \multirow{2}{*}{$\begin{array}{c}\text { Vel. } \\
\text { Sessão }\end{array}$} & \multicolumn{5}{|c|}{$60 \% / \mathrm{s}$} & \multicolumn{5}{|c|}{$180^{\circ} / \mathrm{s}$} & \multicolumn{5}{|c|}{$300 \% \mathrm{~s}$} \\
\hline & CON & $\mathrm{C} / \mathrm{C}$ & $\mathrm{C} / \mathrm{P}$ & $\mathrm{P} / \mathrm{C}$ & $\mathrm{P} / \mathrm{P}$ & $\mathrm{CON}$ & $\mathrm{C} / \mathrm{C}$ & $\mathrm{C} / \mathrm{P}$ & $\mathrm{P} / \mathrm{C}$ & $\mathrm{P} / \mathrm{P}$ & $\mathrm{CON}$ & $\mathrm{C} / \mathrm{C}$ & $\mathrm{C} / \mathrm{P}$ & $P / C$ & $\mathrm{P} / \mathrm{P}$ \\
\hline & TM & TM & TM & TM & TM & TM & TM & TM & TM & TM & TM & TM & TM & TM & TM \\
\hline Volun. & (J) & (J) & (J) & (J) & $(\mathrm{J})$ & (J) & (J) & (J) & (J) & (J) & (J) & (J) & (J) & (J) & $(\mathrm{J})$ \\
\hline 1 & 299,9 & 306,3 & 303,6 & 310,2 & 293,3 & 249,7 & 234,1 & 228,7 & 238 & 235,2 & 198,4 & 187,5 & 178,5 & 193,8 & 224,5 \\
\hline 2 & 351,6 & 355,3 & 334,9 & 372,5 & 360,9 & 280 & 283 & 264,2 & 281,2 & 263,3 & 234,9 & 232,2 & 213,6 & 227,7 & 211,6 \\
\hline 3 & 276 & 304,8 & 296,6 & 288,9 & 280 & 212,1 & 230,5 & 207,6 & 210,7 & 197,1 & 166,8 & 178,3 & 164,9 & 171,3 & 161,8 \\
\hline 4 & 316,6 & 348,7 & 312,2 & 302,9 & 333,5 & 227,2 & 248,5 & 210,3 & 224,3 & 233,4 & 193,6 & 195,7 & 171,2 & 188,9 & 192,4 \\
\hline 5 & 320,2 & 312,5 & 256,1 & 329,8 & 318,3 & 238,5 & 228,5 & 176 & 244,6 & 231,9 & 201,3 & 185,6 & 161,5 & 198,2 & 193,7 \\
\hline 6 & 380,7 & 405,1 & 397 & 389,8 & 394,4 & 294,9 & 312,4 & 308,7 & 301,6 & 315,7 & 252,3 & 255,3 & 252,4 & 250,2 & 253,5 \\
\hline 7 & 260,3 & 278,5 & 286,4 & 297,5 & 285,9 & 210,7 & 207,4 & 202,8 & 215,2 & 209,5 & 167,7 & 168,2 & 180,2 & 172,6 & 165,8 \\
\hline 8 & 287,6 & 284,9 & 280 & 284,1 & 257,3 & 213,6 & 230,1 & 227 & 222,3 & 204,2 & 181,8 & 196,9 & 191,6 & 170,8 & 162,9 \\
\hline 9 & 305,1 & 338,3 & 331,4 & 311,8 & 323,1 & 265,8 & 286,7 & 270,1 & 284,8 & 258,9 & 211,7 & 235 & 209,1 & 231,9 & 211,8 \\
\hline 10 & 306,5 & 315,6 & 299,5 & 293,4 & 296,3 & 216,9 & 216 & 212,3 & 204,2 & 211,6 & 170,2 & 167,3 & 172,4 & 162,8 & 166,4 \\
\hline 11 & 253,4 & 313,8 & 301,8 & 284,1 & 294,2 & 199,3 & 233,4 & 226 & 221,7 & 220,5 & 171,5 & 187,9 & 183,3 & 192,2 & 175,4 \\
\hline 12 & 282,5 & 295,1 & 285,1 & 317,3 & 304,9 & 206,8 & 219,4 & 231,9 & 233,9 & 241,3 & 178 & 181,1 & 188 & 206,2 & 203,6 \\
\hline 13 & 164,8 & 189 & 171,5 & 177,7 & 164,4 & 124,5 & 157,4 & 134,5 & 143,1 & 132,5 & 124,5 & 133,7 & 114 & 121,9 & 123 \\
\hline 14 & 283,2 & 317,4 & 305,7 & 298,9 & 272 & 211,4 & 229,3 & 217,5 & 222,9 & 219,5 & 186,9 & 179,5 & 186,5 & 190,4 & 183,4 \\
\hline 15 & 285 & 282,6 & 286,1 & 304,4 & 283,5 & 217,6 & 221,9 & 217,9 & 235,1 & 214,5 & 183,8 & 191,1 & 189,1 & 198,4 & 175,1 \\
\hline 16 & 182,1 & 226,2 & 223,8 & 250 & 228,1 & 150,7 & 177,7 & 181,8 & 198,6 & 190,6 & 139,2 & 145,4 & 155,3 & 152,4 & 141 \\
\hline Média & 284,7 & 304,6 & 292,0 & 300,8 & 293,1 & 220,0 & 232,3 & 219,8 & 230,1 & 223,7 & 185,2 & 188,8 & 182,0 & 189,4 & 184,1 \\
\hline DP & 54,0 & 49,9 & 49,0 & 46,8 & 52,3 & 42,7 & 38,3 & 40,0 & 37,5 & 39,0 & 31,7 & 31,2 & 29,6 & 31,7 & 32,5 \\
\hline
\end{tabular}

Vel: Velocidade; Con: Controle; Volun: Voluntário; TM: Trabalho Máximo; DP: Desvio Padrão. 
APÊNDICE VI

Tabela A5 - Resultados do teste de endurance muscular em número de repetições.

\begin{tabular}{|c|c|c|c|c|c|c|c|c|c|c|c|c|c|c|c|c|c|c|c|c|}
\hline Sessão & CON & $\mathrm{C} / \mathrm{C}$ & $\mathrm{C} / \mathrm{P}$ & $\mathrm{P} / \mathrm{C}$ & $\mathrm{P} / \mathrm{P}$ & $\mathrm{CON}$ & $\mathrm{C} / \mathrm{C}$ & $\mathrm{C} / \mathrm{P}$ & $\mathrm{P} / \mathrm{C}$ & $\mathrm{P} / \mathrm{P}$ & $\mathrm{CON}$ & $\mathrm{C} / \mathrm{C}$ & $\mathrm{C} / \mathrm{P}$ & $\mathrm{P} / \mathrm{C}$ & $\mathrm{P} / \mathrm{P}$ & $\mathrm{CON}$ & $\mathrm{C} / \mathrm{C}$ & $\mathrm{C} / \mathrm{P}$ & $\mathrm{P} / \mathrm{C}$ & $\mathrm{P} / \mathrm{P}$ \\
\hline & Set1 & Set1 & Set1 & Set1 & Set1 & Set2 & Set2 & Set2 & Set2 & Set2 & Set3 & Set3 & Set3 & Set3 & Set3 & Total & Total & Total & Total & Total \\
\hline Volun & (Reps) & Reps. & Reps. & Reps. & Reps. & Reps. & Reps. & Reps. & Reps. & Reps. & Reps. & Reps. & Reps. & Reps. & Reps. & Reps. & Reps. & Reps. & Reps. & Reps. \\
\hline 1 & 14 & 22 & 16 & 19 & 20 & 6 & 9 & 9 & 9 & 9 & 8 & 7 & 9 & 10 & 8 & 28 & 38 & 34 & 38 & 37 \\
\hline 2 & 19 & 18 & 22 & 20 & 20 & 13 & 10 & 12 & 11 & 10 & 7 & 8 & 9 & 9 & 9 & 39 & 36 & 43 & 40 & 39 \\
\hline 3 & 23 & 29 & 28 & 26 & 24 & 13 & 16 & 15 & 14 & 16 & 11 & 12 & 11 & 13 & 12 & 47 & 56 & 54 & 53 & 52 \\
\hline 4 & 22 & 23 & 24 & 24 & 20 & 14 & 14 & 15 & 15 & 13 & 10 & 11 & 10 & 12 & 10 & 46 & 48 & 49 & 51 & 43 \\
\hline 5 & 14 & 15 & 17 & 17 & 12 & 11 & 11 & 10 & 11 & 8 & 9 & 9 & 9 & 9 & 7 & 34 & 35 & 36 & 37 & 27 \\
\hline 6 & 16 & 19 & 18 & 16 & 17 & 8 & 8 & 10 & 10 & 12 & 5 & 7 & 8 & 6 & 8 & 29 & 34 & 36 & 32 & 37 \\
\hline 7 & 15 & 13 & 12 & 14 & 16 & 10 & 10 & 11 & 11 & 11 & 8 & 8 & 7 & 6 & 11 & 33 & 31 & 30 & 31 & 38 \\
\hline 8 & 12 & 18 & 15 & 18 & 18 & 7 & 10 & 9 & 13 & 12 & 5 & 9 & 9 & 8 & 10 & 24 & 37 & 33 & 39 & 40 \\
\hline 9 & 12 & 14 & 13 & 12 & 12 & 9 & 10 & 10 & 8 & 8 & 8 & 7 & 8 & 5 & 8 & 29 & 31 & 31 & 25 & 28 \\
\hline 10 & 16 & 17 & 21 & 19 & 17 & 10 & 13 & 12 & 11 & 13 & 10 & 10 & 10 & 9 & 10 & 36 & 40 & 43 & 39 & 40 \\
\hline 11 & 7 & 10 & 10 & 12 & 10 & 6 & 7 & 6 & 8 & 7 & 5 & 6 & 6 & 5 & 5 & 18 & 23 & 22 & 25 & 22 \\
\hline 12 & 10 & 17 & 13 & 16 & 14 & 9 & 10 & 11 & 9 & 8 & 6 & 7 & 9 & 7 & 7 & 25 & 34 & 33 & 32 & 29 \\
\hline 13 & 17 & 19 & 18 & 15 & 17 & 10 & 9 & 12 & 11 & 11 & 8 & 7 & 10 & 8 & 8 & 35 & 35 & 40 & 34 & 36 \\
\hline 14 & 15 & 14 & 12 & 16 & 12 & 9 & 8 & 8 & 8 & 7 & 7 & 6 & 7 & 7 & 7 & 31 & 28 & 27 & 31 & 26 \\
\hline 15 & 20 & 18 & 20 & 17 & 19 & 15 & 10 & 14 & 12 & 11 & 11 & 8 & 9 & 10 & 8 & 46 & 36 & 43 & 39 & 38 \\
\hline 16 & 18 & 20 & 18 & 19 & 17 & 12 & 12 & 16 & 11 & 3 & 10 & 10 & 9 & 10 & 8 & 40 & 42 & 43 & 40 & 28 \\
\hline Média & 15,6 & 17,9 & 17,3 & 17,5 & 16,6 & 10,1 & 10,5 & 11,3 & 10,8 & 9,9 & 8,0 & 8,2 & 8,8 & 8,4 & 8,5 & 33,8 & 36,5 & 37,3 & 36,6 & 35,0 \\
\hline DP & 4,3 & 4,5 & 4,9 & 3,8 & 3,8 & 2,7 & 2,4 & 2,7 & 2,1 & 3,1 & 2,1 & 1,7 & 1,3 & 2,3 & 1,8 & 8,4 & 7,7 & 8,3 & 7,7 & 7,7 \\
\hline
\end{tabular}

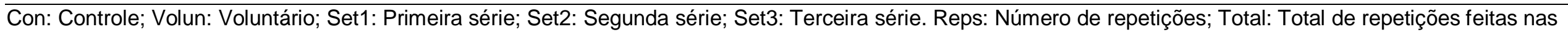
três séries; DP: Desvio Padrão. 


\section{APÊNDICE VII}

Tabela A6 - Resultados do teste de endurance muscular em termos de volume.

\begin{tabular}{|c|c|c|c|c|c|c|c|c|c|c|c|c|c|c|c|c|c|c|c|c|}
\hline Sessão & CON & $\mathrm{C} / \mathrm{C}$ & $\mathrm{C} / \mathrm{P}$ & $\mathrm{P} / \mathrm{C}$ & $\mathrm{P} / \mathrm{P}$ & CON & $\mathrm{C} / \mathrm{C}$ & $\mathrm{C} / \mathrm{P}$ & $\mathrm{P} / \mathrm{C}$ & $\mathrm{P} / \mathrm{P}$ & CON & $\mathrm{C} / \mathrm{C}$ & $\mathrm{C} / \mathrm{P}$ & $\mathrm{P} / \mathrm{C}$ & $\mathrm{P} / \mathrm{P}$ & CON & $\mathrm{C} / \mathrm{C}$ & $\mathrm{C} / \mathrm{P}$ & $\mathrm{P} / \mathrm{C}$ & $\mathrm{P} / \mathrm{P}$ \\
\hline & Set1 & Set1 & Set1 & Set1 & Set1 & Set2 & Set2 & Set2 & Set2 & Set2 & Set3 & Set3 & Set3 & Set3 & Set3 & Total & Total & Total & Total & Total \\
\hline & Vol & Vol & Vol & Vol & Vol & Vol & Vol & Vol & Vol & Vol & Vol & Vol & Vol & Vol & Vol & Vol & Vol & Vol & Vol & Vol \\
\hline Volun & $(\mathrm{kg})$ & $(\mathrm{kg})$ & $(\mathrm{kg})$ & $(\mathrm{kg})$ & $(\mathrm{kg})$ & $(\mathrm{kg})$ & $(\mathrm{kg})$ & $(\mathrm{kg})$ & $(\mathrm{kg})$ & $(\mathrm{kg})$ & $(\mathrm{kg})$ & $(\mathrm{kg})$ & $(\mathrm{kg})$ & $(\mathrm{kg})$ & $(\mathrm{kg})$ & $(\mathrm{kg})$ & $(\mathrm{kg})$ & $(\mathrm{kg})$ & $(\mathrm{kg})$ & $(\mathrm{kg})$ \\
\hline 1 & 1092 & 1716 & 1248 & 1482 & 1560 & 468 & 702 & 702 & 702 & 702 & 624 & 546 & 702 & 780 & 624 & 2184 & 2964 & 2652 & 2964 & 2886 \\
\hline 2 & 1778 & 1685 & 2059 & 1872 & 1872 & 1217 & 936 & 1123 & 1030 & 936 & 655 & 749 & 842 & 842 & 842 & 3650 & 3370 & 4025 & 3744 & 3650 \\
\hline 3 & 1849 & 2814 & 2251 & 2090 & 1930 & 1045 & 1528 & 1206 & 1126 & 1286 & 884 & 965 & 884 & 1045 & 965 & 3779 & 5306 & 4342 & 4261 & 4181 \\
\hline 4 & 1518 & 1587 & 1656 & 1656 & 1380 & 966 & 966 & 1035 & 1035 & 897 & 690 & 759 & 690 & 828 & 690 & 3174 & 3312 & 3381 & 3519 & 2967 \\
\hline 5 & 1378 & 1476 & 1673 & 1673 & 1181 & 1082 & 1082 & 984 & 1082 & 787 & 886 & 886 & 886 & 886 & 689 & 3346 & 3444 & 3542 & 3641 & 2657 \\
\hline 6 & 1574 & 1870 & 1771 & 1574 & 1673 & 787 & 787 & 984 & 984 & 1181 & 492 & 689 & 787 & 590 & 787 & 2854 & 3346 & 3542 & 3149 & 3641 \\
\hline 7 & 1305 & 1131 & 1044 & 1218 & 1392 & 870 & 870 & 957 & 957 & 957 & 696 & 696 & 609 & 522 & 957 & 2871 & 2697 & 2610 & 2697 & 3306 \\
\hline 8 & 720 & 1080 & 900 & 1080 & 1080 & 420 & 600 & 540 & 780 & 720 & 300 & 540 & 540 & 480 & 600 & 1440 & 2220 & 1980 & 2340 & 2400 \\
\hline 9 & 1116 & 1302 & 1209 & 1116 & 1116 & 837 & 930 & 930 & 744 & 744 & 744 & 651 & 744 & 465 & 744 & 2697 & 2883 & 2883 & 2325 & 2604 \\
\hline 10 & 1584 & 1683 & 2079 & 1881 & 1683 & 990 & 1287 & 1188 & 1089 & 1287 & 990 & 990 & 990 & 891 & 990 & 3564 & 3960 & 4257 & 3861 & 3960 \\
\hline 11 & 399 & 570 & 570 & 684 & 570 & 342 & 399 & 342 & 456 & 399 & 285 & 342 & 342 & 285 & 285 & 1026 & 1311 & 1254 & 1425 & 1254 \\
\hline 12 & 900 & 1530 & 1170 & 1440 & 1260 & 810 & 900 & 990 & 810 & 720 & 540 & 630 & 810 & 630 & 630 & 2250 & 3060 & 2970 & 2880 & 2610 \\
\hline 13 & 1071 & 1197 & 1134 & 945 & 1071 & 630 & 567 & 756 & 693 & 693 & 504 & 441 & 630 & 504 & 504 & 2205 & 2205 & 2520 & 2142 & 2268 \\
\hline 14 & 1206 & 1126 & 965 & 1286 & 965 & 724 & 643 & 643 & 643 & 563 & 563 & 482 & 563 & 563 & 563 & 2492 & 2251 & 2171 & 2492 & 2090 \\
\hline 15 & 1632 & 1469 & 1632 & 1387 & 1550 & 1224 & 816 & 1142 & 979 & 898 & 898 & 653 & 734 & 816 & 653 & 3754 & 2938 & 3509 & 3182 & 3101 \\
\hline 16 & 1156 & 1284 & 1156 & 1220 & 1091 & 770 & 770 & 1027 & 706 & 193 & 642 & 642 & 578 & 642 & 514 & 2568 & 2696 & 2761 & 2568 & 1798 \\
\hline Média & 1267,4 & 1469,9 & 1407,3 & 1412,8 & 1335,9 & 823,9 & 861,5 & 909,4 & 863,5 & 810,2 & 649,5 & 666,3 & 708,2 & 673,1 & 689,8 & 2740,8 & 2997,7 & 3024,9 & 2949,4 & 2835,8 \\
\hline DP & 391,6 & 480,9 & 479,5 & 373,1 & 362,7 & 265,1 & 277,4 & 246,5 & 196,6 & 294,7 & 203,7 & 179,1 & 162,4 & 203,3 & 189,0 & 806,5 & 881,4 & 847,1 & 741,2 & 795,0 \\
\hline
\end{tabular}

Con: Controle; Volun: Voluntário; Set1: Primeira série; Set2: Segunda série; Set3: Terceira série; Total: Volume total feito nas três séries; Vol: Volume (séries $\mathrm{x}$ repetições $x$ carga); DP: Desvio Padrão. 
APÊNDICE VIII

Tabela A7 - Valores de lactato sanguíneo em cada sessão.

\begin{tabular}{|c|c|c|c|c|c|c|c|c|c|c|c|c|c|c|c|c|}
\hline \multirow{2}{*}{$\begin{array}{l}\text { Sessão } \\
\text { Tempo }\end{array}$} & \multicolumn{4}{|c|}{$\mathrm{C} / \mathrm{C}$} & \multicolumn{4}{|c|}{$\mathrm{C} / \mathrm{P}$} & \multicolumn{4}{|c|}{$\mathrm{P} / \mathrm{C}$} & \multicolumn{4}{|c|}{$\mathrm{P} / \mathrm{P}$} \\
\hline & $R$ & 2 & 4 & 6 & $R$ & 2 & 4 & 6 & $R$ & 2 & 4 & 6 & $R$ & 2 & 4 & 6 \\
\hline Volun. & $\begin{array}{c}\mathrm{Lac} \\
\mathrm{mmol} / \mathrm{L}\end{array}$ & $\begin{array}{c}\mathrm{Lac} \\
\mathrm{mmol} / \mathrm{L}\end{array}$ & $\begin{array}{c}\mathrm{Lac} \\
\mathrm{mmol} / \mathrm{L}\end{array}$ & $\begin{array}{c}\mathrm{Lac} \\
\mathrm{mmol} / \mathrm{L}\end{array}$ & $\begin{array}{c}\mathrm{Lac} \\
\mathrm{mmol} / \mathrm{L}\end{array}$ & $\begin{array}{c}\mathrm{Lac} \\
\mathrm{mmol} / \mathrm{L}\end{array}$ & $\begin{array}{c}\mathrm{Lac} \\
\mathrm{mmol} / \mathrm{L}\end{array}$ & $\begin{array}{c}\mathrm{Lac} \\
\mathrm{mmol} / \mathrm{L}\end{array}$ & $\begin{array}{c}\mathrm{Lac} \\
\mathrm{mmol} / \mathrm{L}\end{array}$ & $\begin{array}{c}\mathrm{Lac} \\
\mathrm{mmol} / \mathrm{L}\end{array}$ & $\begin{array}{c}\mathrm{Lac} \\
\mathrm{mmol} / \mathrm{L}\end{array}$ & $\begin{array}{c}\mathrm{Lac} \\
\mathrm{mmol} / \mathrm{L}\end{array}$ & $\begin{array}{c}\mathrm{Lac} \\
\mathrm{mmol} / \mathrm{L}\end{array}$ & $\begin{array}{c}\mathrm{Lac} \\
\mathrm{mmol} / \mathrm{L}\end{array}$ & $\begin{array}{c}\mathrm{Lac} \\
\mathrm{mmol} / \mathrm{L}\end{array}$ & $\begin{array}{c}\mathrm{Lac} \\
\mathrm{mmol} / \mathrm{L}\end{array}$ \\
\hline 1 & 1,0 & 10,7 & 12,6 & 12,6 & 1,2 & 8,9 & 10,7 & 10,6 & 1,5 & 10,3 & 10,9 & 11,4 & 1,4 & 8,6 & 10,7 & 11,0 \\
\hline 2 & 0,7 & 13,8 & 14,8 & 14,1 & 1,3 & 10,4 & 11,5 & 11,6 & 1,4 & 11,4 & 13,9 & 14,9 & 1,3 & 8,8 & 10,9 & 12,1 \\
\hline 3 & 1,8 & 12,3 & 12,7 & 12,2 & 1,7 & 11,8 & 12,1 & 12,4 & 0,9 & 8,8 & 12,9 & 11,7 & 1,2 & 8,4 & 9,3 & 9,6 \\
\hline 4 & 1,1 & 12,7 & 13,6 & 15,6 & 1,1 & 9,5 & 10,8 & 11,0 & 0,8 & 9,5 & 13,9 & 12,5 & 0,8 & 9,1 & 11,6 & 9,6 \\
\hline 5 & 1,1 & 9,5 & 10,4 & 11,3 & 1,1 & 8,2 & 9,9 & 10,3 & 1,2 & 10,1 & 11,2 & 12,2 & 0,9 & 8,4 & 10,0 & 10,4 \\
\hline 6 & 0,9 & 10,7 & 13,5 & 13,2 & 1,0 & 11,9 & 13,8 & 11,7 & 0,9 & 10,8 & 11,7 & 13,2 & 1,1 & 11,0 & 13,2 & 11,9 \\
\hline 7 & 1,0 & 8,4 & 9,7 & 9,3 & 1,4 & 8,6 & 9,0 & 8,7 & 1,0 & 7,7 & 8,2 & 8,2 & 2,0 & 6,6 & 6,7 & 7,1 \\
\hline 8 & 0,7 & 10,2 & 11,9 & 12,2 & 1,1 & 9,2 & 10,3 & 10,2 & 1,4 & 7,2 & 10,9 & 10,6 & 1,4 & 8,5 & 9,8 & 10,8 \\
\hline 9 & 1,7 & 11,2 & 11,1 & 12,2 & 1,5 & 10,8 & 11,6 & 12,2 & 1,1 & 9,0 & 9,5 & 9,7 & 1,2 & 9,2 & 9,8 & 9,6 \\
\hline 10 & 0,8 & 13,0 & 12,9 & 13,0 & 0,8 & 12,3 & 14,2 & 14,6 & 1,0 & 14,9 & 13,6 & 12,7 & 1,3 & 12,4 & 12,1 & 7,9 \\
\hline 11 & 1,6 & 8,5 & 9,6 & 9,6 & 1,2 & 6,3 & 8,2 & 7,0 & 1,3 & 10,2 & 10,7 & 10,5 & 1,2 & 8,8 & 8,8 & 7,2 \\
\hline 12 & 0,9 & 10,7 & 13,1 & 11,4 & 0,8 & 6,3 & 9,8 & 7,3 & 1,6 & 8,8 & 7,8 & 9,0 & 1,1 & 7,3 & 8,6 & 7,7 \\
\hline 13 & 0,9 & 11,4 & 11,3 & 12,8 & 1,2 & 11,4 & 11,2 & 11,9 & 1,0 & 12,7 & 14,2 & 14,0 & 1,6 & 9,4 & 7,0 & 11,9 \\
\hline 14 & 0,9 & 10,4 & 9,8 & 11,2 & 2,1 & 10,4 & 10,5 & 10,3 & 0,9 & 9,8 & 10,2 & 9,7 & 0,8 & 7,9 & 9,1 & 7,9 \\
\hline 15 & 1,3 & 10,7 & 9,6 & 8,0 & 0,9 & 9,9 & 9,9 & 9,4 & 0,7 & 9,3 & 9,1 & 10,4 & 1,0 & 9,6 & 9,7 & 9,1 \\
\hline 16 & 0,9 & 9,5 & 10,3 & 10,1 & 0,6 & 8,8 & 10,2 & 10,5 & 1,6 & 8,6 & 8,7 & 10,2 & 0,8 & 8,8 & 10,7 & 10,1 \\
\hline Média & 1,1 & 10,9 & 11,7 & 11,8 & 1,2 & 9,7 & 10,9 & 10,6 & 1,1 & 9,9 & 11,1 & 11,3 & 1,2 & 8,9 & 9,9 & 9,6 \\
\hline DP & 0,3 & 1,5 & 1,7 & 1,9 & 0,4 & 1,8 & 1,6 & 1,9 & 0,3 & 1,9 & 2,1 & 1,9 & 0,3 & 1,4 & 1,7 & 1,7 \\
\hline
\end{tabular}

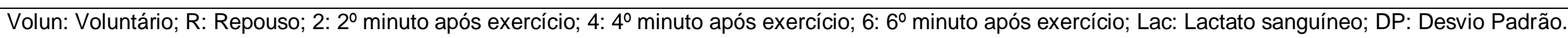


ANEXO I

\section{ESCALA DE PERCEPÇÃO DO ESTADO DE RECUPERAÇÃO:}

10 Muito bem recuperado / Com muita energia

9

8 Bem recuperado / Com certa energia

7

6 Moderadamente recuperado

5 Adequadamente recuperado

4 Um pouco recuperado

3

$2 \mathrm{Mal}$ recuperado / Com certo cansaço

1

0 Muito mal recuperado / Com muito cansaço 
ANEXO II

Concentração de cafeina em alimentos populares, bebidas, refrigerantes e energéticos

\begin{tabular}{|c|c|c|c|}
\hline \multicolumn{4}{|c|}{ CAFEÍNA EM ALIMENTOS E BEBIDAS } \\
\hline Café (xícara de $150 \mathrm{ml}$ ) & $\begin{array}{c}\text { Cafeina } \\
\text { (mg) }\end{array}$ & Produtos com chá & $\begin{array}{c}\text { Cafeina } \\
\text { (mg) }\end{array}$ \\
\hline De máquina & $110-150$ & Chá instantâneo (xíc. de $150 \mathrm{ml}$ ) & $12-28$ \\
\hline De coador & 64-124 & Chá gelado (xíc. de $350 \mathrm{ml}$ ) & $22-36$ \\
\hline Instantâneo & $40-108$ & & \\
\hline Descafeinado & $2-5$ & & \\
\hline Instantâneo descafeinado & 2 & & \\
\hline \multicolumn{4}{|l|}{ Chá (granel ou saquinhos) } \\
\hline Infusão de um minuto & $9-33$ & Feito a partir de mistura & 6 \\
\hline Infusão de três minutos & $20-46$ & Chocolate ao leite $(28 \mathrm{~g})$ & 6 \\
\hline Infusão de cinco minutos & $20-50$ & Chocolate de confeiteiro $(28 \mathrm{~g})$ & 35 \\
\hline \multicolumn{2}{|c|}{ CAFEÍNA EM REFRIGERANTES } & \multicolumn{2}{|l|}{ CAFEÍNA EM ENERGÉTICOS } \\
\hline & $\begin{array}{c}\text { Cafeína } \\
(\mathrm{mg} / 350 \mathrm{ml})\end{array}$ & & $\begin{array}{c}\text { Cafeina } \\
(\mathrm{mg} / 250 \mathrm{ml})\end{array}$ \\
\hline Coca-Cola & 46 & Flash Power & 80 \\
\hline Diet Coke & 46 & Flying Horse & 80 \\
\hline Pepsi Cola & 38,4 & Dynamite & 80 \\
\hline Diet Pepsi & 36 & Red Bull & 80 \\
\hline Pepsi Light & 36 & On Line & 80 \\
\hline Melo Yello & 36 & Blue Energy Xtreme & 80 \\
\hline
\end{tabular}

Fonte: Altimari e cols., (2006a) adaptado de Slavin e Joensen (1995). 
ANEXO III

Principais fontes de cafeína na dieta ${ }^{\mathrm{a}}$

\section{Produto}

\section{Conteúdo de cafeína (mg)}

Café (xícara $150 \mathrm{~mL}$ )

Torrado e moído

85

Instantâneo

60

Descafeinado

3

Chá (xícara $150 \mathrm{~mL}$ )

Folhas

30

Instantâneo

20

Chocolate

Barra de chocolate ao leite $(29 \mathrm{~g})^{\mathrm{b}} \quad 6$

Barra de chocolate escuro $(29 \mathrm{~g})^{\mathrm{b}} \quad 20$

Achocolatados $(180 \mathrm{~mL})$

4

Outros produtos $(100 \mathrm{~g})$

$5-20$

Refrigerantes tipo cola $(180 \mathrm{~mL})$

18

Coca-cola (lata $360 \mathrm{~mL})^{\mathrm{c}}$

46

Pepsi-cola (lata $360 \mathrm{~mL})^{\mathrm{c}}$

38

Fonte: Altimari e cols., (2006b) adaptado de Barone, Roberts (1996); Ellenhorn's Medical Toxicology (1997); Harland (2000). 